\begin{abstract}
UNIVERSIDADE DE SÃO PAULO
ESCOLA DE ENGENHARIA DE SÃO CARLOS DEPARTAMENTO DE ENGENHARIA DE PRODUÇÃO
\end{abstract}

RUY VICTOR BARBOSA DE SOUZA

\author{
Aplicação do método FMEA para \\ priorização de ações de melhoria em \\ fluxos de processos
}

São Carlos

2012 



\section{Aplicação do método FMEA para priorização de ações de melhoria em fluxos de processos}

Dissertação apresentada ao Programa de Pósgraduação em Engenharia de Produção da Escola de Engenharia de São Carlos, da Universidade de São Paulo (EESC-USP), como parte dos requisitos para obtenção do título de Mestre em Engenharia de Produção.

Área de Concentração: Gestão da Melhoria e Mudança Organizacional

Orientador: Prof. Dr. Luiz Cesar Ribeiro Carpinetti

São Carlos 
AUTORIZO A REPRODUÇÃO TOTAL OU PARCIAL DESTE TRABALHO, POR QUALQUER MEIO CONVENCIONAL OU ELETRÔNICO, PARA FINS DE ESTUDO E PESQUISA, DESDE QUE CITADA A FONTE.

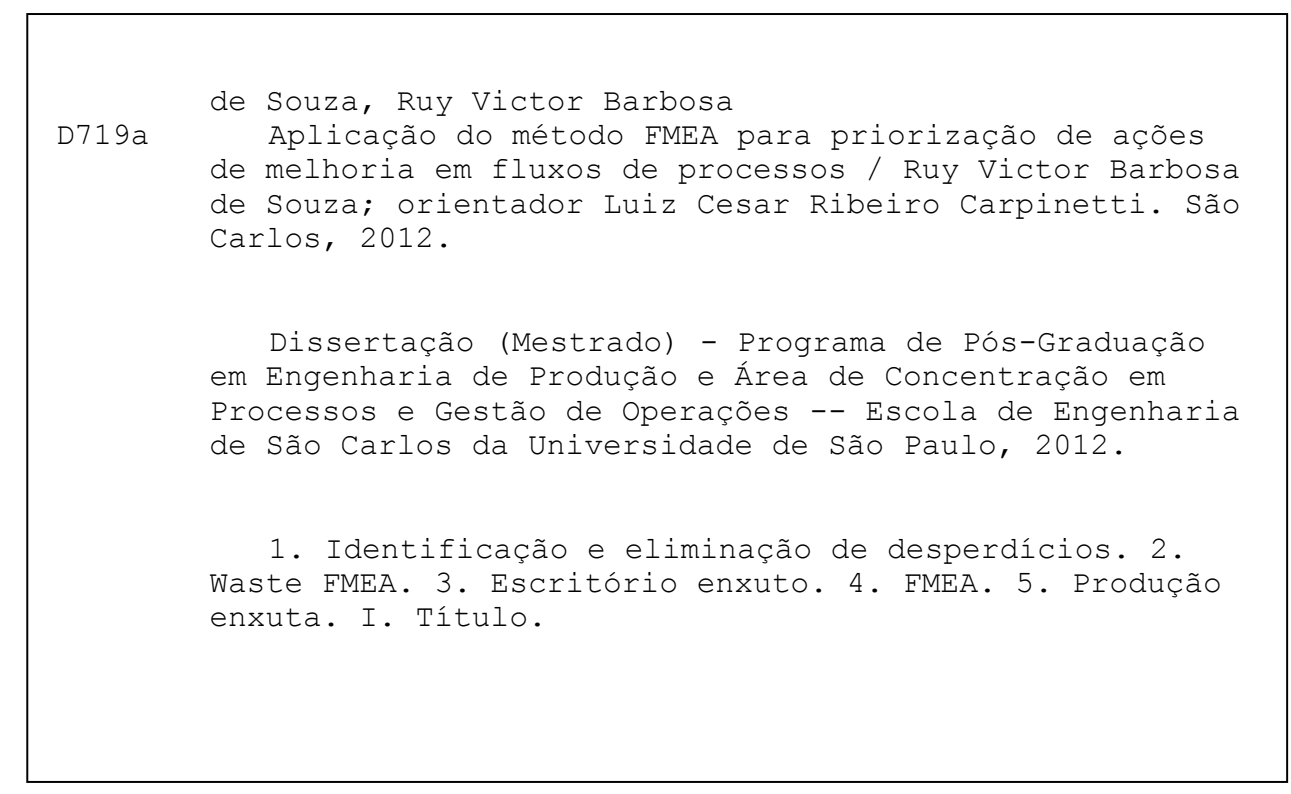




\section{FOLHA DE IULGAMENTO}

Candidato: Engenheiro RUY VICTOR BARBOSA DE SOUZA.

Título da dissertação: "Aplicação do método FMEA para priorização de ações de melhoria em fluxos de processos".

Data da defesa: 21/09/2012

Comissão Julgadora:

Resultado:

Prof. Associado Luiz Cesar Ribeiro Carpinetti (Orientador)

APROVADO

(Escola de Engenharia de São Carlos/EESC)

Prof. Associado Antonio Freitas Rentes

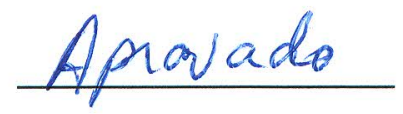

(Escola de Engenharia de São Carlos/EESC)

Prof. Dr. Roberto Antonio Martins

APROVADO

(Universidade Federal de São Carlos/UFSCar)

Coordenador do Programa de Pós-Graduação em Engenharia de Produção:

Prof. Titular Henrique Rozenfeld

Presidente da Comissão de Pós-Graduação:

Prof. Titular Denis Vinicius Coury 



\section{Resumo}

DE SOUZA, R. V. B. Aplicação do método FMEA para priorização de ações de melhoria em fluxos de processos. Dissertação de Mestrado (Mestrado) - Escola de Engenharia de São Carlos, Universidade de São Paulo, São Carlos, 2012.

Os diversos conceitos e técnicas de melhoria contínua de processos têm sido aplicados, nos dias de hoje, em indústrias de diversos setores e empresas prestadoras de serviços. Tanto em ambientes de manufatura quanto em ambientes administrativos, muitas empresas têm enxergado a oportunidade de aplicar técnicas de melhoria de processos e de qualidade, como as técnicas da Produção Enxuta e da Gestão da Qualidade. Entretanto, têm-se notado que algumas iniciativas de melhoria falham por não terem sido devidamente planejadas e priorizadas. Por isso, métodos que busquem melhorar a eficácia de iniciativas de melhoria, aumentando a taxa de sucesso das implantações, têm se tornado muito importantes

Este trabalho apresenta uma proposta de adaptação do método FMEA (Failure Mode and Effect Analysis) para a análise de desperdícios abordados pela Produção Enxuta e definição de ações prioritárias para eliminação ou minimização de desperdícios baseado nos critérios de severidade, ocorrência e detecção. O uso da técnica proposta pode auxiliar a minimizar duas das grandes dificuldades no planejamento de implantação ou manutenção de Produção Enxuta, que são a identificação dos desperdícios e a definição de quais serão eliminados ou minimizados prioritariamente. A proposta foi desenvolvida a partir de um estudo de campo, analisando um fluxo de informação de processamento de pedidos em uma empresa, paralelamente ao desenvolvimento de um projeto de Produção Enxuta. A proposta inova também ao propor um índice de risco que prioriza ação sobre as causas que geram desperdícios mais severos. Os resultados obtidos sugerem que a sistemática proposta pode contribuir para a melhoria da eficácia de programas de Produção Enxuta.

Palavras-chave: FMEA, Produção Enxuta, Escritório Enxuto, Identificação e eliminação de desperdícios, Waste FMEA. 



\begin{abstract}
DE SOUZA, R. V. B. Application of FMEA method for improvement actions prioritization in processes flows. Master's Thesis (MA) - School of Engineering of São Carlos, University of São Paulo, São Carlos, 2012.

The concepts and techniques for processes continuous improvement have been applied, nowadays, in industries of a lot of sectors and service provider companies. Both in manufacturing and office environments, a lot of companies have identified the opportunity of applying quality and process improvement techniques such as the ones of Lean Production and Quality Management. However, it has been noticed that some improvement initiatives fail because they are not correctly planned and prioritized. Therefore, methods that aim at increasing improvement initiatives effectiveness, by enhancing the implementation success rates, have become very important.

This paper presents a proposal of use of the FMEA (Failure Mode and Effect Analysis) to analyze wastes (to be tackle by Lean Production implementations) and define priorities of improvement actions aimed at minimization or elimination of these wastes based on the criteria of severity, occurrence and detection. The adoption of the proposed technique can aid to mitigate one of the major difficulties in implementing and maintaining Lean production programs, related to which wastes should be eliminate first. The proposal was developed in a field research, based on the analysis of a flow of information for order processing in parallel to the implementation of a Lean Production system. The good results suggest that the proposal can contribute to the effectiveness of Lean Production programs. The thesis is finalized with suggestions of improvements of the proposal and possibilities for further applications.
\end{abstract}

Keywords: FMEA, Lean Production, Lean Office, Waste identification and elimination, Waste FMEA. 



\section{Lista de Figuras}

Figura 1: Princípios de Lean Thinking e ações necessárias (adaptado de SHETTY; ALI; CUMMINGS, 2010) 33

Figura 2: Método PDCA para melhorias (adaptado de SENRRA, 2010) 48

Figura 3: Exemplo de Diagrama Ishikawa (Ferramentas Básicas da Qualidade, 2011) 49

Figura 4: Exemplo da ferramenta 5 Por quê's (adaptado de Lean Term: 5 Whys, 2011) 49

Figura 5: Exemplo da Aplicação da Ferramenta FMEA (http://gerisval.blogspot.com/2011/01/serieferramentas-de-gestao-fmea.html, 2011) 51

Figura 6: Correlação entre os elementos de análise do FMEA (CARPINETTI, 2010) 54

Figura 7: Fluxograma do passo a passo de aplicação do FMEA (adaptado de TENG; HO, 1996) 58

Figura 8: Custos das falhas, detectados internamente e externamente (adaptado de VON ASHEN, 2008) 70

Figura 9: Formulário padrão do SFMEA (ROTONDARO, 2002) 72

Figura 10: Etapas da pesquisa-ação (adaptado de MIGUEL et al., 2010) 82

Figura 11: Fluxo de reservas de hotel em análise no clico preliminar de aplicação do método 85

Figura 12: Posicionamento do W-FMEA no Ciclo de Melhoria 93

Figura 13: Exemplo de cálculo do lead time de um fluxo hipotético 111

Figura 14: Exemplo de mapa de fluxo de informação (LOCHER, 2008) 113

Figura 15: Mapa macro do fluxo de informação dos Produtos de Madeira 114 



\section{Lista de Tabelas}

Tabela 1: Possíveis soluções para os desperdícios (adaptado de NAZARENO 2003) 42

Tabela 2: Tabela para definição da pontuação em quatro casos diferentes (adaptado de PALADY, 1997) 56

Tabela 3: Formulário padrão da ferramenta FMEA (PALADY, 1997) 59

Tabela 4: Escala detalhada de severidade dos efeitos das falhas (ROOS et al., 2007) 61

Tabela 5: Escala simples de severidade dos efeitos das falhas (CAPALDO; TOLEDO; ROZENDFELD, 1999) 61

Tabela 6: Escala simples e qualitativa de probabilidade de ocorrência (adaptado de INOUE; YAMADA, 2010)

Tabela 7: Escala qualitativa de dez níveis de probabilidade de ocorrência (ROOS et al., 2007) 62

Tabela 8: Escala quantitativa de dez níveis de probabilidade de ocorrência (adaptado de BEN-DAYA; RAOUF, 1996) 63

Tabela 9: Escala qualitativa de cinco níveis de detecção (TOLEDO; AMARAL, 199-) 64

Tabela 10: Escala qualitativa de dez níveis de detecção (adaptado de OOKALKAR, A; JOSHI; OOKALKAR, D, 2009) 64

Tabela 11: Escala quantitativa de dez níveis de detecção (adaptado de BEN-DAYA; RAOUF, 1996)65

Tabela 12: Fatos assumidos incorretamente sobre o RPN (adaptado de SANKAR; PRABHU, 2001) 66

Tabela 13: Escala de severidade para processos de sistemas de saúde (adaptado de OOKALKAR, A., JOSHI E OOKALKAR, D.; 2009) 76

Tabela 14: Possíveis falhas de eficiência e qualidade em pesquisa e desenvolvimento farmacêutico (adaptado de INOUE; YAMADA, 2010) 78

Tabela 15: Formulário FMEA da aplicação piloto do método, sem ações recomendadas 87

Tabela 16: Os cinco modos de desperdício prioritários de acordo com cada forma de priorização 88 
Tabela 17: Os cinco modos de desperdício menos prioritários de acordo com cada forma de priorização

Tabela 18: Ações recomendas para os modos de desperdício prioritários 89

Tabela 19: Formulário do W-FMEA não preenchido 94

Tabela 20: Checklist dos modos de desperdício em ambientes administrativos (categorias de 1 a 5)_96

Tabela 21: Checklist dos modos de desperdício em ambientes administrativos (categorias de 6 a 10) 97

Tabela 22: Checklist dos modos de desperdício em ambientes de manufatura (categorias de 1 a 4)__98

Tabela 23: Checklist dos modos de desperdício em ambientes de manufatura (categorias de 5 a 8)__98

Tabela 24: Escala de referência para pontuação da Probabilidade de Ocorrência (PO) 101

Tabela 25: Escala de referência para pontuação do Nível de Detecção (ND) 102

Tabela 26: Escala de referência para pontuação da Severidade Financeira (SF) 103

Tabela 27: Formulário do W-FMEA preenchido (parte 1) 118

Tabela 28: Formulário do W-FMEA preenchido (parte 1) 119

Tabela 29: Resultado compilado da aplicação do W-FMEA com a utilização do GINC 120

Tabela 30: W-FMEA com índices de priorização RPN e RAV (parte 1) 121

Tabela 31: W-FMEA com índices de priorização RPN e RAV (parte 2) 122

Tabela 32: W-FMEA revisado depois das implantações (parte 1) 127

Tabela 33: W-FMEA revisado depois das implantações (parte 2) 128

Tabela 34: W-FMEA resultado depois das implantações 129

Tabela 35: Modos de desperdício incluídos no checklist de desperdícios de escritório 131

Tabela 36: Formulário de apoio para cálculo do GINC do W-FMEA não preenchido 132 


\section{Lista de Gráficos}

Gráfico 1: Necessidades nos projetos de consultoria da Elo Group (Quais as motivações para adotar iniciativas de BPM?, 2011) 20

Gráfico 2: Relação entre projetos de melhoria bem-sucedidos, abandonados e fracassados (A união entre a sua empresa e a gestão de projetos, 2011)

Gráfico 3: Histograma dos possíveis valores de RPN (SANKAR; PRABHU, 2001) 66

Gráfico 4: Gráfico de Área para interpretação dos resultados do FMEA (PALADY, 1997) 67

Gráfico 5: Gráfico de Áreas da Aplicação Piloto do Método 88

Gráfico 6: Comparação do lead time médio do fluxo de processamento de pedidos no período de maio a agosto dos anos de 2010 e 2011 126

Gráfico 7: Comparação da quantidade de pedidos processados por semana entre maio e agosto de 2010 e de 2011 126 



\section{Lista de Abreviaturas e Siglas}

DMAIC - Define, Measure, Analyze, Improve, Control

E-RPN - Efficiency Risk Priority Number

EUA - Estados Unidos da América

FMEA - Failure Mode and Effect Analysis

FMECA - Failure Mode and Effect Criticality Analysis

GINC - Grau de Impacto Negativo da Causa

GM - General Motors

ISO - International Organization for Standardization

JIT - Just In Time

LM - Lean Manufacturing

$\mathbf{L P}$ - Lean Production

ND - Nível de Detecção

NPR - Número de Prioridade de Risco

PDCA - Plan, Do, Check, Act

PE - Produção Enxuta

PEx - Process Excellence

PO - Probabilidade de Ocorrência

Q-RPN - Quality Risk Priority Number

RAV - Risk Assessment Value

RPN - Risk Priority Number

SERVQUAL - Service Quality

SFMEA - Service Failure Mode and Effect Analysis 
SF - Severidade Financeira

STP - Sistema Toyota de Produção

TPS - Toyota Production System

W-FMEA - Waste Mode, Failure Mode and Effect Analysis

WIP - Work In Process 


\section{Sumário}

1. INTRODUÇÃO

1.1. Objetivos 23

1.2. Classificação da Pesquisa ___ 23

1.3. Etapas de Desenvolvimento da Pesquisa ___ 25

1.4. Estrutura do Texto __ 27

2. PRODUÇÃO ENXUTA: CONCEITOS E CATEGORIZAÇÃO DE DESPERDÍCIOS ___ 29

2.1. Conceitos Fundamentais __ 30

2.2. Os Desperdícios na Manufatura e no Escritório___ 37

3. FMEA NO CONTEXTO DE MELHORIA CONTÍNUA_ 47

3.1. Método FMEA _ 51

3.2. Abordagens Alternativas do FMEA___ 68

4. PLANO DE DESENVOLVIMENTO___ 81

4.1. Etapas da Pesquisa-ação ___ 81

4.2. Ciclo Preliminar de Pesquisa __ 83

4.3. Proposta Conceitual do Método W-FMEA ___ 91

4.3.1. Objetivos e Formulação ___ 91

4.3.2. Checklists dos desperdícios____ 94

4.3.3. Escalas de Probabilidade de Ocorrência, Nível de Detecção e Severidade Financeira ___ 99

4.3.4. Resultados e Interpretação do W-FMEA __ 104

4.4. Planejamento da Aplicação __ 106

5. W-FMEA: APLICAÇÃO E RESULTADOS _ 109

5.1. Definição da Equipe e dos Indicadores de Resultado __ 110

5.2. Mapeamento do Fluxo _ 112

5.3. Aplicação do Método W-FMEA __ 116

5.4. Ações Implantadas e Compilação dos Indicadores __ 123

5.5. Adaptações da Proposta Inicial __ 130

6. CONSIDERAÇÕES FINAIS___ 133

6.1. Questão de Pesquisa e Objetivos___ 133

6.2. Conclusões _ 135

6.3. Limitações e Trabalhos Futuros __ 137

7. REFERÊNCIAS__ 139 
8.1. Mapa de Fluxo de Informação dos Produtos de Madeira 147

8.2. Análise Crítica do Mapa de Fluxo de Informação dos Produtos de Madeira 149 


\section{INTRODUÇÃO}

A competição em diversos segmentos de todos os setores da economia tem aumentado com o passar do tempo. As empresas, portanto, têm buscado formas de obter diferenciais competitivos e reduzir seus custos para conseguirem manter suas fatias de mercado e seus lucros.

A necessidade de redução de custos e melhora no desempenho dos processos internos da organização coincide com a demanda do mercado por produtos e serviços de alta qualidade e alto valor agregado.

Taj e Morosan (2011) corroboram estes fatos mencionando que, hoje em dia, para se tornarem ou continuarem competitivas, as empresas têm enfrentado um cenário sem precedentes. Os autores citam que é necessário que as empresas ofereçam produtos e serviços de alta qualidade e, além disso, melhorem suas operações administrativas e de manufatura para conseguirem obter baixos custos. Ainda segundo Taj e Morosan (2011), para que as empresas consigam obter estes baixos custos, é necessário que consigam eliminar desperdícios e perdas, reduzindo, ao máximo, as atividades que não agregam valor aos seus produtos ou serviços.

Corrêa e Corrêa (2005) acrescentam que a qualidade de um produto ou serviço é adquirida durante seus processos de produção e não é apenas um kit que pode ser instalado ao fim. Assim, o foco das iniciativas de melhoria de qualidade deve ser nos processos, e também deve ser simultâneo aos mesmos.

Entretanto, Parasuraman (2002) alerta para o fato de que, apesar do consenso existente em relação à necessidade que as empresas têm de melhorar seus processos para entregar mais valor e maior qualidade, os custos disso são muitas vezes desconhecidos e negligenciados.

Portanto, para melhorar a qualidade dos processos de uma empresa e reduzir os custos de seu sistema de maneira sustentável, conclui-se que devem ser tomadas ações para melhorar a qualidade dos processos e para eliminar os desperdícios existentes nos fluxos destes processos. Neste contexto, nota-se uma importância crescente de conceitos, metodologias, técnicas e ferramentas de melhoria contínua, entre as quais, se destacam as seguintes abordagens: 
- Produção Enxuta, que têm como objetivo melhorar o desempenho de sistemas produtivos (manufatureiros e de serviços) em termos de redução de custos e aumento de velocidade de entrega por meio da eliminação de desperdícios e perdas (atividades que não agregam valor ao produto ou serviço); e

- Gestão da Qualidade, que têm como objetivo melhorar a qualidade dos produtos e serviços por meio do aumento da qualidade e da confiabilidade de seus processos de produção.

Um estudo de 2008 da consultoria Elo Group revelou que a maior parte de sua demanda se refere a projetos de melhoria com foco em gestão, agilidade para mudanças, redução de custos e aumento de produtividade (Gráfico 1). Experiências anteriores do autor levam a mesma conclusão.

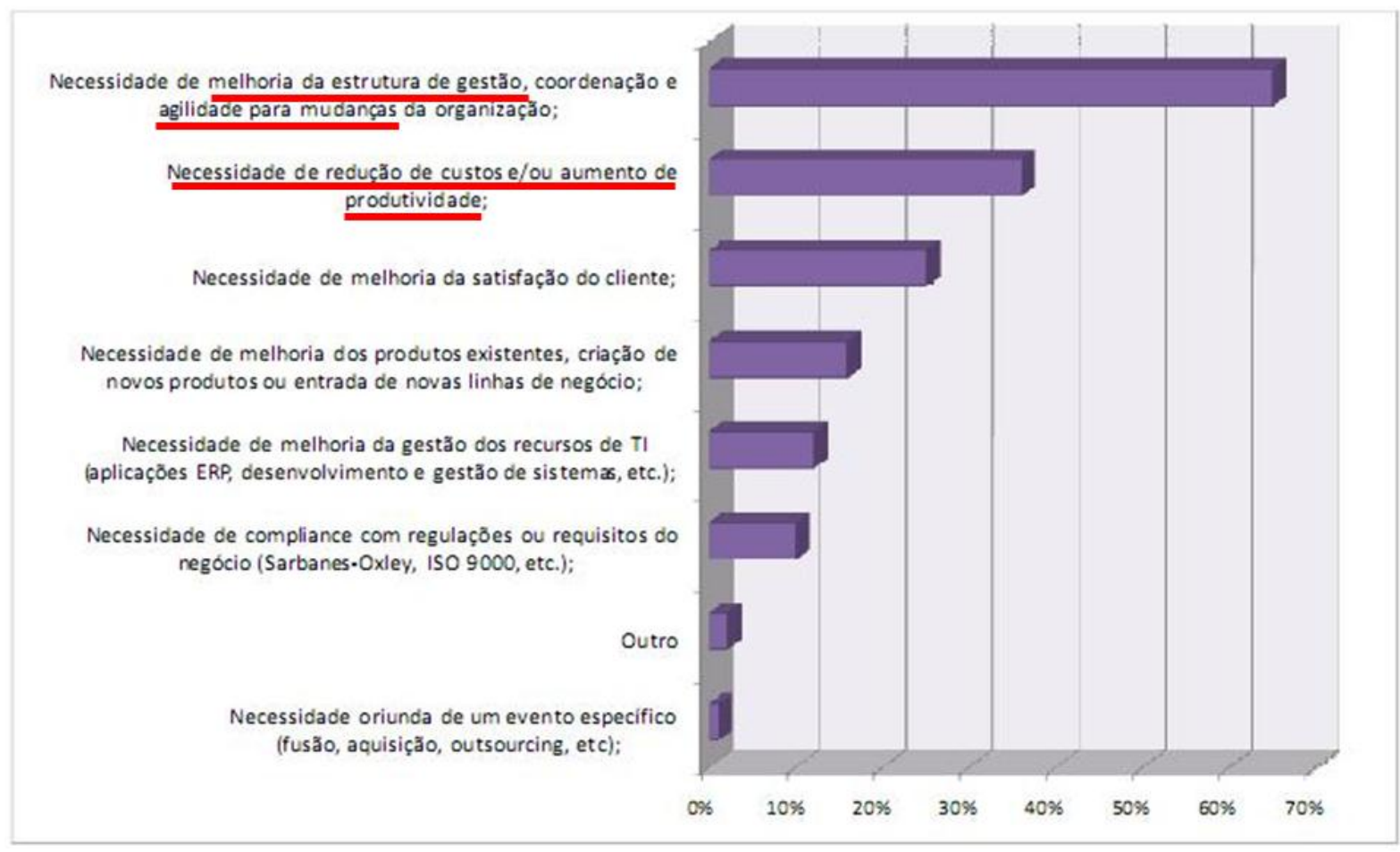

Gráfico 1: Necessidades nos projetos de consultoria da Elo Group (Quais as motivações para adotar iniciativas de BPM?, 2011)

Com essa demanda latente por estes tipos de projetos de melhoria, as técnicas da Produção Enxuta vêm sendo cada vez mais aplicadas nas empresas. Porém, autores como, Shah e Ward (2003), McLachlin (1997) e Furini (2009), destacam que, embora os conceitos e 
técnicas da Produção Enxuta tenham sido amplamente divulgados e aplicados, poucas empresas conseguem sucesso pleno na implantação.

Apesar de aparentemente não existirem muitos estudos e dados sobre a taxa de sucesso de projetos de melhoria em geral, um levantamento da Revista Fortune, realizado no ano de 1999, demonstra que o cenário era preocupante na época (Gráfico 2). Levando em conta os outros estudos dos autores citados no parágrafo anterior, a situação não melhorou muito.

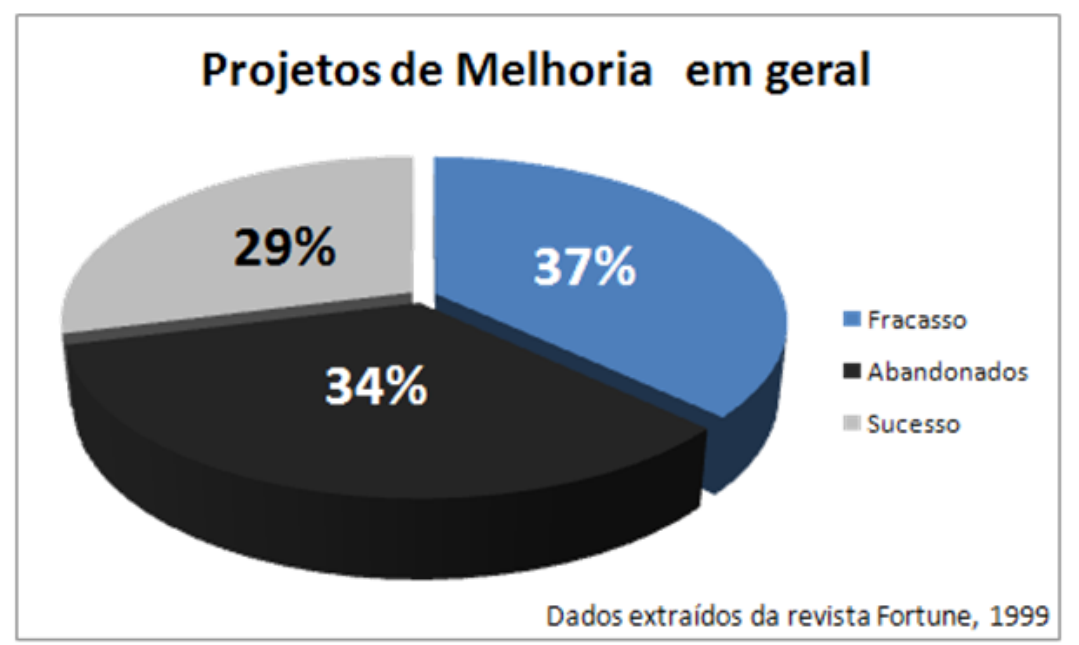

Gráfico 2: Relação entre projetos de melhoria bem-sucedidos, abandonados e fracassados (A união entre a sua empresa e a gestão de projetos, 1999)

A Revista Fortune de 1999 cita que definição deficiente ou não realista de objetivos e planejamento deficiente ou inexistente são as principais causas do fracasso dos projetos de melhoria analisados no Gráfico 2.

Empresas têm enfrentado esses tipos de problemas quando, nas tentativas de melhorias em seus processos por meio da aplicação dos conceitos do Lean, têm sentido dificuldade em identificar os pontos mais críticos do sistema, e assim conseguir priorizar as ações de melhoria capazes de gerar mais impacto positivo.

Sawhney et al. (2010) confirmam essa afirmação expondo fatos que contribuem para o insucesso das implantações de Produção Enxuta como, por exemplo: a falta de planejamento de algumas empresas para as implantações, que acabam por transferir os desperdícios de um local do sistema para outro, e a utilização dos conceitos e ferramentas do Lean com o único objetivo de obter ganhos de curto prazo.

Tendo em vista a grande necessidade de aplicação de técnicas de redução de custos e melhoria de qualidade e a alta taxa de insucesso das implantações destas técnicas devido, 
principalmente, a uma deficiência de planejamento e priorização de ações, surge a oportunidade de criar um método capaz de auxiliar a priorização de ações de melhoria, com o objetivo de melhorar a taxa de sucesso dos projetos de Produção Enxuta e Gestão da Qualidade.

Uma técnica consagrada no contexto de melhoria contínua de produtos e processos, que tem como objetivo, segundo Sankar e Prabhu (2001), identificar falhas existentes ou potenciais e priorizar a eliminação ou prevenção das mesmas, é o FMEA (Failure Mode and Effect Analysis), em português, Análise dos Modos/Tipos de Falha e seus Efeitos.

August (2002) cita que o FMEA, primeiramente usado para desenvolvimento e melhorias de produtos, tem sido cada vez mais usado para melhorias em processos de manufatura e de manutenção, também para identificação de falhas e suas consequiências. Outros autores como, por exemplo, Ookalkar A., Joshi e Ookalkar D. (2009), Inoue e Yamada (2010) e Sawhney et al. (2010), apresentam abordagens do FMEA diferentes das tradicionais, ou seja, para priorização de ações de melhoria em contextos diferentes.

Então, nota-se que o FMEA é um método bastante aceito e aplicado como método de priorização e planejamento de ações de melhoria.

Tradicionalmente, o FMEA é utilizado como método para identificação de falhas e defeitos e priorização de ações de melhoria de confiabilidade e qualidade em produtos e processos. Para a Produção Enxuta, falhas e defeitos fazem parte de apenas uma categoria de desperdícios, entre as sete clássicas: superprodução, estoques, esperas, transporte, movimentação, processos inadequados e defeitos. As análises realizadas com o método FMEA (causas, efeitos, probabilidade de ocorrência, severidade e nível de detecção de falhas e defeitos) poderiam também ser feitas para as outras categorias de desperdício classificadas pela Produção Enxuta. Logo, justifica-se um estudo de como utilizar o FMEA aliado aos conceitos do Lean, para guiar melhorias de confiabilidade, qualidade e redução de desperdícios em fluxos de processos manufatureiros ou administrativos.

Sawhney et al. (2010) mencionam que uma revisão exaustiva da literatura feita por eles não identificou nenhum método explicitamente desenvolvido para melhorar a confiabilidade de sistemas Lean, além da proposição de integração destes conceitos feita por Smart et al. ${ }^{1}$ (2003). Ainda, o método proposto por Sawhney et al. (2010) têm como principal objetivo a

\footnotetext{
${ }^{1}$ Smart, P. K., Tranfield, D., Deasley, P., Levene, R., Rowe, A. and Corley, J. (2003), “Integrating 'Lean' and 'high reliability' thinking”, Proceedings of the Institution of Mechanical Engineers, Vol. 217 No. 5, pp. 733-9.
} 
garantia de sustentabilidade dos sistemas Lean, e não a identificação, priorização e eliminação de desperdícios em manufatura e serviços.

Portanto, com a necessidade existente de uma forma eficaz de priorização e planejamento de ações de melhoria em implantações de Produção Enxuta, a questão de pesquisa que esse trabalho pretende responder é:

1. Como usar o FMEA para analisar os desperdícios de fluxos de processos (de acordo com a classificação da Produção Enxuta) e priorizar ações de melhoria?

\subsection{Objetivos}

Tendo em vista o que foi abordado anteriormente na contextualização e justificativa da pesquisa, o que se propõe como objetivo principal deste trabalho é: Desenvolver uma adaptação do método FMEA para gestão de melhoria em manufatura e processos administrativos baseada na análise dos desperdícios classificados pelas teorias da Produção Enxuta.

Para isso, foram definidos os seguintes objetivos secundários:

- Identificar, na literatura, teorias do Lean para os conceitos de desperdícios e suas fontes, em processos de manufatura e administrativos;

- Identificar, também na literatura, as formas alternativas de aplicação do FMEA em manufatura, serviços e aliado aos conceitos de Lean;

- Desenvolver dois checklists de fontes de desperdícios (um para manufatura e um para processos administrativos) para servir de guia para identificação das causas dos desperdícios durante a aplicação do método; e

- Estruturar uma proposta do método a partir de uma aplicação do mesmo.

\subsection{Classificação da Pesquisa}

Segundo Gil (1991), uma pesquisa é um procedimento racional e sistemático para responder às questões que são propostas. Gil (1991) ainda menciona que, apesar de as pesquisas serem geralmente classificadas como "puras" (quando "decorrem do desejo de 
conhecer pela própria satisfação de conhecer") ou "aplicadas" (quando "decorrem do desejo de conhecer com vistas a fazer algo de maneira mais eficiente ou eficaz"), é errado considerar essas duas classificações como mutuamente exclusivas. Uma pesquisa "pura" pode gerar conhecimento pronto para ser aplicado na prática, e uma pesquisa "aplicada" possivelmente conduzirá a agregação de novos conceitos científicos.

Para formular um problema de pesquisa, deve ser levado em conta o componente da criatividade no processo, já que, dificilmente, a formulação de um problema é decorrente de procedimentos rígidos e sistemáticos. Porém, algumas regras podem auxiliar a formulação do problema, são elas: o problema deve ser formulado como pergunta, o problema deve ser claro e preciso, o problema deve ser empírico, o problema deve ser suscetível de solução e o problema deve ser delimitado a uma dimensão viável (GIL, 1991).

Todas as regras descritas no parágrafo anterior foram consideradas para a formulação dos problemas de pesquisa deste trabalho.

Para Silva e Menezes (2005), as pesquisas podem ser classificadas de quatro pontos de vista:

1- Natureza da pesquisa: pode ser pesquisa básica, que tem como objetivo gerar novos conhecimentos úteis para a ciência e envolve assuntos universais; ou pode ser pesquisa aplicada, que objetiva gerar conhecimentos para serem aplicados na prática e envolve assuntos locais.

2- Abordagem do problema: pode ser pesquisa quantitativa, que considera o que pode ser quantificado e requer o uso de técnicas estatísticas; ou pode ser pesquisa qualitativa, que considera uma relação entre o mundo real e o sujeito, não requer o uso de técnicas estatísticas e coloca o pesquisador como elemento chave, já que este tende a analisar indutivamente os resultados.

3- Objetivos da pesquisa: pode ser pesquisa exploratória, que objetiva tornar explícito um problema ou construir hipóteses sobre o mesmo (geralmente envolve pesquisa bibliográfica e estudo de caso); pode ser pesquisa descritiva, que objetiva estabelecer relações entre variáveis e descrição de características, envolve o uso de técnicas de coleta de dados e geralmente se configura em um levantamento; ou pode ser pesquisa explicativa, que tem como objetivo identificar fatores que acarretam na ocorrência de fenômenos e explicar a razão das coisas (GIL, 1991) (SILVA; MENEZES, 2005).

4- Procedimentos técnicos: pesquisa bibliográfica, que se baseia em material já publicado; pesquisa documental, baseada em material que não recebeu tratamento analítico; pesquisa experimental, baseada na escolha de um objeto de estudo e 
monitoramento das variáveis capazes de influenciá-lo; levantamento, baseada em interrogação de pessoas cujo comportamento é objeto de conhecimento; estudo de caso, baseado no estudo de um ou poucos elementos para permitir detalhado conhecimento; pesquisa expoxt-facto, baseada em experimentos realizados depois de fatos; pesquisa ação, baseada em uma ação ou resolução de um problema coletivo, onde os pesquisadores são participantes do processo; ou pesquisa participante, baseada no envolvimento do pesquisador com as pessoas da situação investigada.

Essa pesquisa será enquadrada como:

- Pesquisa aplicada, do ponto de vista de sua natureza, já que o método a ser desenvolvido tem o objetivo de ser aplicado na prática;

- Pesquisa qualitativa, do ponto de vista de sua abordagem, já que o pesquisador será elemento-chave na análise e a pesquisa vai buscar a relação entre o real e o método proposto;

- Pesquisa descritiva, do ponto de vista de seus objetivos, já que buscará estabelecer relações entre variáveis e características por meio da aplicação de um método e coleta de dados; e

- Pesquisa ação, do ponto de vista dos procedimentos técnicos, já que a pesquisa foi realizada paralelamente com uma ação ou resolução de um problema coletivo e o pesquisador participará de modo cooperativo da aplicação.

\subsection{Etapas de Desenvolvimento da Pesquisa}

Identificou-se, primeiramente, uma oportunidade de pesquisa, pelo fato de que existe certa dificuldade para identificação de tipos de desperdícios e suas causas em fluxos de processos. Por isso, muitas vezes há dificuldade de planejamento e priorização de ações de melhoria para estes fluxos e, assim, alguns esforços realizados podem não obter o êxito almejado.

Depois de identificada esta oportunidade, a partir de conceitos amplamente difundidos como o método FMEA e a metodologia da Produção Enxuta, desenvolveu-se uma idéia de utilizar o método FMEA para análise de todos os tipos de desperdícios possíveis em um fluxo de processos, ao invés de utilizá-la apenas para análise do desperdício de falhas, defeitos e não conformidades. 
Com a idéia formulada, buscou-se na literatura contextualizar a necessidade da busca por melhoria da qualidade e por redução de custos vivenciada pelas empresas em geral. Além disso, foi contextualizada a problemática que consiste na dificuldade de planejamento, priorização e confiabilidade das ações de melhoria de qualidade e redução de custos mencionada.

O próximo passo foi definir o objetivo principal deste trabalho e, também, os objetivos secundários que guiariam a pesquisa para o cumprimento das metas estabelecidas no objetivo principal.

Então, com a idéia primordial e os objetivos estabelecidos, iniciou-se a fase de levantamento da bibliografia. Buscou-se, primeiramente, identificar os conceitos de desperdícios sob a ótica da Produção Enxuta e como estes desperdícios poderiam ser desdobrados, tanto para ambientes de manufatura, quanto para ambientes de escritório. A segunda parte da revisão da literatura foi focada na identificação dos principais conceitos do método FMEA, inclusive algumas metodologias de melhoria contínua e ferramentas da qualidade necessárias para o seu entendimento. O principal objetivo da revisão da literatura sobre FMEA foi identificar maneiras alternativas de priorização dos elementos em análise e abordagens alternativas do FMEA como, por exemplo, a aplicação do método para serviços, desenvolvimento de produtos, sistemas de saúde e sistemas de Produção Enxuta.

A fase seguinte, de planejamento da aplicação do método proposto, teve como principal objetivo descrever uma proposta conceitual do método, com o auxílio de uma aplicação piloto. Esta aplicação piloto foi realizado com uma proposta inicial, essa proposta foi revisada e acrescentada de alguns novos conceitos e, ao fim desta fase, definiu-se o local da aplicação principal deste trabalho.

Para a aplicação principal, foi definida uma equipe da empresa onde o método foi aplicado para acompanhar o pesquisador e foram definidos também os indicadores de resultado da aplicação. O início da aplicação do método se deu ao fim do mapeamento e entendimento do fluxo analisado e, após sua aplicação, foram descritas as ações implantadas e demonstrados os seus resultados. Por fim, foram enumeradas as adaptações identificadas como necessárias para a proposta conceitual do método.

Depois da aplicação e da análise crítica dos resultados foram descritas as conclusões deste trabalho e as propostas de trabalhos futuros, na última seção deste texto. 


\subsection{Estrutura do Texto}

Este texto está dividido em seis capítulos, além de uma seção, ao fim, com a listagem das referências bibliográfica utilizadas e outra com os apêndices. Os capítulos principais deste texto são:

- Introdução;

- Produção Enxuta: Conceitos e Categorização de Desperdícios;

- FMEA no Contexto de Melhoria Contínua;

- Plano de Desenvolvimento;

- W-FMEA: Aplicação e Resultados; e

- Considerações Finais.

O primeiro capítulo, 1. INTRODUÇÃO, contém a contextualização do problema e mais quatro seções: 1.1. Objetivos, 1.2. Classificação da Pesquisa, 1.3. Etapas de Desenvolvimento da Pesquisa e esta seção, última do capítulo, 1.4. Estrutura do Texto, que aborda e explicita a organização do texto, principalmente deste ponto em diante.

O segundo capítulo, 2. PRODUÇÃO ENXUTA: CONCEITOS E CATEGORIZAÇÃO DE DESPERDÍCIOS, contempla o levantamento bibliográfico do assunto, bastante focado nos conceitos de desperdícios e suas fontes. O capítulo está dividido em duas seções: 2.1. Conceitos Fundamentais e 2.2. Os Desperdícios na Manufatura e no Escritório. A seção 2.1. consiste na contextualização da evolução dos conceitos da Produção Enxuta, tanto para manufatura como para serviços e processos administrativos, e na apresentação dos principais conceitos relacionados a este tema como, por exemplo, os princípios que o norteiam. Já a seção 2.2 é totalmente focada no conceito de desperdícios, talvez o principal da Produção Enxuta, e o mais relevante para este trabalho. Primeiramente, são abordados os desperdícios sob o ponto de vista da manufatura e, então, são abordados estes conceitos, também sob o ponto de vista de processos administrativos, cada vez mais importantes para as empresas.

O terceiro capítulo, 3. FMEA NO CONTEXTO DE MELHORIA CONTÍNUA, apresenta os principais conceitos do método FMEA e está dividido em duas seções: 3.1. Método FMEA e 3.2. Abordagens Alternativas do FMEA. O capítulo aborda, no início, uma breve contextualização do FMEA e as principais teorias relacionadas, entre elas, as metodologias de melhoria contínua e ferramentas de análises de causas de problemas. A seção 3.1. contempla os principais conceitos do FMEA, desde sua definição, sob o ponto de vista de diversos 
autores, até as técnicas para sua aplicação e interpretação. Por fim, a seção 3.2. busca compilar da literatura algumas abordagens alternativas do FMEA, desenvolvida por autores ao redor do mundo e selecionadas por apresentarem alguma relação com este trabalho.

O quarto capítulo do trabalho, 4. PLANO DE DESENVOLVIMENTO, contém conceitos sobre o tipo de pesquisa desenvolvida neste trabalho (seção 4.1), o relato de uma aplicação piloto e os resultados dessa aplicação (seção 4.2), a proposta conceitual do método em desenvolvimento neste trabalho (seção 4.3) e planejamento da aplicação principal (seção 4.4).

O capítulo cinco 5. W-FMEA: APLICAÇÃO E RESULTADOS, dividido em cinco seções descreve toda a aplicação principal, bem como seus resultados, e, ainda, enumera as adaptações inseridas do método, na proposta conceitual. As seções deste capítulo são: 5.1. Definição da Equipe e dos Indicadores de Resultado, 5.2. Mapeamento do Fluxo, 5.3. Aplicação do Método W-FMEA, 5.4. Ações Implantadas e Compilação dos Indicadores e 5.5. Adaptações da Proposta Inicial.

Por fim, o sexto capítulo, 6. CONSIDERAÇÕES FINAIS, aborda, novamente a questão de pesquisa e os objetivos, demonstrando a conclusão sobre estes (seção 6.1.), aborda, também, as conclusões gerais do trabalho (seção 6.2.) e as limitações e possibilidades de trabalhos futuros (seção 6.3.). 


\section{PRODUÇÃO ENXUTA: CONCEITOS E CATEGORIZAÇÃO DE DESPERDÍCIOS}

A Produção Enxuta, ou Lean, surgiu como um novo sistema produtivo na Toyota Motor Company no final da década de 1940, entretanto, apenas no fim da década de 1980, os conceitos foram popularizados para o mundo ocidental (NAZARENO, 2003).

Segundo Liker (2004), líderes da Toyota costumavam visitar os EUA desde a década de 1930 em busca de aprendizado sobre os conceitos e técnicas dos sistemas produtivos da Ford e da GM. Porém, havia um abismo entre as características do mercado norte-americano e do japonês, na época, que impossibilitava a aplicação das técnicas de produção em massa fordistas no país oriental. Devastado pela Segunda Guerra Mundial, o Japão também não dispunha de muitos recursos, o que fez Taiichi Ohno, engenheiro da Toyota na época, buscar uma nova forma de produzir carros que não necessitasse muitos recursos e que conseguisse atender a uma demanda bastante estratificada, o que exigia grande flexibilidade de suas linhas de produção.

Neste contexto, começava a surgir um novo sistema produtivo, quebrando diversos paradigmas da produção em massa, o Sistema Toyota de Produção - STP (Toyota Production System - TPS), que hoje, em virtude da disseminação de seus conceitos pelo livro "A máquina que mudou o mundo" de Womack e Jones, também é conhecido como Lean, Lean Manufacturing (LM), Lean Production (LP) ou Produção Enxuta (PE). Neste trabalho qualquer um dos termos abordados neste parágrafo se referirão ao sistema produtivo cujos conceitos serão tratados neste Capítulo.

Com a disseminação dos conceitos e técnicas empregadas no Sistema Toyota de Produção para o mundo ocidental, o Lean passou, então, a ser amplamente aplicado na indústria automobilística, principalmente, e em outros setores da indústria, desde o início da década de 1990 (FRANCISCHINI; MIYAKE; GIANNINI, 2006).

Em 1996, de acordo com Piercy e Rich (2009), Womack e Jones propuseram a adaptação dos conceitos do Lean Manufacturing para melhorias em serviços também, e muitos pesquisadores e praticantes do Lean atenderam a esse chamado.

As primeiras extensões da aplicação dos conceitos do Lean fora da manufatura podem ser identificadas, primeiramente, na gestão de cadeias de suprimentos. Era perceptível que 
construir relações mais próximas entre clientes e fornecedores poderia gerar benefícios para todos, como melhor compartilhamento de informações, inovações e reduções de custos. Depois, a segunda adaptação dos conceitos de Lean foi feita para sistemas de saúde, com a adoção de gestão de compras para diminuição de estoques, melhorando a resposta do sistema e enxugando os custos (PIERCY; RICH, 2009).

Para Bowen e Youngdahl (1998), é possível perceber que o conceito de linha de produção, que foi concebido em ambientes de manufatura, é aplicado para organizar fluxos administrativos, por exemplo. Além disso, outros conceitos e técnicas do Lean estão sendo considerados, atualmente, para o aperfeiçoamento de fluxos administrativos, de ambientes de sistemas de saúde (healthcare systems), fluxos logísticos, entre outros, com o objetivo de torná-los mais enxutos.

Este capítulo resume os principais conceitos da Produção Enxuta, com enfoque especial para o conceito de desperdícios e suas fontes, tanto em ambientes de manufatura quanto administrativos. O conceito de desperdício é parte fundamental do método em desenvolvimento nesta pesquisa.

\subsection{Conceitos Fundamentais}

Taj e Morosan (2011) mencionam estudos sobre o Sistema Toyota de Produção e identificam que este é composto por duas principais vertentes: o sistema de produção Just-intime (JIT) e o sistema de respeito ao trabalhador que foca em participação ativa e consideração pela segurança dos funcionários e eliminação de movimentos desnecessários feitos por eles. Sobre o JIT, os autores identificam seis práticas: redução dos tempos de setup, flexibilidade de programação, manutenção, layout dos equipamentos, sistema Kanban (produção puxada) e relacionamento Just-in-time com os fornecedores.

Porém, ao contrário do que algumas empresas entendem, de acordo com Badurdeen, Wijekoon e Marksberry (2011), o Lean não é apenas um kit de ferramentas (5S, gestão visual, kaizen, etc.), mas sim um sistema criado a partir de conceitos fundamentais e de uma mudança de cultura.

Um resultado importante das pesquisas de Womack e Jones acerca desses conceitos, que vão além das ferramentas, empregados nas indústrias japonesas, principalmente na Toyota, foi apresentado no livro "Lean Thinking - Banish waste and create wealth in your corporation", 
primeira edição de 1996. Os autores definiram, o que consideraram na época, os princípios que norteavam o Sistema Toyota de Produção.

O termo Lean Thinking, em português, Pensamento Enxuto, popularizado depois do lançamento do livro citado no parágrafo anterior, é definido por Shetty, Ali e Cummings (2010) como uma metodologia que muitas empresas de manufatura, de serviços e governamentais têm adotado para adquirir a competitividade necessária atualmente. Para estes autores, os conceitos do Pensamento Enxuto permitem que essas empresas encontrem formas de fazer mais com menos esforço humano, menos tempo, menos equipamentos e menos espaço.

Uma vez identificado o principal propósito do STP, que, segundo Liker (2004) é eliminar perdas e desdeperdícios e para Turati e Museti (2006) traduz-se como gerenciar a produção e o trabalho de forma a "atender aos clientes no menor tempo possível, na mais alta qualidade e com o menor custo possível", para Womack e Jones (2003), e ratificados por Cabral e Andrade (1998), Lago, Carvalho e Ribeiro (2008), Piercy e Rich (2009), Silva e Rentes (2002), Hines \& Taylor (2000), Shetty, Ali e Cummings (2010), Shah e Ward (2003), os cinco princípios que definem o Lean são:

1- Encontrar o valor: esse princípio consiste no esforço da empresa para encontrar e especificar o valor sob a ótica do cliente. Erroneamente, algumas empresas definem o valor de seus produtos sob suas próprias perspectivas, enquanto, na realidade, quem enxergará valor no produto e, assim, escolherá um produto entre produtos concorrentes será o cliente. O objetivo é descobrir por quais requisitos e características os clientes estão dispostos a pagar.

2- Enxergar o fluxo de valor: esse princípio consiste em enxergar o fluxo de atividades necessárias para transformar um produto ou serviço partindo de um estágio inicial para um estado futuro desejado. O fluxo de valor engloba todas as atividades no âmbito de desenvolvimento do produto/serviço (concepção ao lançamento), gerenciamento das informações (pedido à entrega) e transformação física (matéria-prima a produto/serviço acabado). A partir do entendimento do fluxo de valor, é possível determinar quais atividades serão consideradas atividades que agregam valor ao produto, isto é, aquelas por quais os clientes estão dispostos a pagar, e quais atividades não agregam valor (chamadas desperdícios) que devem ser eliminadas. 
3- Fazer as atividades fluírem: esse princípio consiste em, a partir da visão do fluxo de valor, eliminar os passos desnecessários e as esperas entre as atividades que agregam valor, atuando de forma a fazer com que as atividades fluam sem paradas e interrupções, eliminando qualquer desperdício que impeça o fluxo contínuo.

4- Puxar a produção: esse princípio consiste em definir o momento certo para fazer as atividades fluírem. Esse momento é definido pelo cliente (interno ou externo) e, só a partir da demanda do cliente deve ser disparada a produção, em fluxo contínuo, do produto ou serviço requisitado.

5- Buscar a perfeição: esse princípio consiste na busca incessante por desperdícios e causas de interrupções dos fluxos com o intuito de eliminá-los continuamente e seguir em direção à perfeição.

Shetty, Ali e Cummings (2010) definiram os princípios do Lean de maneira mais direta e simples, que validam os princípios da literatura, por meio das informações coletadas em uma pesquisa de seis meses em empresas predominantemente manufatureiras. De acordo com esses autores, pode-se concluir de sua pesquisa que os princípios do Lean Thinking são: padronização, cultura, pessoas, melhoria contínua, qualidade superior, eliminação de desperdícios e entendimento das necessidades dos clientes. Na Figura 1, pode-se enxergar a proposta de princípios definida por Shetty, Ali e Cummings (2010), onde constam além dos princípios, as ações necessárias em um ambiente Lean, baseadas em três pilares (Tecnologia, Sistema e Pessoas): produção em lotes pequenos, redução dos tempos de ciclo, fluxo estruturado na manufatura, equipamento adequados, produção nivelada, manutenção preventiva, parcerias com fornecedores, sistema puxado de produção, envolvimento total dos funcionários, controle visual de processos, organização e limpeza e foco total na qualidade. 


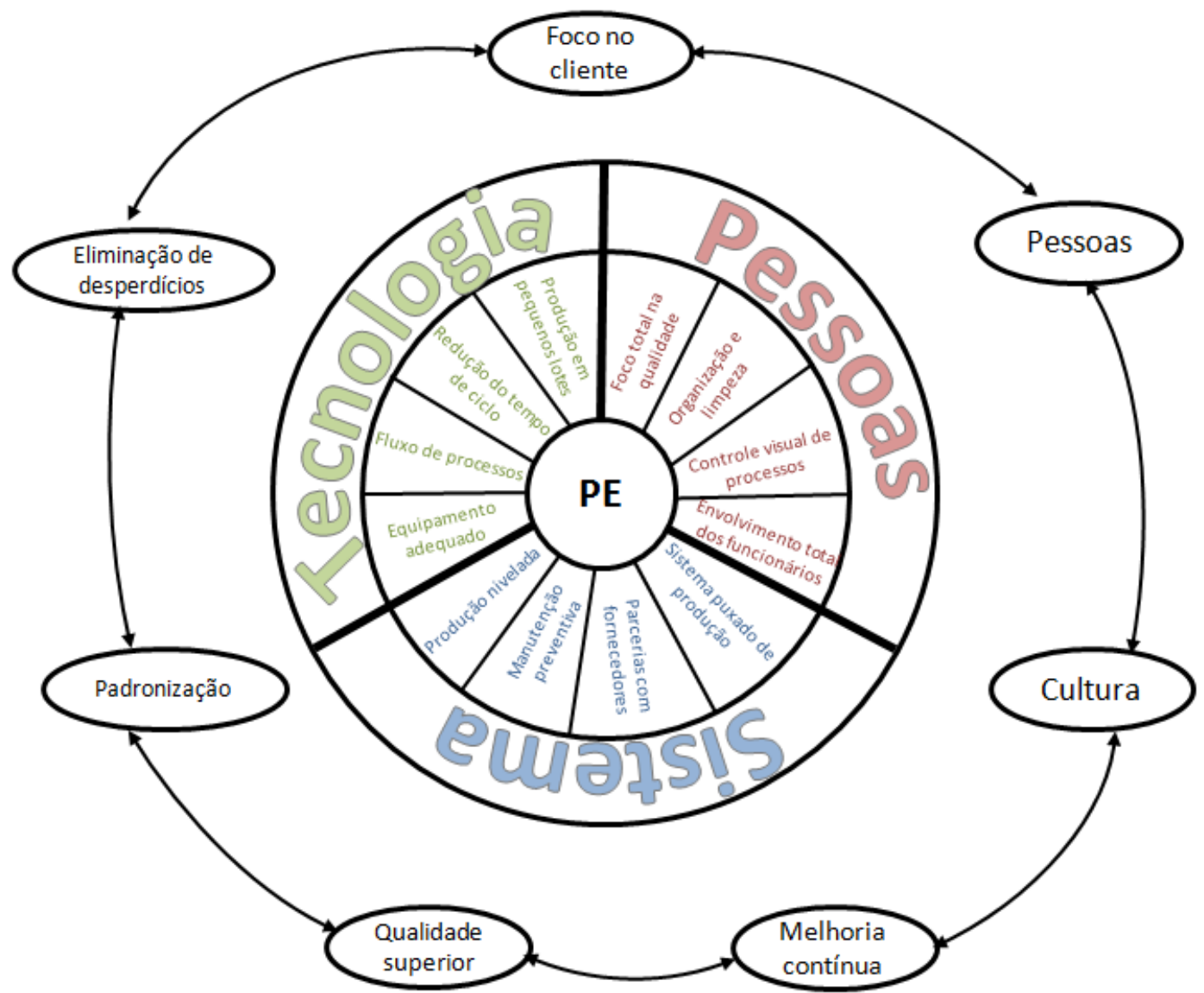

Figura 1: Princípios de Lean Thinking e ações necessárias (adaptado de SHETTY; ALI; CUMMINGS, 2010)

Liker (2004) ainda define alguns outros princípios que norteiam a produção enxuta que podem ser aplicados a qualquer ambiente: eliminação de desperdícios de tempo e recursos, construção de qualidade nos sistemas dos locais de trabalho, descoberta de alternativas confiáveis e de baixo custo para tecnologias novas e caras, aperfeiçoamento dos processos administrativos e construção de uma cultura de aprendizagem e melhoria contínua.

Como se pode concluir, esses princípios são aplicáveis tanto na manufatura como em processos administrativos e serviços, e alguns autores pesquisaram, recentemente, tanto formas para traduzir estes conceitos para processos administrativos quanto os empecilhos encontrados nos ambientes administrativos e de serviços, criando vertentes do Lean, conhecidas como Lean Office ou Escritório Enxuto, e Lean Service, a aplicação do Lean para empresas de serviços. Essas duas vertentes (Lean Office e Lean Service) muitas vezes se confundem, principalmente pelo fato de que os principais tipos de desperdícios encontrados em prestação de serviços são identificados no back office (escritório) e, portanto, as técnicas de combate a estes desperdícios muitas vezes são chamadas de Lean Office. Entre os autores 
que tratam de Lean Service e Lean Office, pode-se citar: Bowen e Youngdahl (1998), Tapping e Shuker (2003), Lareau (2002), Lago, Carvalho e Ribeiro (2008), Turati e Musetti (2006).

Lago, Carvalho e Ribeiro (2008) afirmam que, na maioria das empresas, as operações administrativas podem representar $25 \%$ do custo total de um produto e contribuir com mais da metade do lead time (tempo de atravessamento) entre o pedido do cliente e a entrega do produto/serviço, por isso a importância dos processos nestes ambientes. Os autores enumeram algumas características que fazem com que as atenções fiquem mais concentradas na manufatura do que nos fluxos administrativos, apesar do fato de os processos administrativos serem tão críticos quanto os processos de manufatura:

- Inexistência e/ou dificuldade de medição dos lead times dos processos administrativos;

- Análise de custo baseada no trabalho direto;

- Falta de visão dos benefícios atrelados à redução do lead time dos processos administrativos; e

- Falta de conhecimento sobre como aplicar as técnicas do Lean para fluxos administrativos e de serviços.

Para McManus² (2003), apud TURATI; MUSETTI (2006, p.3), uma dificuldade presente em maior escala nos fluxos administrativos do que nos fluxos de manufatura é a definição do fluxo de valor e das atividades que agregam ou não valor ao serviço. Isso decorre do fato de que a medição dos lead times e a diferenciação entre tempo gasto com agregação de valor e tempo desperdiçado é bastante dificultada.

Lago, Carvalho e Ribeiro (2008) ainda acrescentam uma lista de possíveis obstáculos enfrentados pelas pessoas com maior freqüência em ambientes administrativos do que em ambientes de manufatura, são eles: as pessoas serem constantemente interrompidas, as pessoas estarem geralmente muito atarefadas, as pessoas atrasarem-se na entrega de relatórios e/ou compra de materiais, as pessoas seguirem procedimentos muito burocráticos, as pessoas não se comunicarem, as pessoas desconhecerem os processos internos e as pessoas se utilizarem de documentos desnecessários.

\footnotetext{
${ }^{2}$ McMANUS, H. (2003). Product Development value stream analysis and mapping manual (PDVMS) - Alpha Draft. Lean Aerospace Initiative. Cambridge: Massachusetts Institute of Technology.
} 
Bowen e Youngdahl (1998) também comentam características que diferem a manufatura dos ambientes administrativos e, potencialmente, também colaboram para maior dificuldade na transformação destes últimos em ambientes enxutos, como, por exemplo: maior padronização das atividades e procedimentos melhor definidos nos ambientes de manufatura do que nos ambientes administrativos e melhor uso da tecnologia aliada às necessidades dos operadores e maior divisão do trabalho em ambientes de manufatura, proporcionando a especialização dos operadores em atividades mais rotineiras e menos extensas. Essas características são fundamentais para ganho de produtividade de ambientes de manufatura.

Assim, Bowen e Youngdahl (1998) analisam os princípios do Lean e adicionam alguns outros princípios que podem guiar empresas na melhoria dos fluxos de manufatura e, também, nos fluxos administrativos e nos seus serviços, gerando a lista de princípios que segue:

1- Reduzir o tradeoff de performance entre produção em massa e flexibilidade de produção: o Lean é capaz de combinar técnicas de produção em massa e de flexibilização da produção se beneficiando de aumentar a variedade de oferta de seus produtos/serviços sem perder eficiência e produtividade. Em conseqüência, os clientes são beneficiados com o aumento da variedade dos produtos/serviços ofertados.

2- Fazer os processos de agregação de valor fluírem e puxar a produção pelo cliente: abandonar a produção em escala e as interrupções e esperas entre os processos para garantir que as atividades ocorram em fluxo contínuo. Disparar a produção pelas demandas dos clientes (internos ou externos) auxiliando a redução e eliminação de estoques em processos e de produtos acabados.

3- Eliminar os desperdícios da cadeia de valor que compreende as atividades desde o desenvolvimento do produto até sua entrega: eliminar todas as atividades que não agregam valor implantando técnicas para resolução de problemas e identificando atividades geradoras de desperdícios. Muitas das fontes de desperdícios que acontecem em ambientes de produção em grandes lotes podem ser identificadas através da análise do fluxo de valor.

4- Aumentar o foco e envolvimento dos clientes no desenvolvimento dos produtos e nos processos de entrega: fazer com que os clientes participem ativamente das etapas onde sejam necessárias análises e aprovações dos mesmos. Estimular a troca de informações entre clientes e fornecedores, inclusive de programação da produção, pode auxiliar a cadeia a operar com desempenho cada vez melhor. 
5- Dar poder aos trabalhadores e aos times: estimular e dar a responsabilidade da resolução de problemas e tomadas de decisão para times e trabalhadores. Empowerment dos times e trabalhadores e grande participação em decisões, estímulo do trabalho em equipe, rotação no trabalho e treinamentos diversos, participação em resultados da empresa e programas de socialização são aspectos que auxiliam o emprego deste princípio.

Bowen e Youngdahl (1998) ainda acrescentam outros princípios identificados na empresa Taco Bell que são fundamentais em empresas prestadoras de serviços e em ambientes administrativos de outras empresas:

- Dar igual ou maior importância aos investimentos em pessoas em relação aos investimentos em equipamento;

- Usar a tecnologia como meio para suporte dos trabalhadores ao invés de usá-la como substituta;

- Fazer do recrutamento e contratação aspectos importantes para todos os trabalhadores, e não só os de nível de gerência; e

- Atrelar compensações ao desempenho dos trabalhadores de todos os níveis.

Para nortear o caminho das empresas rumo ao Lean Office, além das considerações sobre os princípios que devem servir de base, Tapping e Shuker (2003) e Lareau (2002) propõem métodos passo a passo de condução das atividades, que podem ser adaptados como:

1- Comprometer-se com o Lean: promover o comprometimento de todos os envolvidos à implantação dos conceitos;

2- Escolher o fluxo de valor a ser atacado: de preferência um fluxo que seja representativo na empresa e para os clientes;

3- Aprender sobre o Lean: promover a multiplicação dos conceitos do Lean para todos da empresa;

4- Mapear o estado atual: para ter claro entendimento da situação e identificar as fontes de desperdício;

5- Identificar as medidas de desempenho do sistema: propor métricas alinhadas aos conceitos de Lean para guiar a implantação no sentido do estado futuro almejado;

6- Mapear o estado futuro: incorporar as propostas de melhoria buscando o fluxo contínuo, a puxada da demanda dos clientes e o nivelamento da carga de trabalho; 
7- Criar planos Kaizen: estabelecendo prazos e formas de se atingir o estado futuro; e

8- Implantar os Kaizen: modificando a situação atual para a situação futura desejada.

Para Rubrich e Watson ${ }^{3}$ (2004) apud LAGO; CARVALHO; RIBEIRO (2008, p.7) e Suri ${ }^{4}$ (1998) apud LAGO; CARVALHO; RIBEIRO (2008, p.7), os resultados da aplicação desses conceitos em ambientes administrativos e de serviços devem ser: mudança da abordagem funcional para abordagem por processos, substituição de meios de comunicação em papel por eletrônicos eficientes, simplificação e padronização de documentos, redução de deslocamento de pessoas, redução de esperas, eliminação de etapas desnecessárias de processamento e conseqüente redução/eliminação de desperdícios.

Para melhor identificar os desperdícios e suas fontes em fluxos de manufatura e administrativos ou de serviços, a próxima seção deste capítulo abordará as categorias de desperdícios existentes na literatura e quais são suas possíveis fontes de acordo com os autores pesquisados.

\subsection{Os Desperdícios na Manufatura e no Escritório}

As atividades dentro de uma empresa são, comumente, classificadas pelos autores de trabalhos sobre Produção Enxuta, entre eles Hines e Taylor (2000) como:

- Atividades que agregam valor: São as atividades realizadas em determinado fluxo que adicionam valor ao produto sob a ótica do cliente. Ou seja, são as atividades de transformação das matérias-primas em produtos acabados pelas quais o cliente está disposto a pagar. Geralmente, essas atividades representam a menor parcela do total das atividades realizadas em um fluxo de material ou de informação.

- Atividades que não agregam valor: São todas as atividades realizadas em determinado fluxo que não adicionam valor algum ao produto, são chamadas também de desperdícios. De fato, essas atividades não adicionam nada além de custo aos produtos ou serviços. Elas podem ser divididas em dois grupos:

\footnotetext{
${ }^{3}$ Rubrich L., Watson M. Implementing World Class Manufacturing, Second Edition, WCM Associates, 2004.

${ }^{4}$ Suri R. Quick Response Manufacturing: A Companywide approach to Reducing Lead Times, Productivity Press, Portland, 1998
} 
necessárias e desnecessárias. As atividades necessárias que não agregam valor são, por exemplo, os setups (regulagem das máquinas) e os transportes de materiais, atividades que não agregam valor, mas que devem ser realizadas por limitações do sistema produtivo em questão. As atividades desnecessárias que não agregam valor são, por exemplo, esperas e produção além do necessário.

Hines e Taylor (2000) identificaram, em pesquisas, que, geralmente, o tempo utilizado para as atividades que agregam valor corresponde apenas a 5\% do tempo disponível total em ambientes de manufatura, enquanto nos setores administrativos a situação é ainda pior: somente $1 \%$ do tempo é utilizado para adicionar valor ao serviço.

Em ambos os casos a situação é preocupante quanto ao volume de tempo e recursos gastos com atividades que não agregam valor ao produto e agregam custo ao sistema.

De acordo com Womack e Jones (2003) os desperdícios são todas as atividades que não agregam valor, tanto as que não são necessárias, que devem ser eliminadas urgentemente, quanto as que são necessárias pelas limitações do sistema produtivo onde se encontram, como, por exemplo, tempos de setup e movimentação.

Para Liker (2004), a eliminação de perdas e desperdícios é o principal princípio do Sistema Toyota de Produção. O autor acrescenta que muitas das ferramentas do STP derivam do conceito da incessante busca por eliminação das atividades que não agregam valor.

Singh et al. (2010) confirmam a afirmação de Liker (2004) acrescentando que o principal objetivo do Lean é reduzir desperdícios de esforço humano, inventário, time to market e espaço no chão de fábrica para tornar o sistema altamente flexível à demanda dos clientes e capaz de produzir com qualidade da maneira mais econômica e eficiente. Singh et al. (2010) mencionam, ainda, que os desperdícios consomem recursos mas não adicionam valor ao produto, e podem ser encontrados a qualquer hora em qualquer local do sistema.

Os desperdícios do Lean foram, primeiramente, identificados por Taiichi Ohno em rondas que este engenheiro costumava fazer, quando trabalhava na Toyota Motor Company, em sua busca incessante pela eliminação de atividades que não agregavam valor. De suas reflexões posteriores, Ohno classificou as atividades que não agregavam valor, denominando-as desperdícios, em sete categorias: superprodução, excesso de estoque, transporte desnecessário, defeitos, espera, superprocessamento ou processamento incorreto e movimentação desnecessária. (LIKER, 2004)

Os desperdícios do Lean do ponto de vista da manufatura podem ser entendidos (SHINGO, 1996) (WOMACK; JONES, 2003) (OHNO, 1988) (LIKER, 2004) (CORRÊA; 
GIANESI; CAON, 2001) (RENTES; SILVA, A; SILVA, V, 2003) (SANCHÉZ; PERÉZ, 2001) (SILVEIRA; COUTINHO, 2008) (WEBER, 2005) (NAZARENO, 2003) como:

- Superprodução é o primeiro desperdício a ser abordado por ser, possivelmente, causa de alguns dos outros. Superproduzir significa produzir mais do que o necessário (demandado) ou produzir antes da hora que será necessário ter o produto. A superprodução gerará um nível de estoque mais alto, excesso de pessoal para lidar com o excesso de peças, demandará mais movimentação de materiais para colocar e tirar das áreas de estoque e acarretará em esperas das peças para serem vendidas, entregues ou processadas pelos próximos processos. Para Nazareno (2003), áreas grandes de depósitos, custos altos de transporte e falhas na programação da produção são possíveis causas que acarretam em superprodução. Corrêa, Gianesi e Caon (2001) acrescentam que altos tempos de setup, incerteza na ocorrência de defeitos nos produtos e processos e falta de coordenação entre a produção e a demanda são outras fontes do desperdício de superprodução.

- Excesso de estoque é decorrência do desperdício de superprodução. Manter excesso de estoque (de matérias-primas, inventário em processo e estoque de produtos acabados) mascara alguns problemas como quebras de máquina, altos tempos de troca das máquinas, desbalanceamento dos processos de produção e defeitos. Também consiste em armazenamento excessivo e falta de informação ou produtos (RENTES; SILVA, A; SILVA, V, 2003). O excesso de estoque é o efeito mais visível da superprodução e segundo Almeida (2009), “é o desperdício mais nocivo sob a ótica da produção enxuta". Nazareno (2003) cita, como principais causas para o desperdício de excesso de estoque, a prática de superprodução e existência de grande flutuação da demanda e, ainda, comenta o risco de se perder material parado por obsolescência.

- Transporte desnecessário é o excesso de transporte de materiais em forma de matéria-prima, material em processo ou produto acabado dentro da fábrica, de galpões de estoque para as máquinas e vice-versa. Também é decorrência de superprodução, já que quanto mais antecipadamente se produz ou quanto maior a quantidade extra que se produz maior será o transporte destes itens entre máquinas e estoque. Corrêa, Gianesi e Caon (2001) destacam esse fato citando que existem fábricas onde há grande necessidade de produção em altos volumes, para 
minimizar custos de transporte em layouts inadequados com grande distanciamento entre os processos. Para Nazareno (2003) as fontes de desperdício das perdas por transporte são layouts inadequados, produção em lotes grandes e antecipação da produção de itens.

- Defeitos podem ser tanto defeitos em peças que impossibilitem a utilização das mesmas, ou atividades extras, como retrabalho e transporte extra, que requerem maior uso de recursos (humanos e de materiais). Quanto maior o nível de estoque, mais difícil é enxergar este desperdício, já que as peças defeituosas são substituídas por peças boas em abundância no estoque. Algumas causas possíveis para o desperdício de defeitos são: processos de fabricação inadequados, falta de treinamento dos operadores e matéria-prima defeituosa (NAZARENO, 2003). Corrêa, Gianesi e Caon (2001) verificam que a produção de defeitos acarreta em utilização desnecessária de tempo de equipamentos, mão de obra e recursos de material.

- Espera pode ser espera das pessoas por informações, materiais ou ferramentas, devido a interrupções em processos anteriores, falta de balanceamento da linha de produção ou existência de gargalos de capacidade. E, também, pode ser espera das peças para serem processadas pelo próximo processo ou serem entregues para os clientes (decorrência de estoques altos). Nazareno (2003) cita outras fontes deste desperdício como, por exemplo, layout inadequado e imprevistos na produção.

- Superprocessamento ou processamento incorreto pode ser utilização maior de recursos para processar do que o necessário, produção de itens com qualidade superior à necessária, utilização de ferramentas e procedimentos inadequados para a realização do trabalho, problemas nas cartas e seqüenciamento dos processos ou produção freqüente de peças com defeitos.

- Movimentação desnecessária é qualquer movimento realizado durante a operação, antes dela ou depois que não agregue valor ao produto. Pode ser decorrência de superprodução e estoques, já que para o transporte extra de peças, geralmente, é necessária a utilização de recursos. E pode ser decorrência, também, de falta de procedimentos padrão de trabalho e má organização do arranjo físico do chão de fábrica (layout). Além dos inúmeros movimentos realizados pelos operadores para alcançar objetos, insumos, ferramentas, que segundo Weber (2005) constitui a maior fonte de desperdícios na operação, Nazareno (2003) ainda 
cita a possibilidade de desperdício de movimentação para procura de peças e ferramentas perdidas.

- Desperdício de talento e criatividade dos funcionários especificamente para Liker (2004), esse desperdício é bastante recorrente e significa o desperdício de tempo das pessoas consertando erros de produção e realizando movimentos desnecessários, impedindo que possam se dedicar a aprender novas técnicas e aprimorar os processos.

Para Weber (2005) os desperdícios com movimentação desnecessária são os mais críticos e comuns na operação, porque devido a uma má organização dos postos de trabalho, e à má disposição dos insumos e ferramentas nestes postos, com muita freqüência os operadores realizam pequenos movimentos para alcançar os itens que precisam. No fim do dia, a soma dos pequenos tempos gastos com esses pequenos movimentos acarreta em grande desperdício nos sistemas produtivos.

Já Sánchez e Pérez (2001) acreditam que o maior desperdício dos sistemas produtivos é o excesso de inventário, razão das maiores ineficiências industriais. Os autores ainda citam que os estoques costumam esconder outros problemas como uma máquina que costuma quebrar, que força a manutenção de grandes estoques com o objetivo de evitar gargalos de produção.

Um desperdício bastante dispendioso é o excesso de transporte de peças pelo chão de fábrica, que acarreta diretamente em aumento do lead time, principal medida de desempenho de sistemas enxutos. Quanto menor o lead time mais enxuto é o sistema produtivo. (SÁNCHEZ; PÉREZ, 2001)

Portanto, pode-se observar grande correlação entre as oito categorias de desperdício encontradas na literatura e citadas nessa seção, principalmente o desperdício de talento e criatividade dos funcionários, possível conseqüência de todos os outros desperdícios.

Devido a essas relações de causa e efeito entre os desperdícios, muitas vezes, as possíveis soluções para um desperdício consistem na eliminação de outro e, alguns autores como (SHINGO, 1996) (SÁNCHEZ; PÉREZ, 2001) (SINGH et al., 2010) citam ferramentas que auxiliam a identificação e eliminação das fontes dos desperdícios, tais como:

- Fluxo unitário de peças: que consiste em eliminar os estoques intermediários entre processos para reduzir o lead time e evidenciar possíveis processos não confiáveis;

- Controle visual dos processos: para identificar prontamente qualquer anomalia e qualquer desvio do procedimento padrão; 
- Trabalho padrão: essencial para conseguir diferenciar atividades extras e desnecessárias em uma operação;

- Produção em lotes pequenos: para reduzir os ciclos de produção, minimizando, também, transportes e movimentações excessivas de peças;

- Redução dos tempos de setup: diminuição dos tempos gastos com trocas de ferramentas para trocas de produção nos processos. Ação necessária para viabilização da produção em pequenos lotes;

- Inspeção na fonte: técnicas para identificação de problemas e defeitos para que estes sejam resolvidos o mais rápido possível, almejando a zero quebra e o zero defeito; e

- Redução de quebras e paradas nas máquinas: consiste em técnicas de gestão da manutenção para aumentar a confiabilidade das máquinas.

Nazareno (2003) também apresenta, na Tabela 1, possíveis soluções para os desperdícios dos sistemas produtivos. Essa tabela, adaptada, é observada a seguir.

Tabela 1: Possíveis soluções para os desperdícios (adaptado de NAZARENO 2003)

\begin{tabular}{|c|c|}
\hline Desperdícios & Possíveis Soluções: \\
\hline \multirow{3}{*}{ 1. Perda por superprodução } & reduzir o setup \\
\hline & fazer só o necessário \\
\hline & "puxar" a produção \\
\hline \multirow{2}{*}{ 2. Perda por transporte } & projetar layout para minimização de transporte \\
\hline & reduzir a movimentação de material \\
\hline \multirow{6}{*}{ 3. Perdas por estoques } & sincronizar o fluxo \\
\hline & reduzir setup \\
\hline & reduzir lead times \\
\hline & realizar produção acompanhando a demanda \\
\hline & promover a utilização de projeto modular dos produtos \\
\hline & reduzir os demais tipos de desperdícios \\
\hline \multirow{3}{*}{ 4. Perda por espera } & sicronizar o fluxo de material \\
\hline & balancear a linha com trabalhadores flexíveis \\
\hline & realizar manutenção preventiva \\
\hline \multirow{2}{*}{$\begin{array}{l}\text { 5. Perda por produzir produtos com } \\
\text { defeitos }\end{array}$} & utilizar mecanismos de prevenção de falhas \\
\hline & não aceitar defeitos \\
\hline \multirow[b]{2}{*}{ 6. Perda no processamento } & analisar e padronizar processos \\
\hline & $\begin{array}{l}\text { garantir a qualidade do material, ferramentas e } \\
\text { dispositivos }\end{array}$ \\
\hline \multirow{3}{*}{ 7. Perda por movimentos desnecessáros } & realizar estudos de movimentos e melhorá-los \\
\hline & reduzir deslocamentos \\
\hline & adotar sistemas de controle pertinentes \\
\hline
\end{tabular}


Sánchez e Pérez (2001) ainda mostram alguns indicadores que aumentam (porcentagem de partes comuns entre os produtos da empresa, giro de estoque e porcentagem da manutenção preventiva entre o total de manutenção) ou diminuem (valor do inventário em processo em relação a vendas, número de vezes e distância que as peças são transportadas e tempo necessário para trocas de ferramentas) à medida que as iniciativas Lean se tornam mais maduras dentro de uma organização.

Para Francischini, Miyake e Giannini (2006), os conceitos e ferramentas do Lean são embasados e tem como objetivos propiciar identificação e eliminação sistemática de desperdícios nos processos, que são chamadas também de atividades que não agregam valor.

De acordo com Piercy e Rich (2009), muitos pesquisadores, recentemente, têm notado ser possível traduzir os conceitos e aplicar ferramentas do Lean, primeiramente usadas para o chão de fábrica, agora para fluxos exclusivamente administrativos e de serviços, como, por exemplo, processamento de ordens e faturamento, cotações, processamento de vendas, contabilidade e atividades de recursos humanos.

Diversos autores (LAREAU, 2002), (LOCHER, 2008), (ALMEIDA, 2009), (PIERCY; RICH, 2009), (FRANCISCHINI; MIYAKE; GIANNINI, 2006), (CUATRECASAS, 2004), (SILVA et al., 2007), (RASTEIRO; NAZARENO; SILVA, 2010), (FARIA, 2011), (LAGO; CARVALHO; RIBEIRO, 2008) traduzem os desperdícios do Lean do ambiente de chão de fábrica para o ambiente de escritório e propõem interpretações, do ponto de vista de fluxos administrativos, dos desperdícios classificados por Ohno para a manufatura. Além disso, algumas perdas classificadas por Hammer e Champy (1994) nos estudos de reengenharia também são considerados desperdícios de processos administrativos. Para esses autores, os desperdícios do Lean, para ambientes administrativos e de serviços podem ser classificados como:

a) Superprodução ou excesso de produção: projetar ou processar elementos ou informações que não vão ser usados em seguida, incluir serviços e características em projetos que não constituem valor na ótica do cliente (interno ou externo). (LAREAU, 2002) (LOCHER, 2008) (CUATRECASAS, 2004) (RASTEIRO; NAZARENO; SILVA, 2010)

b) Esperas, interrupções ou atrasos: espera por aprovações de supervisores, aprovação de clientes. Espera por informações dos processos anteriores, por manutenção de equipamentos, por geração de relatórios. Interrupções das pessoas quando essas estão 
realizando atividades que agregam valor. Qualquer espera entre o final de uma atividade e o início da próxima. (LAREAU, 2002) (LOCHER, 2008) (CUATRECASAS, 2004) (RASTEIRO; NAZARENO; SILVA, 2010) (PIERCY; RICH, 2009) (FARIA, 2011) (SILVA et al., 2007) (FRANCISCHINI; MIYAKE; GIANNINI, 2006) (LAGO; CARVALHO; RIBEIRO, 2008)

c) Estoques intermediários e finais e armazenamento: caixas cheias de documentos e papéis, caixas de email cheias de emails não lidos, transporte apenas em grandes lotes, retenção de documentos por tempo maior que o necessário, recursos gastos para controle de filas entre processos e produtos prontos. (LAREAU, 2002) (LOCHER, 2008) (CUATRECASAS, 2004) (RASTEIRO; NAZARENO; SILVA, 2010) (FRANCISCHINI; MIYAKE; GIANNINI, 2006)

d) Movimentação ou deslocamento: entre escritórios, dentro de escritórios, entre atividades subseqüentes, de pessoas. Movimentações para imprimir documentos, para fax, reuniões em outros departamentos. Qualquer tipo de recurso gasto com movimentação, que não agregam valor para o cliente. (LAREAU, 2002) (LOCHER, 2008) (CUATRECASAS, 2004) (RASTEIRO; NAZARENO; SILVA, 2010) (PIERCY; RICH, 2009) (FARIA, 2011) (FRANCISCHINI; MIYAKE; GIANNINI, 2006) (LAGO; CARVALHO; RIBEIRO, 2008)

e) Transporte: de documentos, informações via email, relatórios distribuídos, papéis que circulam para pessoas assinarem. Recursos gastos, desnecessariamente, com transporte de informações que não estejam integradas em um sistema único e acessível para os envolvidos em determinado fluxo. (LAREAU, 2002) (LOCHER, 2008) (CUATRECASAS, 2004) (RASTEIRO; NAZARENO; SILVA, 2010) (PIERCY; RICH， 2009) (FRANCISCHINI; MIYAKE; GIANNINI, 2006) (LAGO; CARVALHO; RIBEIRO, 2008)

f) Processos inadequados ou ineficientes e falta de comunicação: má utilização dos recursos na condução das atividades, falta de padronização das atividades, geração de cópias extras de documentos, falta de comunicação entre os envolvidos no fluxo, generalização dos fluxos e o fato de tratar todos os tipos de informação da mesma forma, excesso de departamentalização e qualquer processo desnecessário no fluxo de geração do serviço para o cliente. (LAREAU, 2002) (LOCHER, 2008) (CUATRECASAS, 2004) (RASTEIRO; NAZARENO; SILVA, 2010) (PIERCY; RICH， 2009) (FRANCISCHINI; MIYAKE; GIANNINI, 2006) (LAGO; CARVALHO; RIBEIRO, 2008) (HAMMER; CHAMPY, 1994) 
g) Defeitos, erros e imperfeições: processamento de informações com defeitos, omissões de informações, erros de projetos ou produtos, não entendimento das necessidades dos clientes. Qualquer atividade que gera informações erradas da primeira vez é classificada como atividade que gera defeitos, erros e imperfeições. (LAREAU, 2002) (LOCHER, 2008) (CUATRECASAS, 2004) (PIERCY; RICH, 2009) (FARIA, 2011) (FRANCISCHINI; MIYAKE; GIANNINI, 2006)

h) Revisões, traduções e retrabalhos: informações com baixa acurácia e completude, não atendimento das necessidades dos clientes, Reprogramações e requisições especiais. Inspeções em busca de erros e omissões. Conversão de arquivos para uso em diferentes tipos de mídia. Recursos gastos com qualquer tipo de atividade feita para corrigir um erro ou uma ineficiência dos processos. (LAREAU, 2002) (RASTEIRO; NAZARENO; SILVA, 2010) (PIERCY; RICH, 2009) (FARIA, 2011) (LAGO; CARVALHO; RIBEIRO, 2008)

i) Sub-utilização da mão de obra, do talento e dos recursos: limitação de autonomia para questões básicas, potencial subestimado das pessoas e compartilhamento de conhecimento ineficaz. Mau gerenciamento dos recursos de pessoas, materiais e equipamentos. (LOCHER, 2008) (PIERCY; RICH, 2009) (RASTEIRO; NAZARENO; SILVA, 2010) (FARIA, 2011)

j) Excesso de capacidade instalada: capacidade instalada para absorver picos de demanda que fica em excesso em períodos de demanda menor. Consequiência de provável desbalanceamento de atividades e processos. (LAREAU, 2002) (FRANCISCHINI; MIYAKE; GIANNINI, 2006) (LAGO; CARVALHO; RIBEIRO, 2008)

As oito categorias de desperdício em fluxos de manufatura são clássicas e tratadas por diversos autores e as dez categorias de desperdício em fluxos administrativos citadas nessa seção são baseadas e adaptadas de conceitos de desperdícios de chão de fábrica, e de acordo com Ahlstrom ${ }^{5}$ (2004 apud FRANCISCHINI; MIYAKE; GIANNINI, 2006, p.3) e Apte e Goh $^{6}$ (2004 apud FRANCISCHINI; MIYAKE; GIANNINI, 2006, p.3) são perfeitamente

\footnotetext{
${ }^{5}$ AHLSTROM, P. (2004) - Lean service operations: translating lean production principles to service operation. International Journal of Sevice Technology and Management. Vol. 5, n. 5/6, p.545-564.

${ }^{6}$ APTE, U.M.; GOH, C.H. (2004) - Applying lean manufacturing principles to information intensive services.
} 
aplicáveis em ambientes de escritório e são conceitos fundamentais para implantação de Lean em serviços. Ainda, segundo Piercy e Rich (2009), o mapeamento do fluxo de valor dos serviços, assim como da manufatura, é essencial para aplicabilidade, tanto dos conceitos de desperdícios quanto das ferramentas de melhoria do Lean, nesses fluxos. 


\section{FMEA NO CONTEXTO DE MELHORIA CONTÍNUA}

Corrêa e Corrêa (2005) destacam que, apesar do fato de ser grande a preocupação com qualidade desde a década de 1950, apenas a partir dos anos 1980 as indústrias ocidentais promoveram esforços significativos para alterar os conceitos de qualidade e de sua gestão. De acordo com os mesmos autores, devido ao acirramento da competição nos mercados e a exigência de baixos custos atrelados a qualidade por parte da demanda, constatou-se dois pontos essenciais no entendimento da gestão da qualidade:

1- A qualidade é formada durante os processos de produção, e não é um kit possível de ser acrescentado a um produto acabado, portanto o foco de qualidade deve ser nos processos e não nos produtos; e

2- Como o foco da qualidade deve ser nos processos, suas ações devem ser simultâneas a eles.

Uma das mais importantes metodologias de melhoria contínua é o PDCA (Plan, Do, Check, $\boldsymbol{A} c t$ ) ou, em português, Planejar, Fazer, Checar e Agir, que segundo Corrêa e Corrêa (2005) foi concebido por W. Shewhart e William Deming e popularizada pelo segundo. O PDCA (Figura 2) é uma ferramenta chave em planos de melhoria contínua. Para Corrêa e Corrêa (2005) e Slack, Chambers e Johnston (2008) o PDCA pode ser definido como:

- Plan (Planejar): Etapa na qual a situação ou o processo é estudado, os problemas identificados e as melhorias propostas

- Do (Fazer): Etapa na qual o que foi definido na etapa anterior é implantado de forma experimental para medição e registro de resultados.

- Check (Checar): Etapa na qual as melhorias implantadas experimentalmente são avaliadas e, eventualmente, aprimoradas.

- Act (Agir): Etapa na qual as melhorias são implantadas como novos procedimentos operacionais. 


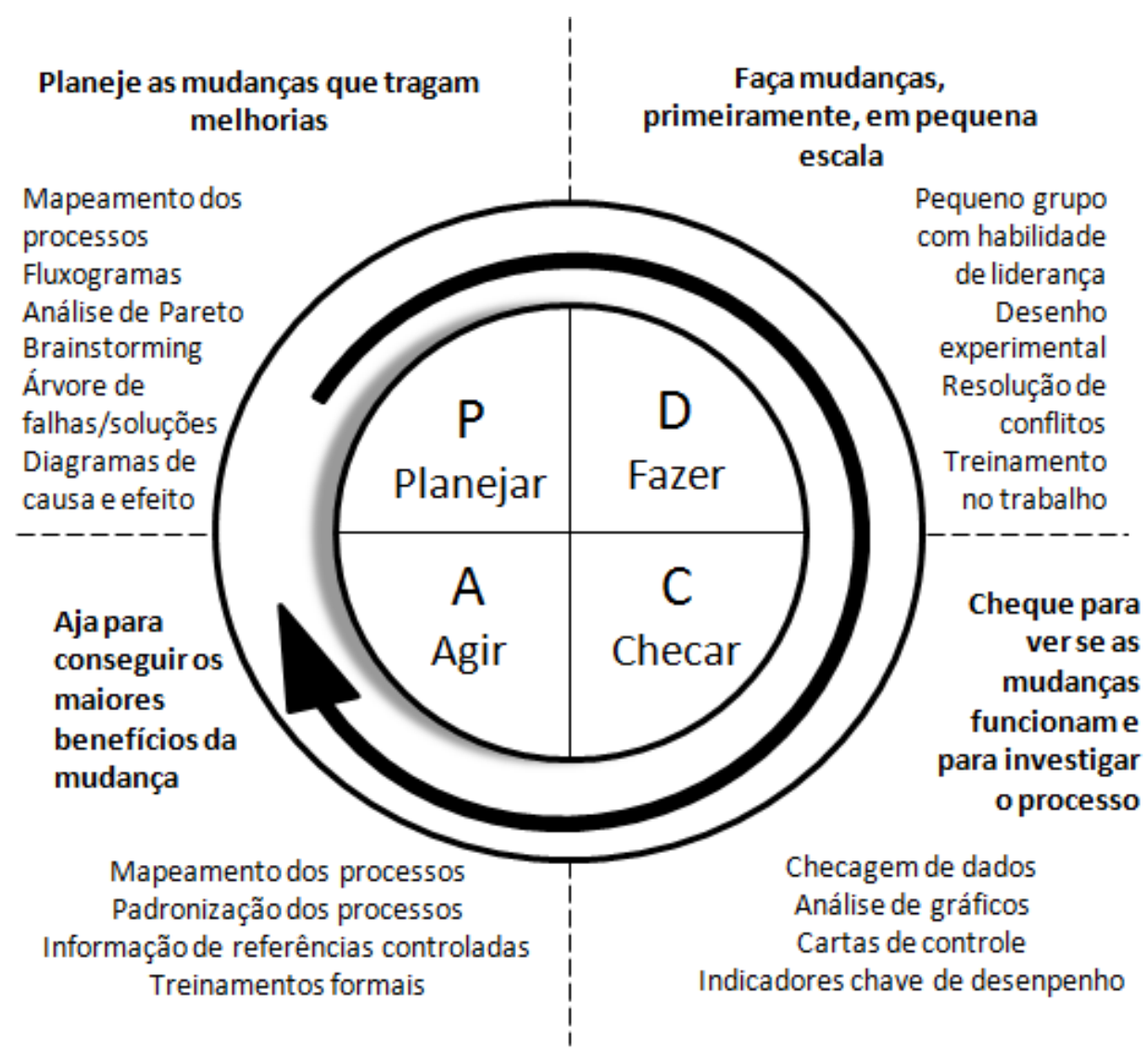

Figura 2: Método PDCA para melhorias (adaptado de SENRRA, 2010)

Outras ferramentas da qualidade importantes são as ferramentas de identificação de causas raízes de problemas e falhas. Entre elas se destacam o Diagrama de Ishikawa (devido a seu criador Karou Ishikawa), Diagrama Espinha de Peixe (devido a sua aparência) ou, simplesmente, Diagrama de Causa e Efeito e o método dos 5 Por quê's.

Corrêa e Corrêa (2005) e Slack, Chambers e Johnston (2008) propõem um passo a passo para a construção do Diagrama de Ishikawa (Figura 3): colocar o problema na caixa do "Efeito", identificar as principais categorias para causas possíveis de problema (as mais comuns são equipamento, mão-de-obra, materiais, métodos, meio ambiente, medição e dinheiro), usar a busca de fatos e causas raízes por meio da discussão em grupos e registrar todas as causas no diagrama e discuti-las novamente para validá-las. 


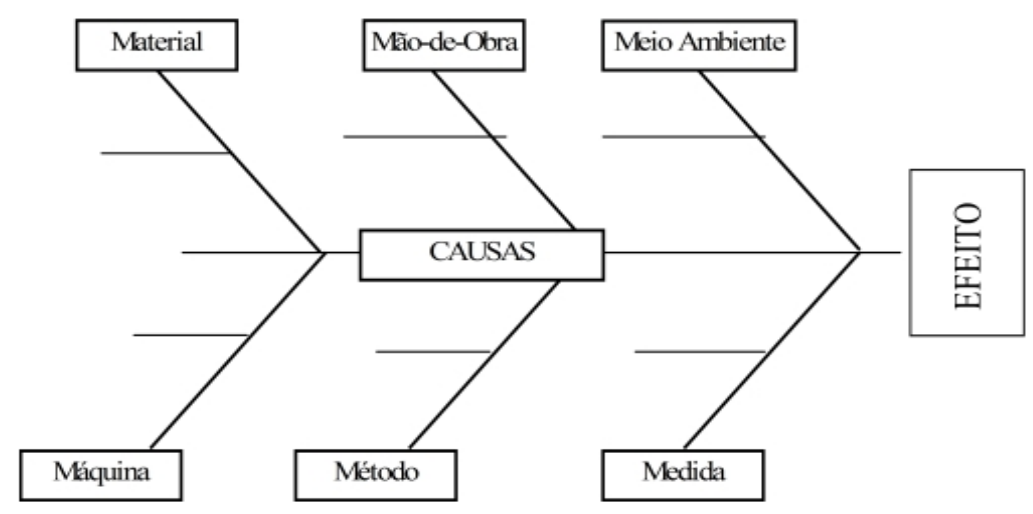

Figura 3: Exemplo de Diagrama Ishikawa (Ferramentas Básicas da Qualidade, 2011)

Talvez mais simples, o método dos 5 Por quê's ou Análise Por que-por quê (Figura 4) consiste, de acordo com Slack, Chambers e Johnston (2008) em perguntar o motivo da ocorrência de determinado problema, repetidas vezes, até que se encontre a causa raiz do problema principal. A pergunta "Por quê?" deve ser realizada até que uma causa seja entendida como a causa raiz de um problema, ou seja, resolvendo essa causa evita-se que o problema volte a acontecer.

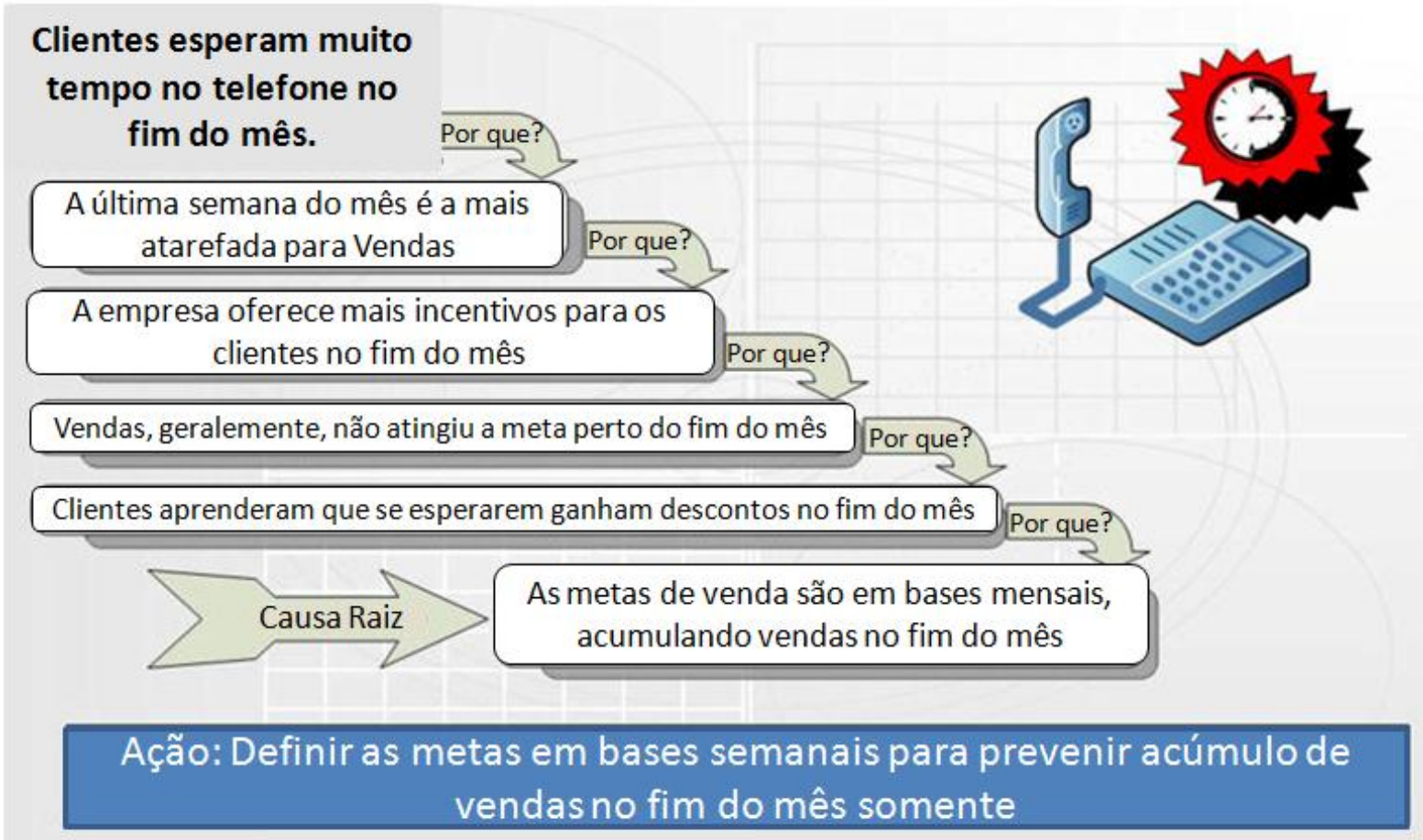

Figura 4: Exemplo da ferramenta 5 Por quê's (adaptado de Lean Term: 5 Whys, 2011) 
Outras ferramentas importantes da qualidade também surgiram no contexto da Gestão da Qualidade. Entre elas, algumas desenvolvidas nas indústrias bélicas e nucleares nos EUA, foram influenciadas pelas exigências de segurança dessas aplicações. Estudos das falhas de segurança nessas indústrias levaram à conclusão de que estas eram provocadas, principalmente, por problemas sistêmicos. (LINS, 2009)

Esses estudos, realizados nas indústrias bélicas e nucleares norte-americanas, acarretaram no desenvolvimento, pelas Forças Armadas dos Estados Unidos da América de um procedimento formal para análise de falhas, em 9 de novembro de 1949. (AUGUST, 2002)

Essas aplicações e outras, relatadas por autores como Ginn et al. (1998), Inoue e Yamada (2010), Fernandes (2005), em meados dos anos 1960, acabaram culminando no surgimento do FMEA.

FMEA é a sigla para o nome de uma das mais importantes ferramentas da qualidade: Failure Mode and Effect Analysis, que, em português pode ser traduzido como: Análise dos Modos de Falha e seus Efeitos. Por vezes, o FMEA também é denominado FMECA, sigla para Failure Mode and Effect Criticality Analysis, ou Análise de Nível Crítico dos Modos de Falha e seus Efeitos.

Para August (2002) o FMEA começou a ser concebido nas Forças Armadas dos EUA em resposta a uma demanda por melhora da confiabilidade e segurança dos equipamentos utilizados por essa instituição. O autor acrescenta que, primeiramente o método foi denominado Procedures for Performing a Failure Mode, Effects and Criticality Analysis, que pode ser traduzido como (tradução livre pelo autor) Procedimentos para Realização de Análises de Nível Crítico dos Modos de Falha e seus Efeitos.

August (2002) cita o fato de que, mais tarde, em 1988, a International Organization for Standardization (ISO) lançou a série de padrões de gerenciamento de negócios ISO-9000, incentivando as empresas a formalizarem sistemas de gestão da qualidade e, em paralelo, a indústria automotiva norte-americana, com sua série de padrões QS-9000, impôs aos fornecedores de peças automotivas que utilizassem FMEA de processos e de desenvolvimento de produtos para obter certificação QS-9000.

Hoje, dada sua importância e eficácia, encontra-se aplicação do método FMEA em diversos segmentos da indústria e em serviços. Nesta seção será abordado o método FMEA, seus objetivos e as interpretações e vantagens da utilização do FMEA como método para ações de melhoria contínua. Serão abordadas, também, formas alternativas de utilização do FMEA. 


\subsection{Método FMEA}

O exemplo da Figura 5 apresenta o formulário do método FMEA preenchido hipoteticamente. O FMEA é um método para identificação de falhas (existentes ou potenciais), análise de seus índices de ocorrência, severidade e detecção e priorização de ações de melhoria.

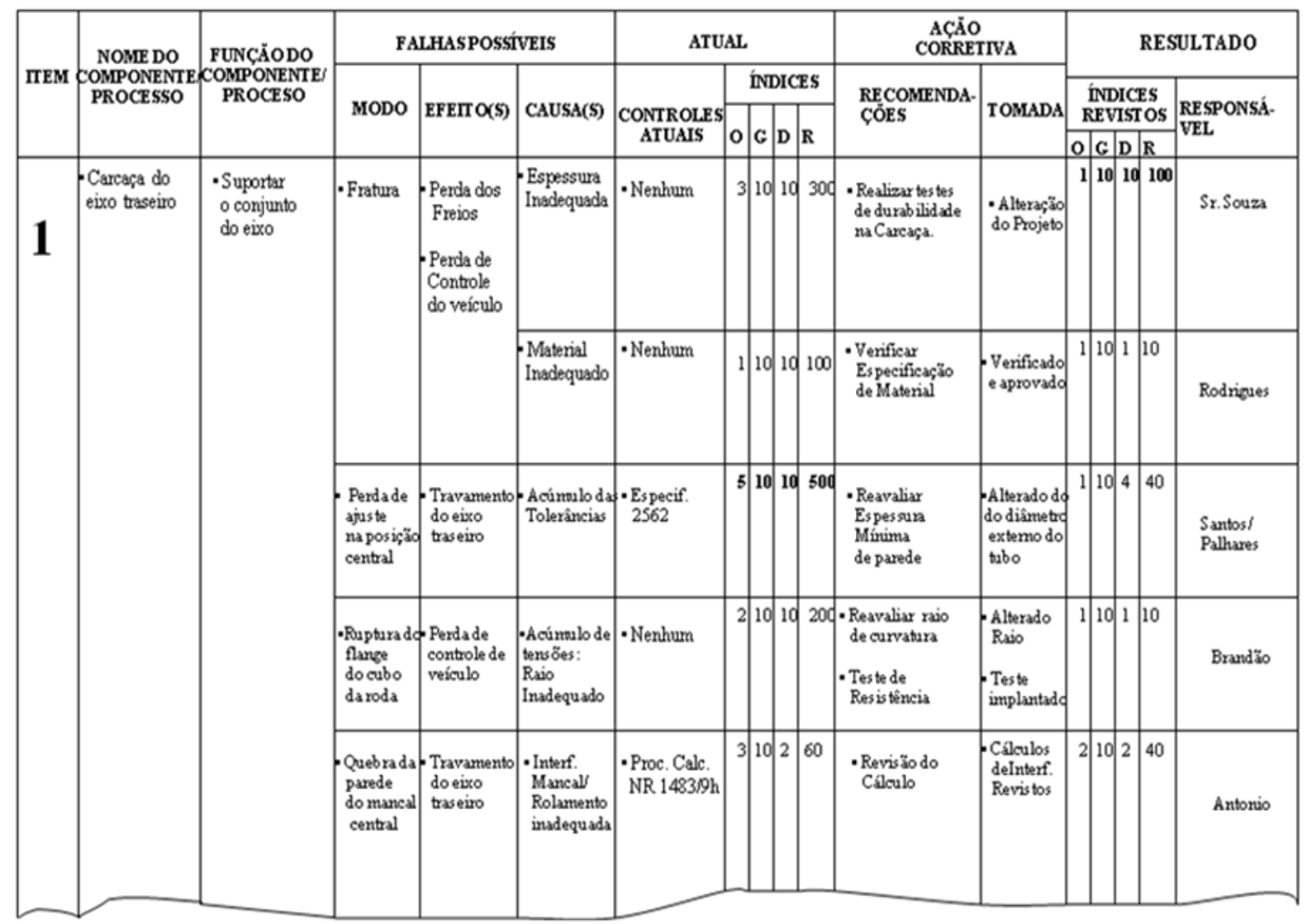

Figura 5: Exemplo da Aplicação do Método FMEA (http://gerisval.blogspot.com/2011/01/serieferramentas-de-gestao-fmea.html, 2011)

Para utilizar o método FMEA, basicamente, devem ser seguidos os seguintes passos: identificação da função do produto/componente/processo/serviço, identificação de seus modos de falha (como podem falhar), identificação dos efeitos e das causas das falhas, identificação dos controles atuais para detecção das falhas, pontuação dos índices de severidade, ocorrência e detecção, cálculo do índice de prioridade de risco (RPN), priorização das ações e brainstorming de recomendações para melhorias. 
Diversos autores apresentam definições para o FMEA que, em linhas gerais, se assemelham. Seguem algumas definições encontradas na literatura sobre o assunto:

- Para Palady (1997) o FMEA é “uma ferramenta para prognóstico de problemas” é, também, "um procedimento para desenvolvimento e execução de projetos, processos ou serviços, novos ou revisados" e "o diário do projeto, processo ou serviço". O autor acrescenta que é uma das técnicas de baixo risco mais eficiente para identificação das soluções para prevenir problemas e mais eficaz em termos de custos. Palady (1997) ainda cita que o FMEA é um método estruturado para avaliação e condução de desenvolvimento de projetos e funciona como um diário dos projetos de desenvolvimento e melhoria de produtos, processos e serviços.

- Stamatis (2003) menciona que o objetivo do FMEA é identificar ações corretivas necessárias para prevenir falhas, impedindo que estas atinjam os clientes, melhorando a confiabilidade, durabilidade e qualidade de um produto ou serviço. Para o autor, um FMEA bom consiste em identificar modos de falha conhecidos e potenciais, identificar as causas e efeitos dessas falhas, priorizar as falhas de acordo com o nível crítico da mesma (produto de três variáveis: ocorrência, detecção e severidade) e prover acompanhamento de problemas e das ações corretivas.

- Para Slack, Chambers e Johnston (2008), o FMEA é um método que tem como objetivo proporcionar análises das falhas, através de um checklist constituído de três perguntas chave: "qual é a chance de a falha ocorrer?", “qual seriam os efeitos da falha se esta ocorresse?” e "qual é a chance de detectar essa falha antes que essa atinja o cliente?". Os autores acrescentam que, por meio de uma avaliação quantitativa dessas três questões, calcula-se o Número de Prioridade de Risco (NPR), que serve como informação de quais falhas são mais críticas para o sistema.

- De acordo com Inoue e Yamada (2010), o FMEA consegue auxiliar a identificação, priorização e melhoria de um sistema, projeto ou processo antes que falhas reais ocorram, auxiliando, entre outras coisas, a capturar a percepção coletiva das falhas potenciais. È uma abordagem que pode ser usada para identificar e eliminar problemas potenciais ainda na fase de projeto de um produto ou serviço. 
- Ookalkar A., Joshi e Ookalkar D. (2009) definem o FMEA como um método de análise qualitativa que ajuda a identificar e endereçar pontos fracos e vulneráveis de um produto ou processo. Os autores acrescentam que, originalmente, foi criada com o intuito de prevenir problemas de segurança, mas que hoje é usada na prevenção de diversos tipos de processos e produtos auxiliando os sistemas a se tornarem mais robustos.

- Para Pinho et al. (2008), o objetivo principal do FMEA é determinar os efeitos e conseqüências de falhas em sistemas e equipamentos. Pinho et al. (2008) também mencionam que o FMEA é um método utilizado para busca de falhas potenciais durante a etapa de projeto de um produto ou serviço e, conseqüente, redução de custos com eventuais correções futuras.

- Pillay e Wang (2003) definem o FMEA como um grupo sistematizado de atividades que têm como objetivo identificar e avaliar as falhas potenciais de um produto ou processo, identificar ações que possam eliminar ou reduzir a ocorrência dessas falhas e documentar o processo.

- Chuang (2010) acrescenta que o objetivo do FMEA é prever como e onde sistemas e processos podem falhar e como as pessoas são alertadas das falhas.

- Fernandes (2005) menciona que o FMEA é um método que, por meio de uma seqüência lógica, avalia severidade de falhas, a forma como essas podem ocorrer e como serão detectadas, e tem como resultado a informação de como um sistema, produto ou processo está mais sujeito a falhas.

- Segundo Capaldo, Guerrero e Rozenfeld (1999), o FMEA é uma ferramenta que, com análises dos modos de falha e propostas de melhoria, tem como objetivo básico diminuir as chances de um produto ou processo falhar, aumentando sua confiabilidade.

- Para Sawhney et al. (2010), o FMEA é um método que foca na priorização do nível crítico das falhas potenciais de um produto ou processo, buscando análises e melhorias na segurança, confiabilidade e qualidade desses produtos ou processos. Os autores acrescentam que a priorização é feita por meio de um valor (RPN) que é calculado pela multiplicação dos índices de ocorrência (quanto maior mais ocorre), severidade (quanto maior mais severa) e detecção (quanto maior, mais difícil de detectar). 
- Ben-daya e Raouf (1996) definem o FMEA como um método, comumente, usado na indústria automotiva para quantificar e elencar falhas críticas no estágio de desenvolvimento de um produto ou processo.

- Sankar e Prabhu (2001) citam que o FMEA representa um poderoso método usado por engenheiros, para que estes consigam apresentar de maneira estruturada e formal questões subjetivas em termos de: “o que pode dar errado?”, “o que pode causar isso para que dê errado?" e "que efeitos isso pode ter?".

- Segundo Von Ahsen (2008) o FMEA tem como objetivo prevenir que falhas inaceitáveis atinjam os clientes e auxiliar uma alocação mais eficiente de recursos para melhorias.

Com base nas definições listadas, é possível concluir que o FMEA é um método, bem estruturado e robusto, para identificação, priorização e eliminação de falhas mais críticas, principalmente, em processos e produtos existentes ou para prevenção destas falhas antes que um processo seja iniciado ou um produto lançado. Diversos autores apresentam frameworks de como aplicar o método FMEA.

Uma forma simplificada de definir o FMEA e um exemplo de como os elementos de análise do FMEA se correlacionam são apresentados por Carpinetti (2010) e visualizado na Figura 6.

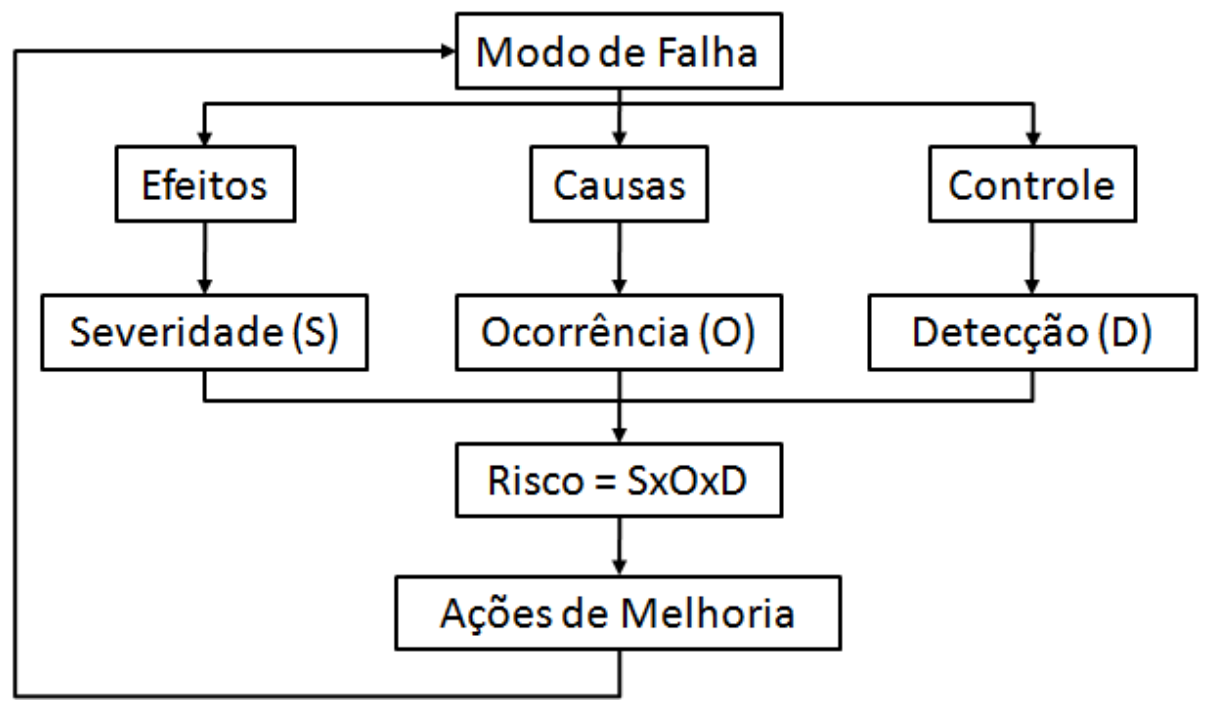

Figura 6: Correlação entre os elementos de análise do FMEA (CARPINETTI, 2010) 
Carpinetti (2010) ainda mostra uma forma simplificada de entender o método FMEA, composta de três etapas: identificação de falhas e definição de prioridades (por meio da análise dos fatores S, O e D), planos de ação para eliminação de falhas e, por fim, análise das falhas após implantação dos planos.

Para obter bom desempenho na aplicação do método FMEA, alguns pré-requisitos, que serão apresentados a seguir, devem ser cumpridos.

Para Palady (1997), esses pré-requisitos devem ser obedecidos antes da aplicação das técnicas de análise do FMEA. O autor cita ações primordiais como: definição de responsáveis, definição da equipe de análise, definição do começo da aplicação do método, definição da abordagem para determinação da ocorrência e detecção (se vão ser analisadas em relação às causas ou às falhas em si) e revisão e determinação das escalas de pontuação dos índices de severidade, ocorrência e detecção.

Palady (1997) ainda cita algumas regras básicas para a condução da aplicação do método como: "não considerar todos os modos de falha concebíveis", "redigir o modo de falha como a expressão negativa da função" (caso haja dificuldade na determinação dos modos de falha) e "desenvolver independentemente cada coluna do FMEA", ou seja, listar todos os modos de falha que serão analisados antes de analisar seus efeitos, analisar os efeitos de todos os modos de falha antes de analisar a severidade de cada um, e assim por diante.

Outro ponto importante segundo Palady (1997) é a definição da equipe de aplicação do FMEA e a dinâmica desta equipe. $\mathrm{O}$ autor sugere uma lista de participantes da equipe que inclui pessoas de: pesquisa e desenvolvimento, engenharia de projeto, engenharia de confiabilidade, engenharia de processo, engenharia de qualidade, manutenção, engenharia de materiais, engenharia de métodos, assistência técnica, produção/manufatura e embalagem. Palady (1997) também ressalta a importância da participação de clientes e fornecedores no processo, para que o FMEA seja mais eficaz na percepção dos efeitos sobre os clientes e na demonstração das causas para os fornecedores. Ookalkar A., Joshi e Ookalkar D. (2009) acrescentam que a equipe deve ser multidisciplinar.

Ao atribuir pontuações para os índices de severidade, ocorrência e detecção, os membros da equipe podem não atingir um consenso, e para isso Palady (1997) propõe um método de análise das pontuações. A Tabela 2 mostra os quatro tipos de pontuações diferentes possíveis em uma equipe de sete pessoas para análise de quatro efeitos de modos de falha (A, B, C e D). 
Tabela 2: Tabela para definição da pontuação em quatro casos diferentes (adaptado de PALADY, 1997)

\begin{tabular}{|c|c|c|c|c|c|c|c|c|c|c|c|}
\cline { 4 - 12 } \multicolumn{4}{c|}{} & \multicolumn{9}{c|}{ Pontuação de cada Membro da Equipe } & \multicolumn{1}{c|}{} \\
\hline Falha & Efeito & Causa & Deteç̧ão & 1 & 2 & 3 & 4 & 5 & 6 & 7 & Média \\
\hline & A & & & 8 & & 8 & & 9 & 9 & 10 & 9 \\
\hline & B & & & 2 & 7 & 7 & 7 & 8 & 9 & 9 & EXTREMO \\
\hline & C & & & 2 & 2 & 3 & 3 & 8 & 8 & 9 & CISÃO \\
\hline & D & & & 7 & 7 & 7 & 7 & 7 & 7 & 7 & 7 \\
\hline
\end{tabular}

No caso dos efeitos A e D, pode-se utilizar a média para definir a pontuação a ser usada no formulário do FMEA. Para o caso B (existência de um extremo), é possível que a pessoa que atribuiu essa pontuação tenha uma percepção ou informação diferente deste efeito, e ela deve ser ouvida pelos outros membros para que seja decidida a pontuação. Para o caso C (existência de uma cisão), quando a equipe fica bem dividida entre notas altas e baixas, esse ponto deve ser discutido novamente pela equipe toda (PALADY, 1997).

Tendo cumprido os pré-requisitos, Palady (1997) propõe um passo a passo da aplicação do FMEA, corroborado por (STAMATIS, 2003), (OOKALKAR, A; JOSHI; OOKALKAR, D, 2009), (CHUANG, 2010), (SANKAR; PRABHU, 2001), (BEN-DAYA; RAOUF, 1996), (FRANK; PEDRINI; ECHEVESTE, 2008), (CARPINETTI, 2010) da seguinte forma:

1. Preenchimento do cabeçalho do FMEA com informações do objetivo do FMEA em questão, envolvidos no desenvolvimento da aplicação da ferramenta, início e última revisão da aplicação e responsável pela manutenção do formulário;

2. Preenchimento da coluna das funções, que consiste na identificação das funções que o produto, processo ou serviço deve desempenhar para satisfazer os clientes;

3. Determinação dos modos de falha, identificando as possíveis maneiras que o produto, processo ou serviço pode falhar em cumprir o que é esperado deste;

4. Determinação dos efeitos das falhas e suas conseqüências, se, eventualmente, essas falhas vierem a ocorrer;

5. Estimativa da severidade dos efeitos das falhas baseada em escala qualitativa e/ou numerada de 1 a 10 ;

6. Determinação das possíveis causas das falhas utilizando ferramentas como o Diagrama de Ishikawa, Análise da Árvore de Falhas e Gráfico de Pareto das causas;

7. Estimativa ou avaliação da probabilidade de ocorrência das causas das falhas baseada em escala qualitativa e quantitativa numerada de 1 a 10; 
8. Levantamento das formas de controle existentes para identificação ou prevenção das falhas;

9. Estimativa da acurácia das formas de controle existentes baseada em escala qualitativa e/ou quantitativa de detecção numerada, também, de 1 a 10;

10. Interpretação dos resultados da análise por meio do cálculo do RPN (Risk Priority Number), em português, NPR (Número de Prioridade de Risco);

11. Determinação das ações recomendadas para resolução das causas, diminuição dos efeitos negativos e melhora dos controles dos modos de falha; e

12. Acompanhamento da situação das ações recomendadas.

Palady (1997) acrescenta ao passo 10 a interpretação dos resultados da análise por meio da utilização do Gráfico de Áreas, a serem explicitados nesta seção.

Ookalkar, A, Joshi e Ookalkar, D (2009) acrescentam, além dos passos já citados, um último passo que consiste no recálculo do NPR, com o objetivo de avaliar a eficácia das ações de melhoria realizadas.

Chuang (2010) ratifica os passos citados e indica que o ponto principal do método é identificação dos modos de falha mais críticos para priorização das ações corretivas.

Inoue e Yamada (2010) resumem o passo a passo de aplicação do FMEA, de forma bastante similar à de Palady (1997), como: identificação de um processo ou produto alvo, seguido de coleta e análise de dados, que consiste em uma equipe identificar a função e os modos de falhas para o processo ou produto, determinar a severidade, a ocorrência e a detecção dos modos de falha para calcular o NPR e assim poder priorizar e conduzir ações corretivas ou preventivas para melhora da confiabilidade e segurança dos processos ou produtos.

Teng e Ho (1996) apresentam um diagrama que resume os passos de aplicação do FMEA, observado a seguir (Figura 7). 


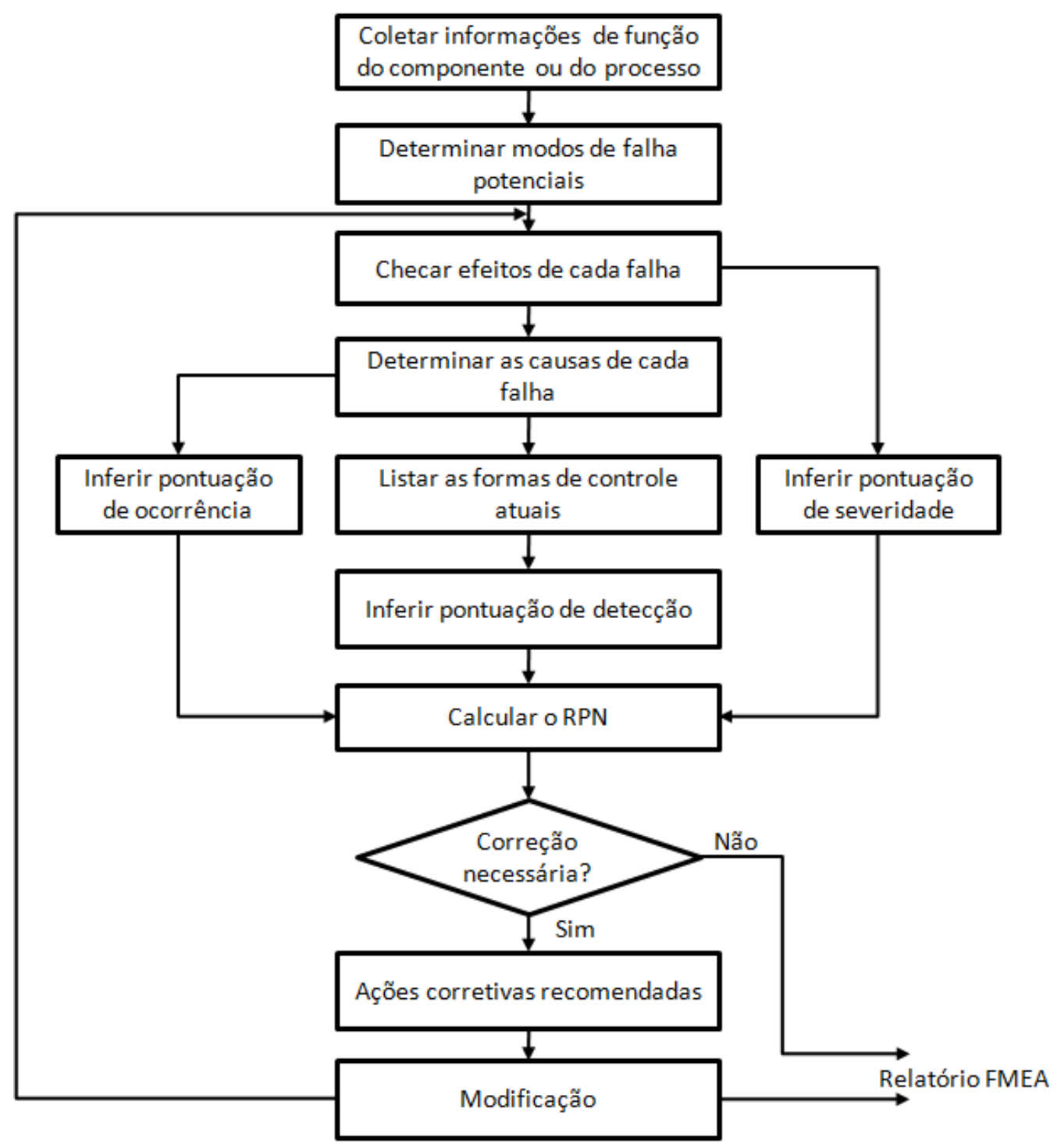

Figura 7: Fluxograma do passo a passo de aplicação do FMEA (adaptado de TENG; HO, 1996)

A seguir, serão detalhadas as etapas de aplicação do FMEA, com base no formulário proposto por Palady (1997), Tabela 3, e nas contribuições de outros autores. 
Tabela 3: Formulário padrão da ferramenta FMEA (PALADY, 1997)

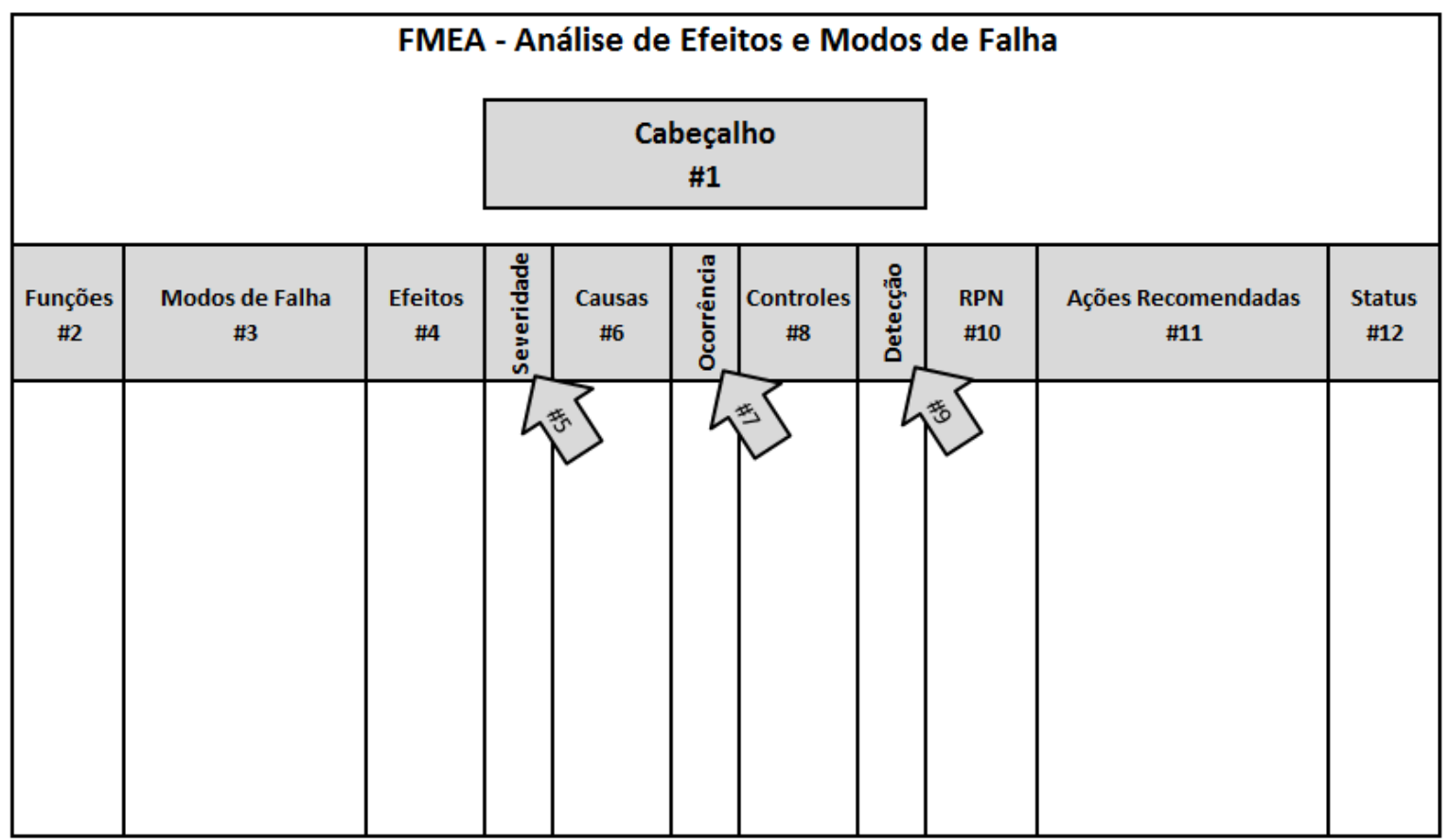

\#1 - Preenchimento do Cabeçalho

O preenchimento do cabeçalho serve para documentação e facilitação do acesso a informação para auxiliar a manutenção e desenvolvimento do FMEA. E dados como escopo de análise do FMEA, pessoas envolvidas no processo, atividades e documentos que podem sofrer alterações e histórico de revisões e aprovações são fundamentais também. (PALADY, 1997)

\#2 - Identificação e listagem das funções do processo, produto ou serviço

Segundo Palady (1997) a pergunta a ser feita para identificar as funções de determinado processo, produto ou serviço é: “o que esse processo, produto ou serviço deve fazer para satisfazer os clientes?". 
\#3 - Identificação e listagem dos modos de falha

Para identificar os modos de falha de um determinado processo, produto ou serviço, de acordo com Palady (1997) a questão a ser respondida é; "como esse processo, produto ou serviço deixa de desempenhar todas as funções que se esperam dele?”.

Como mencionado anteriormente, para Palady (1997) não devem ser considerados todos os modos de falha concebíveis e, em caso de dificuldade na redação do modo de falha, uma forma simples de fazê-lo é redigir a expressão negativa da função.

\#4 - Determinação dos efeitos das falhas

Nessa fase, deve ser determinado o impacto de cada modo de falha no cliente. Dificilmente o preenchimento dessa coluna será preciso sem a participação do cliente na discussão. Deve-se, portanto, evitar não adotar a perspectiva do cliente, minimizar a confusão entre efeito local, global ou de nível superior, simplificando a análise para que seja padrão para todos os modos de falha e evitar descrições técnicas dos efeitos que mascaram a real percepção do cliente e acabam por minimizar a gravidade do modo de falha. (PALADY, 1997)

\#5 - Estimativa da severidade do efeito do modo de falha

Para estimar a severidade podem ser usadas diversas escalas encontradas na literatura, desde escalas mais detalhadas, em dez níveis qualitativos como as apresentadas por Palady (1997), Ookalkar, A., Joshi e Ookalkar, D. (2009), Carpinetti (2010), Roos et al. (2007), por exemplo a Tabela 4, quanto escalas mais simples, baseadas na escala de Likert, como as apresentadas por Ben-daya e Raouf (1996), Inoue e Yamada (2010), Rotondaro (2002), Pinho et al. (2008), McCain (2007), Capaldo, Toledo e Rozenfeld (1999) e Toledo e Amaral (199-), por exemplo a Tabela 5.

Palady (1997) menciona que, em algumas empresas, modos de falha com severidade igual ou superior a nove devem ter atenção especial, por se tratarem de modos de falha que podem por em risco a segurança do cliente ou a saúde financeira da empresa. 
Tabela 4: Escala detalhada de severidade dos efeitos das falhas (ROOS et al., 2007)

\begin{tabular}{|l|c|}
\hline Escala de severidade dos efeitos dos modos de falha & Índice de severidade \\
\hline Efeito não percebido pelo cliente & 1 \\
\hline Efeito bastante insignificante, percebido por $25 \%$ dos clientes & 2 \\
\hline Efeito insignificante, mas percebido por 50\% dos clientes & 3 \\
\hline Efeito moderado e percebido por 75\% dos clientes & 4 \\
\hline Efeito consideravelmente crítico, percebido pelo cliente & 5 \\
\hline Efeito consideravelmente crítico, que perturba o cliente & 6 \\
\hline Efeito crítico, que deixa o cliente um pouco insatisfeito & 7 \\
\hline Efeito crítico, que deixa o cliente consideravelmente insatisfeito & 8 \\
\hline Efeito crítico, que deixa o cliente totalmente insatisfeito & 9 \\
\hline Efeito perigoso, que ameaça a vida do cliente & 10 \\
\hline
\end{tabular}

Tabela 5: Escala simples de severidade dos efeitos das falhas (CAPALDO; TOLEDO; ROZENDFELD, 1999)

\begin{tabular}{|c|c|c|}
\hline \multicolumn{3}{|r|}{ SEVERIDADE } \\
\hline İ́ndice & Severidade & Critério \\
\hline 1 & Minima & O cliente mal percebe que a falha ocorre \\
\hline $\begin{array}{l}2 \\
3\end{array}$ & Pequena & Ligeira deterioração no desempenho com leve descontentamento do cliente \\
\hline $\begin{array}{l}4 \\
5 \\
6\end{array}$ & Moderada & Deterioração significativa no desempenho de um sistema com descontentamento do cliente \\
\hline $\begin{array}{l}7 \\
8 \\
\end{array}$ & Alta & Sistema deixa de funcionar e grande descontentamento do cliente \\
\hline $\begin{array}{l}9 \\
10\end{array}$ & Muito Alta & Idem ao anterior porém afeta a segurança \\
\hline
\end{tabular}

\#6 - Determinação das possíveis causas das falhas

Para Palady (1997) a equipe deve, nessa etapa, se concentrar em responder a pergunta: "que condições provocam esse modo de falha?"

Ookalkar, A, Joshi e Ookalkar, D (2009) propõem que seja conduzida uma discussão detalhada com todos os envolvidos no processo, concepção ou fabricação do produto ou concepção ou geração do serviço para que sejam levantadas as possíveis causas de um modo de falha.

McCain (2007) acrescenta que a técnica de brainstorming pode ser utilizada e geralmente é bastante eficaz. Para Inoue e Yamada (2010), deve ser criado um diagrama de afinidades e conduzida uma análise de causas raízes para identificação das causas dos modos de falha. 
Palady (1997) recomenda não inserir todas as causas possíveis para uma falha no formulário do FMEA. Para esse autor, as causas devem ser analisadas em Diagramas de Ishikawa e gráficos de Pareto para determinação de quais são as principais.

\#7 - Estimativa ou avaliação da probabilidade de ocorrência das causas das falhas

Assim como para estimar a severidade de um efeito, para estimar a probabilidade de ocorrência de uma causa de uma falha, diversos tipos de escala podem ser encontrados na literatura. São encontradas escalas mais simples e qualitativas como as apresentadas por Inoue e Yamada (2010), Rotondaro (2002), Ookalkar, A, Joshi e Ookalkar, D (2009), Ben-daya e Raouf (1996), Toledo e Amaral (199-) e Pinho et al. (2008), por exemplo a Tabela 6. Encontra-se também escalas mais completas (em dez níveis) e qualitativas como as apresentadas por Roos et al. (2007), McCain (2007), Carpinetti (2010) e Palady (1997), por exemplo a Tabela 7. E, também, escalas quantitativas são apresentadas por alguns autores, entre eles, Palady (1997), Ookalkar, A, Joshi e Ookalkar, D (2009), Ben-daya e Raouf (1996), Toledo e Amaral (199-), por exemplo, a Tabela 8.

Tabela 6: Escala simples e qualitativa de probabilidade de ocorrência (adaptado de INOUE; YAMADA, 2010)

\begin{tabular}{cl}
\hline Frequência de Ocorrência \\
\hline 1 & Muito improvável ocorrer \\
2 & Ocorre às vezes \\
3 & Ocorre eventualmente \\
4 & Ocorre frequentemente \\
5 & Muito frequente
\end{tabular}

Tabela 7: Escala qualitativa de dez níveis de probabilidade de ocorrência (ROOS et al., 2007)

\begin{tabular}{|l|c|}
\hline Escala de avaliação de ocorrência das causas e modos de falha & Índice de ocorrência \\
\hline Extremamente remoto, altamente improvável & 1 \\
\hline Remoto, improvável & 2 \\
\hline Pequena chance de ocorrência & 3 \\
\hline Pequeno número de ocorrências & 4 \\
\hline Espera-se um número ocasional de falhas & 5 \\
\hline Ocorrência moderada & 6 \\
\hline Ocorrência freqüente & 7 \\
\hline Ocorrência elevada & 8 \\
\hline Ocorrência muito elevada & 9 \\
\hline Ocorrência certa & 10 \\
\hline
\end{tabular}


Tabela 8: Escala quantitativa de dez níveis de probabilidade de ocorrência (adaptado de BEN-DAYA; RAOUF, 1996)

\begin{tabular}{cr}
\hline Pontuação & Taxa de Ocorrência \\
\hline 1 & 0 \\
2 & $1 / 20.000$ \\
3 & $1 / 10.000$ \\
4 & $1 / 2.000$ \\
5 & $1 / 1.000$ \\
6 & $1 / 200$ \\
7 & $1 / 100$ \\
8 & $1 / 20$ \\
9 & $1 / 10$ \\
10 & $1 / 2$
\end{tabular}

\#8 - Levantamento das formas de controle existentes

Nessa etapa a equipe deve buscar listar as formas de controle que estão em vigor para garantir a identificação das falhas. (PALADY, 1997)

Para Ookalkar, A, Joshi e Ookalkar, D (2009), os controles de detecção podem ser divididos em controles que previnem que a falha ocorra e controles que detectam a ocorrência das falhas.

\#9 - Estimativa da acurácia das formas de controle quanto à detecção de falhas

Diferente dos níveis de severidade e ocorrência, que quanto mais altos significam severidade maior ou probabilidade de ocorrência maior, quanto mais alta a pontuação de detecção, menor é a capacidade de detecção da falha. "No FMEA, os valores altos são ruins e os valores baixos são bons". (PALADY, 1997)

Para estimativa do nível de detecção, também são encontradas escalas mais simples, qualitativas, mais completas e quantitativas na literatura. As escalas mais simples e qualitativas, como as apresentadas por Ben-daya e Raouf (1996), Rotondaro (2002), Pinho et al. (2008), Carpinetti (2010) e Toledo e Amaral (199-), têm como exemplo a Tabela 9. As escalas de dez níveis, qualitativas, como as apresentadas por Palady (1997), Ookalkar, A, Joshi e Ookalkar, D (2009), McCain (2007) e Roos et al. (2007), têm como exemplo a Tabela 
10. E, as escalas de dez níveis, quantitativas, como a apresentada por Ben-daya e Raouf (1996), tem como exemplo a Tabela 11.

Tabela 9: Escala qualitativa de cinco níveis de detecção (TOLEDO; AMARAL, 199-)

\begin{tabular}{|c|c|c|}
\hline \multicolumn{3}{|r|}{ DETECÇÃO } \\
\hline Índice & Detecção & Critério \\
\hline $\begin{array}{l}1 \\
2 \\
\end{array}$ & Muito Grande & Certamente será detectado \\
\hline $\begin{array}{l}3 \\
4\end{array}$ & Grande & Grande probabilidade de ser detectado \\
\hline $\begin{array}{l}5 \\
6\end{array}$ & Moderada & Provavelmente será detectado \\
\hline $\begin{array}{l}7 \\
8\end{array}$ & Pequena & Provavelmente não será detectado \\
\hline $\begin{array}{l}9 \\
10\end{array}$ & Muito Pequena & Certamente não será detectado \\
\hline
\end{tabular}

Tabela 10: Escala qualitativa de dez níveis de detecção (adaptado de OOKALKAR, A; JOSHI; OOKALKAR, D, 2009)

\begin{tabular}{|l|l|c|}
\hline \multicolumn{1}{|c|}{ Detecção } & \multicolumn{1}{|c|}{ Critério } & Pontuação \\
\hline Absolutamente incerto & Quase certo que não será detectado & 10 \\
\hline Muito remota & $\begin{array}{l}\text { Os controles provavelmente não vão } \\
\text { detectar }\end{array}$ & 9 \\
\hline Remota & $\begin{array}{l}\text { Os controles tem uma chance muito } \\
\text { pequena de detectar }\end{array}$ & 8 \\
\hline Muito baixa & $\begin{array}{l}\text { Os controles tem uma chance pequena de } \\
\text { detectar }\end{array}$ & 6 \\
\hline Baixa & Os controles devem detectar & 5 \\
\hline Moderada & Os controles devem detectar & 4 \\
\hline Moderadamente alta & Os controles têm boa chance de detectar & 3 \\
\hline Alta & $\begin{array}{l}\text { Os controles têm chance muito boa de } \\
\text { detectar }\end{array}$ & 2 \\
\hline Muito alta & Os controles quase certamente vão detectar & 1 \\
\hline Quase certeza & Os controles vão detectar & \\
\hline
\end{tabular}


Tabela 11: Escala quantitativa de dez níveis de detecção (adaptado de BEN-DAYA; RAOUF, 1996)

\begin{tabular}{cc}
\hline Pontuação & $\begin{array}{c}\text { Probabilidade de não detectar e } \\
\text { a falha chegar ao cliente (\%) }\end{array}$ \\
\hline 1 & $0-5$ \\
2 & $6-15$ \\
3 & $16-25$ \\
4 & $26-35$ \\
5 & $36-45$ \\
6 & $46-55$ \\
7 & $56-65$ \\
8 & $66-75$ \\
9 & $76-85$ \\
10 & $86-100$
\end{tabular}

\#10 - Interpretação dos resultados (RPN)

Segundo Fernandes (2005), esse é, talvez, o ponto mais controverso do FMEA.

Diversos trabalhos, como Gilchrist (1993), Ben-daya e Raouf (1996), Palady (1997), Sankar e Prabhu (2001), Franceschini e Galetto (2001), Sharma, Kumar, D. e Kumar, P. (2005), Sant'ana e Pinto Júnior (2010), Inoue e Yamada (2010) e Kumar e Chaturvedi (2011) criticam a abordagem tradicional do RPN e buscam maneiras alternativas de interpretar os resultados da combinação das pontuações de severidade, ocorrência e detecção.

A forma clássica de determinação de quais modos de falha são mais críticos é proposta por Stamatis (2003), por exemplo, e consiste na multiplicação das pontuações de severidade, ocorrência e detecção.

Entretanto, Franceschini e Galetto (2001) e Sankar e Prabhu (2001) constataram que nem todos os valores entre 1 e 1.000 (amplitude dos valores de RPN) são possíveis combinações. Sankar e Prabhu (2001) ainda mencionam alguns fatos sobre o RPN, que comumente são assumidos, mas não são verdadeiros, conforme a Tabela 12, e mostram que a distribuição dos possíveis valores de RPN não é uma distribuição normal (Gráfico 3). 
Tabela 12: Fatos assumidos incorretamente sobre o RPN (adaptado de SANKAR; PRABHU, 2001)

\begin{tabular}{ll}
\hline Fatos assumidos incorretamente & Dados estatísticos reais \\
\hline $\begin{array}{l}\text { A média de todos os valores de RPN é } \\
\text { aproximadamente } 500\end{array}$ & O valor médio de RPN é 166 \\
$\begin{array}{l}\text { Aproximadamente } 50 \% \text { dos valores de RPN } \\
\text { são superiores a } 500\end{array}$ & $6 \%$ dos valores de RPN estão acima de 500 \\
Existem 1.000 valores possíveis de RPN & Existem apenas 120 valores possíveis de RPN
\end{tabular}

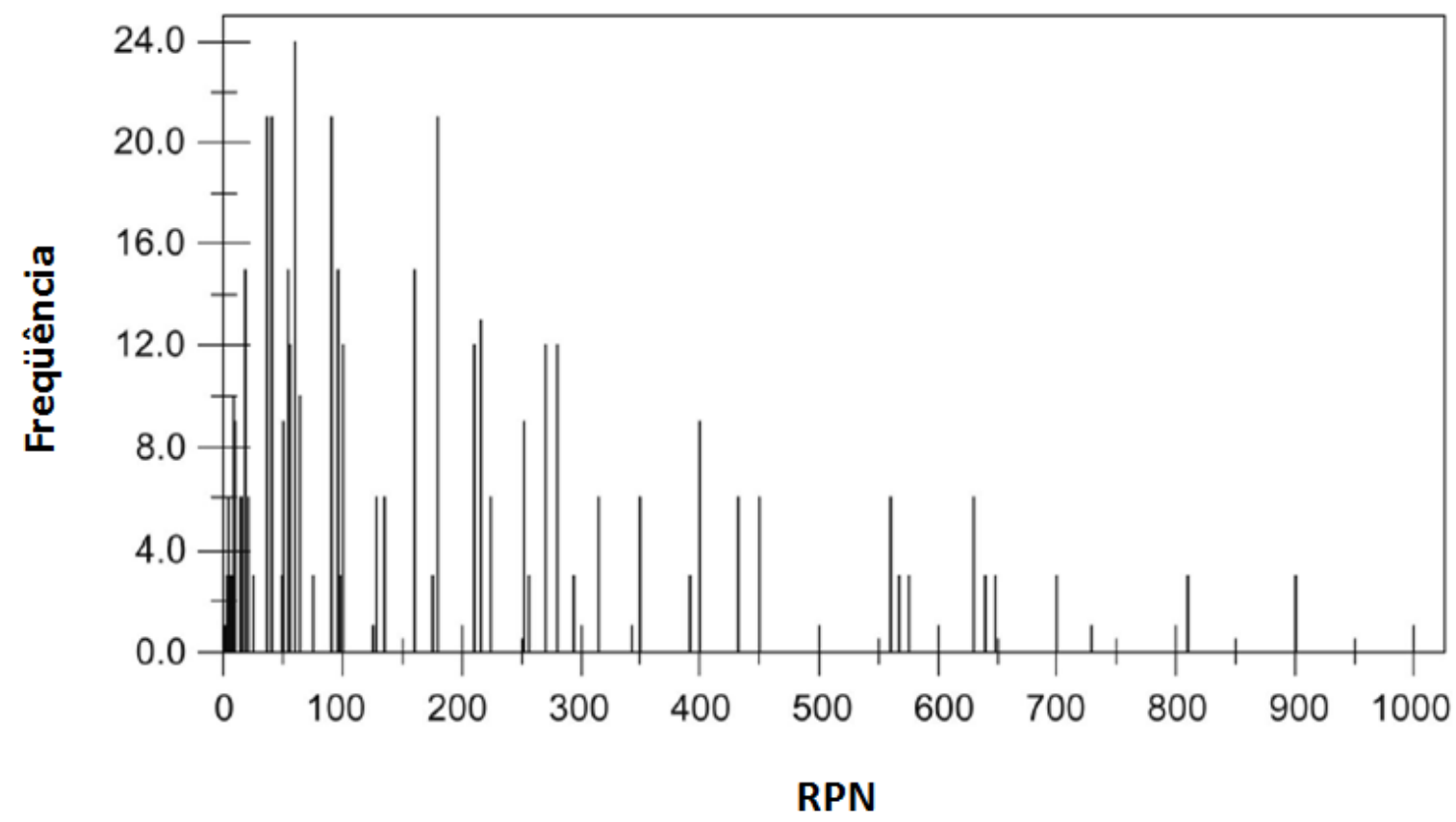

Gráfico 3: Histograma dos possíveis valores de RPN (SANKAR; PRABHU, 2001)

Devido a essas limitações do método tradicional de cálculo do RPN, Palady (2011) propõe a análise dos modos de falha por meio da utilização de um gráfico denominado Gráfico de Áreas (Gráfico 4). Para o autor, a análise deve considerar apenas a severidade e a probabilidade de ocorrência, o que constitui uma visão pró-ativa para a resolução dos problemas. Então os modos de falha devem ser colocados no gráfico, considerando as pontuações de severidade e ocorrência como as coordenadas $(x, y)$ para determinar a localização destes modos de falha no gráfico e, por conseqüência, se ele terá alta, média ou baixa prioridade. 


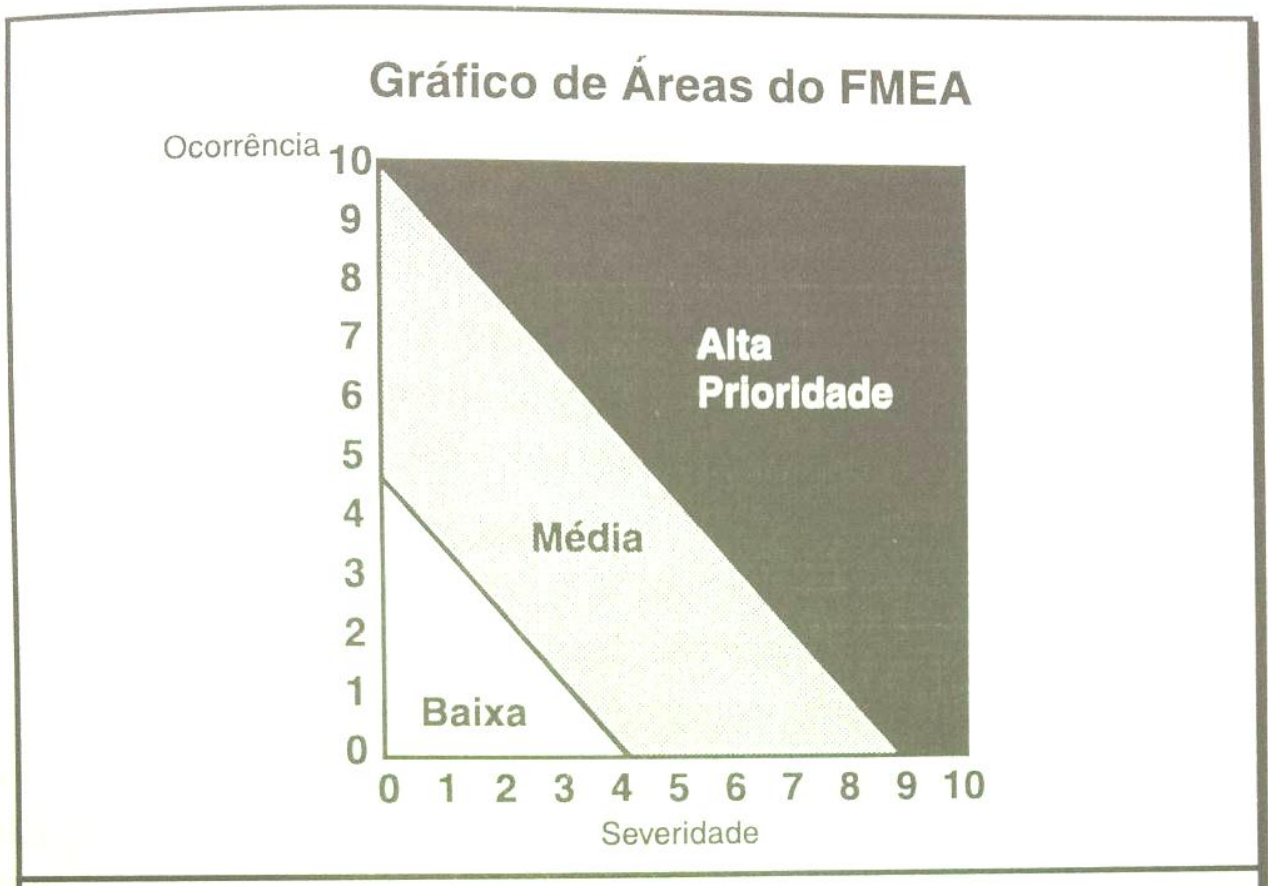

Gráfico 4: Gráfico de Área para interpretação dos resultados do FMEA (PALADY, 1997)

Franceschini e Galetto (2001) criticam o fato de que severidade, ocorrência e detecção tenham pesos iguais no cálculo do RPN, e acreditam que a severidade deveria ter peso maior. E Ben-daya e Raouf (1996) mencionam que se as escalas dos três fatores de análise (severidade, ocorrência e detecção) são iguais os pesos destes três fatores são iguais, portanto eles propõem que sejam adotadas escalas com intervalos maiores para os fatores que consideram mais importantes, no caso o fator probabilidade de ocorrência.

Kumar e Chaturvedi (2011) propõem a utilização da lógica nebulosa, de escalas de pontuação diferentes para os fatores probabilidade de ocorrência e nível de detecção e uma fórmula de cálculo diferente para o RPN.

Sankar e Prabhu (2001) construíram uma escala de RPN de 1 a 1.000, com mil possíveis combinações, tabeladas com a ajuda de especialistas em escalas de risco e adotaram a utilização da lógica "se-então" para determinação do RPN referente a cada combinação das pontuações de severidade, ocorrência e detecção.

Inoue e Yamada (2010) propõem a análise do RPN baseada apenas em dois fatores:

- Para a determinação do Q-RPN, que definem como o RPN referente à qualidade, devem ser multiplicados os valores de impacto e freqüência; e

- Para a determinação do E-RPN, que definem como o RPN referente à eficiência, devem ser multiplicados os valores de tempo e recursos utilizados. 
\#11 - Determinação das ações recomendadas de melhoria

Devem ser consideradas ações que almejem prevenir os problemas, reduzir a severidade dos efeitos das falhas, aumentar a probabilidade de detectar as falhas antes que cheguem aos clientes e que forneçam mecanismos de alerta para o cliente identificar as falhas antes que seus efeitos sejam perigosos. (PALADY, 1997)

\#12 - Acompanhamento da situação das ações recomendadas e recálculo do RPN

Nessa etapa a equipe deve acompanhar o andamento das ações recomendadas para propor possíveis ajustes ao processo e avaliar a eficácia das soluções propostas, além de documentar as ações para possíveis consultas futuras. (PALADY, 1997) (OOKALKAR, A; JOSHI; OOKALKAR, D, 2009)

Com a aplicação do método FMEA, estruturada passo a passo, conforme mostrado nesta seção, algumas vantagens, de acordo com Palady (1997) Stamatis (2003) são esperadas:

- Melhora na qualidade e confiabilidade do processo, produto ou serviço;

- Diminuição do tempo e custo do desenvolvimento do processo, produto ou serviço;

- Redução dos riscos e das falhas; e

- Maior satisfação dos clientes.

\subsection{Abordagens Alternativas do FMEA}

Nesta seção serão apresentadas formas alternativas de aplicação do FMEA, identificadas na literatura sobre o assunto, e adaptações feitas nesse método para sua utilização em ambientes e processos diferentes dos comuns, sendo que os mais comuns contemplam a aplicação do FMEA em processos de fabricação, produtos e serviços, principalmente na indústria.

Para isso, foram selecionadas, da literatura, oito propostas de adaptação e aplicação do FMEA, que, para o autor, correspondem às abordagens alternativas mais representativas para os objetivos deste trabalho. 
Life Cost-based FMEA: para medição de riscos baseados em custos durante o ciclo de vida de um produto (RHEE; ISHII, 2003)

Rhee e Ishii (2003) desenvolveram uma abordagem do FMEA para tentar superar as principais limitações do método clássico. Para isso, os autores propuseram a utilização do FMEA, baseado em análise de riscos em termos de custo, para identificar, priorizar e selecionar alternativas de design, instalações, e processos de manufatura que visassem reduzir o custo total do ciclo de vida de um determinado sistema.

Rhee e Ishii (2003) mencionam que custo é uma linguagem universal, que pode ser facilmente compreendida por engenheiros e outros, e propõem que para estimar o custo de um sistema seja usada uma fórmula simples: somatório da multiplicação da probabilidade de uma determinada falha acontecer pelo custo associado à ocorrência desta falha uma vez.

Os autores afirmam que o custo de uma falha tem três componentes principais: custo de mão-de-obra, custo de material e custo de oportunidade. Os custos de mão-de-obra e de oportunidade, segundo Rhee e Ishii( (2003), podem ser divididos em: tempo de detecção (que consiste no tempo para identificação da ocorrência da falha e diagnóstico exato de sua localização), tempo de conserto (que consiste no tempo gasto para resolução do problema), tempo de atraso (que consiste no tempo gasto com atividades que não agregam valor, como espera por resposta e tempo de setup) e tempo de recuperação (que consiste no tempo gasto, depois do conserto, até que o sistema volte a operar em seu estado normal). Já o custo de material, para os autores, pode ser entendido como o custo da peça ou componente que sofreu a falha.

Rhee e Ishii (2003) concluem que o Life Cost-based FMEA, consegue, além de auxiliar melhorias em concepção e design de um produto ou processo, melhorar o planejamento de manutenções preventivas.

\section{Cost-oriented FMEA: baseado em análise orientada a custos (VON ASHEN, 2008)}

Von Ashen (2008) acredita que os resultados obtidos por meio da aplicação do FMEA são insuficientes, uma vez que não refletem os custos que surgem com as falhas e, para a gestão de melhorias, as informações de custo são indispensáveis. 
Von Ashen (2008) ainda cita que o FMEA clássico não considera os efeitos das falhas do ponto de vista interno, ou seja, o quanto essas falhas acarretam em custos e problemas para a própria empresa. A autora acrescenta, também, que um bom nível de detecção para uma falha (pontuação baixa neste fator) contribui com uma boa redução no valor do RPN, conseqüentemente diminuindo a necessidade de melhora desta falha, mesmo que apesar de detectada, a falha acarrete em custos significantes para a empresa.

A autora cita que diversos autores pesquisaram e discutiram formas de superar os problemas com as escalas de probabilidade de ocorrência e nível de detecção e, também, com o resultado do RPN de acordo com os valores obtidos nos três fatores de análise. Entretanto, Von Ashen (2008) cita que o conceito de severidade, em termos de custo, do ponto de vista da empresa não está muito desenvolvido e, então, propõe um FMEA modificado para tentar superar esta limitação, o qual chama de Cost-oriented FMEA.

Para Von Ashen (2008), é de extrema importância a avaliação de custos em qualquer iniciativa de melhoria, já que, geralmente, um dos objetivos de um projeto de melhoria é reduzir estes custos.

Von Ashen (2008) cita o trabalho de Gilchrist (1993) que propõe uma análise em termos de custo, o qual divide em duas componentes: custo de fornecer garantia e custo de o cliente processar a empresa. Porém, a autora, incorpora na análise de custos outros fatores como, por exemplo, custo de conserto de uma falha, custo de troca de uma peça, custo de perda de receita (no caso de o cliente não aceitar a troca) e custo de perda de potenciais futuros clientes (Figura 8).

\section{Custo das Falhas}

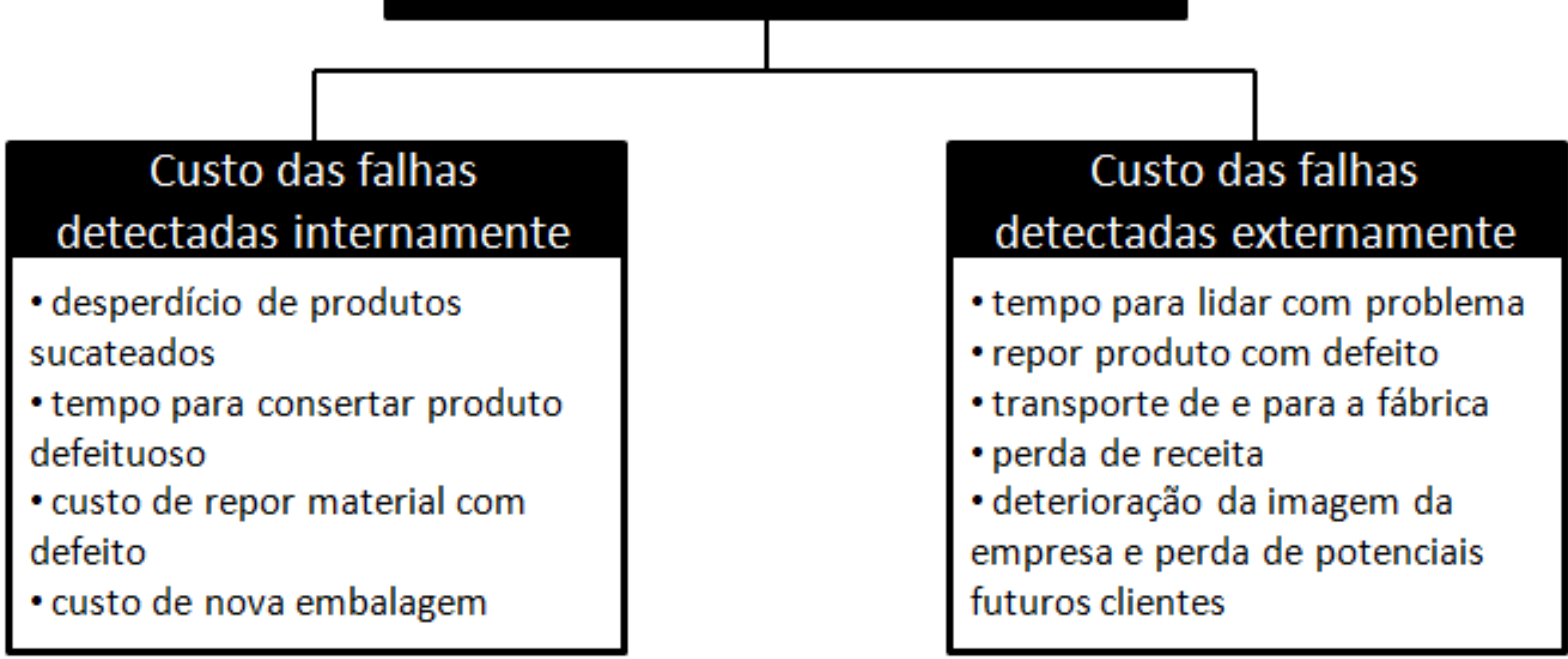

Figura 8: Custos das falhas, detectados internamente e externamente (adaptado de VON ASHEN, 2008) 
Von Ashen (2008) realizou um estudo de caso em um fornecedor automotivo, no qual aplicou o conceito apresentado de modificar a escala de severidade para ser baseada em custos e o cálculo do RPN. A autora concluiu que os resultados advindos de sua aplicação forneceram uma lista de prioridades de risco diferente e mais voltada a problemas de custo da empresa.

Service FMEA: para eliminação de falhas nas entregas dos serviços (ROTONDARO, 2002)

Para Rotondaro (2002), existem três características que são críticas para a percepção de qualidade por parte do cliente dos serviços prestados: intangibilidade (o serviço é percebido de maneira subjetiva pelos clientes e sua qualidade está relacionada aos seus sentimentos), participação do cliente no processo (que introduz um elemento não controlado e acrescenta o fato de o cliente ter de ficar satisfeito com a maneira como o serviço é prestado) e produção e consumo serem simultâneos (o que não permite testar a qualidade antes da entrega do serviço).

O autor evidencia a importância da aplicação de técnicas que promovam o estudo dos pontos mais críticos da prestação de serviço, e então possam auxiliar a prevenção de falhas no fornecimento do serviço. Rotondaro (2002) propõe, então, um método denominado SFMEA, “como ferramenta de prevenção para a área de serviços, para os momentos em que o cliente está presente ao processo de prestação de serviço, e a produção e o consumo são simultâneos". Rotondaro (2002) resume sua proposta como uma adaptação do FMEA clássico com a incorporação de elementos que atendam aos aspectos da prestação de serviços, levando em conta uma técnica denominada Fluxo de Prestação de Serviços (FPS) de Schostack ${ }^{7}$ (1985). O FPS consiste no mapeamento das interações do cliente com a empresa, chamados "momentos da verdade" e desdobramento das atividades necessárias dentro da empresa.

Rotondaro (2002) utiliza a técnica FPS para identificar os "momentos da verdade" e caracterizar a importância deles e, então, analisar que tipos de falha podem ocorrer durante os "momentos da verdade", o modo como as falhas ocorrem, os efeitos para o cliente no caso de

\footnotetext{
${ }^{7}$ SHOSTACK, G. L. Service positioning through structural change, Journal of Marketing, v. 51, p. 34-43, 1985.
} 
ocorrência da falha, os controles existentes nas fases anteriores aos "momentos da verdade" e, em caso de ocorrência da falha, o que deve ser feito para recuperar a satisfação do cliente.

O autor propõe a utilização do formulário exposto a seguir (Figura 9).

\begin{tabular}{|c|c|c|c|c|c|c|c|c|c|c|c|c|c|c|c|c|c|c|}
\hline \multicolumn{19}{|c|}{ ANÁLISE DE MODO E EFEITOS DE FALHA POTENCIAL EM SERVICCOS (SFMEA] } \\
\hline \multicolumn{5}{|c|}{$\begin{array}{l}\text { Descrição do Serviço: } \\
\text { Responsável pelo Projeto: }\end{array}$} & \multicolumn{6}{|c|}{$\begin{array}{l}\text { Item: } \\
\text { Equipe: }\end{array}$} & \multicolumn{8}{|c|}{$\begin{array}{l}\text { SFMEA } n \text { : } \\
\text { Data SFMEA: }\end{array}$} \\
\hline $\begin{array}{c}\text { Momento } \\
\text { da } \\
\text { Verdada }\end{array}$ & \begin{tabular}{|l} 
Mado de \\
Falhe \\
Potencial
\end{tabular} & \begin{tabular}{|c|} 
Efeitos \\
Potenciais
\end{tabular} & 5 & \begin{tabular}{|c|} 
Causas \\
Potenciais
\end{tabular} & 0 & Controles & D & Recuperecào & $\mathbf{R}$ & \begin{tabular}{|l|}
$\mathrm{R}$ \\
$\mathrm{P}$ \\
$\mathrm{N}$ \\
\end{tabular} & \begin{tabular}{|c|} 
ACŌES \\
PREVENTIVAS
\end{tabular} & RESPONSÁVEIS & \begin{tabular}{|l|} 
ACD̃ES \\
TOMADAS
\end{tabular} & s & 0 & D & R & \begin{tabular}{|l}
$R$ \\
$P$ \\
$N$
\end{tabular} \\
\hline & & & & & & & & & & & & & & & & & & \\
\hline & & & & & & & & & & & & & & & & & & \\
\hline
\end{tabular}

Figura 9: Formulário padrão do SFMEA (ROTONDARO, 2002)

Rotondaro (2002) desenvolve duas principais adaptações do FMEA clássico: o uso da análise de falhas nos "momentos da verdade" e o uso de um fator extra na determinação do RPN, o fator "Recuperação (R)". Para a pontuação de todos os fatores o autor propõe a utilização da escala de Likert (de 1 a 5), que no caso do índice de recuperação seria: 1- Existe um processo de recuperação bem definido e ele ocorre antes de o cliente perceber a falha a 5Não há recuperação do serviço. Para calcular o RPN, Rotondaro (2002) propõe a multiplicação dos quatro fatores.

Rotondaro (2002) aplicou o SFMEA em um restaurante e em um ambulatório e conclui que a técnica é eficaz na priorização de pontos críticos da prestação de serviços, auxilia os membros da empresa a adquirirem visão melhor dos processos de back office (retaguarda) e front office (linha de frente), além de gerar a discussão sobre a autonomia que uma pessoa do front office deve ter para tomar ações necessárias para oferecer valor aos clientes.

\section{FMEA para aumento da qualidade percebida dos serviços (CHUANG, 2010)}

Chuang (2010) propõe a incorporação da análise de desserviço, mau serviço, prejuízo ou dano (do inglês disservice) ao FMEA para criar uma ferramenta para melhorar a percepção do cliente quanto à qualidade dos serviços prestados.

Para Chuang (2010) prestar um serviço de qualidade significa atender as expectativas do cliente de forma consistente. $\mathrm{O}$ autor acrescenta que a percepção da qualidade do serviço pode ser avaliada de acordo com a discrepância entre a percepção e a expectativa do cliente. 
Chuang (2010) cita o modelo SERVQUAL de Parasuraman et al. ${ }^{8}$ (1988) que consiste na medição da qualidade dos serviços por meio da avaliação de 22 itens divididos em cinco dimensões da qualidade: confiabilidade, receptividade ou sensibilidade, garantia ou segurança, empatia e tangibilidade. $O$ autor propõe a utilização das categorias do SERVQUAL para a análise de qualidade dos serviços.

Chuang (2010) resume sua proposta como: identificação dos modos de falha potenciais que têm efeito na qualidade do serviço, cálculo do RPN para identificação da prioridade de risco dos modos de falha, determinação dos índices de desserviço para representação dos efeitos adversos das falhas dos serviços, priorização de cada dimensão da qualidade de acordo com os índices de desserviço, alocação dos modos de falha que impactam em cada dimensão da qualidade para priorização dos modos de falha das dimensões de qualidade mais importantes e exploração das causas e efeitos das falhas prioritárias para geração de planos de ação.

O autor propõe a aplicação de sua proposta segundo um passo a passo comum de aplicação do FMEA, com a inclusão do cálculo do índice de desserviço, que representa o efeito de determinado modo de falha em uma dimensão da qualidade particular. Chuang (2010) ainda propõe outro critério para priorização de falhas, que consiste em priorizar as falhas que acarretam em mais efeitos negativos.

Chuang (2010) conclui que a incorporação da análise de desserviço ao FMEA auxilia na identificação de quais modos de falha realmente impactam na percepção do cliente quanto à qualidade do serviço prestado. E o autor ainda cita a importância de as empresas de serviços lidarem com a questão de qualidade e tentarem antever as possíveis falhas que geram impactos negativos na percepção dos clientes sobre determinados serviços.

\section{FMEA para avaliação de risco ambiental (NOGUEIRA; PERES; CARVALHO, 2011)}

Para Nogueira, Peres e Carvalho (2011) a importância da redução do impacto ambiental (qualquer mudança no ambiente resultado das atividades, produtos ou serviços de uma organização) é cada vez mais importante, e as empresas vêm buscando isso pelo fato de que a legislação sobre o tema é cada vez mais rígida, os clientes procuram, cada vez mais, produtos

\footnotetext{
${ }^{8}$ Parasuraman, A., Zeithaml, V.A. and Berry, L.L. (1988), "SERVQUAL: a multiple item scale for measuring consumer perceptions of service quality”, Journal of Retailing, Vol. 64 No. 1, pp. 12-40.
} 
que não causem impacto negativo no meio ambiente e existe uma necessidade por parte das empresas de reduzir suas ineficiências e custos atrelados a impacto ambiental.

Nogueira, Peres e Carvalho (2011) citam que fizeram a aplicação do FMEA em um laticínio e que esse tipo de empresa pertence ao grupo de empresas que mais causam impacto ambiental negativo. Os autores citam como possíveis resíduos de um laticínio, efluentes líquidos (água para lavagem de equipamentos), resíduos sólidos e o soro do leite, subproduto que não é aproveitado.

O passo a passo de aplicação do FMEA que os autores utilizam para avaliação de riscos ambientais possui algumas modificações como, por exemplo, a mudança da coluna de descrição da função de um produto (do FMEA tradicional) pela coluna de descrição das saídas dos processos, adaptação da análise de efeitos e causas para a questão ambiental e a inclusão de um quarto fator de análise: a abrangência do impacto.

Os autores propõem a utilização de escalas de 1 a 3 de:

- Severidade: baixa (1) - produtos pouco danosos ao meio ambiente com curto tempo de decomposição, moderada (2) - produtos danosos ao meio ambiente com longo tempo de decomposição e alta (3) - produtos muito danosos ao meio ambiente que apresentam características como, por exemplo, patogenicidade, reatividade e toxicidade.

- Ocorrência: baixa (1) - o impacto ambiental ocorre semestralmente, anualmente ou é apenas potencial, moderada (2) o impacto ambiental ocorre mensalmente e alta (3) - o impacto ambiental ocorre diariamente.

- Detecção: alta (1) - o impacto ambiental pode ser percebido visualmente, média (2) - o impacto ambiental é percebido com a utilização de medidores simples e baixa (1) - é necessária utilização de tecnologia sofisticada para detecção.

- Abrangência do impacto: baixa (1) - o impacto ocorre no local de trabalho apenas, moderada (2) - o impacto ocorre dentro dos limites da organização e alta (3) - o impacto extrapola os limites da organização.

Nogueira, Peres e Carvalho (2011) conduzem uma aplicação e concluem que o FMEA auxiliou a melhoria dos processos, o aumento da eficiência e a conscientização das pessoas da empresa, fortalecendo a imagem da organização e conseguindo a adequação à legislação. 
FMEA para melhoria de qualidade em processos de hemodiálise (OOKALKAR, A; JOSHI; OOKALKAR, D, 2009)

Ookalkar, A., Joshi e Ookalkar, D. (2009) destacam a utilização do FMEA nos sistemas de saúde como uma ferramenta pró ativa para reduzir os riscos para os pacientes. Os autores citam outros trabalhos de melhoria de qualidade na área de saúde, nos quais foi usado o método FMEA no desenvolvimento de máquinas de diálise e para identificação e prevenção de trauma dos pacientes advindos da medicação.

Ookalkar, A., Joshi e Ookalkar, D. (2009) propõem a utilização do FMEA em processos de hemodiálise para reduzir a incidência de transmissão do vírus $\mathrm{HCV}$, um dos principais problemas, em termos de gravidade, em processos de hemodiálise.

Os autores desenvolvem a aplicação do FMEA por meio do passo a passo clássico para desenvolvimento do método que incluem: criação de um time multidisciplinar, definição das funções do processo, identificação das falhas potenciais (neste caso do processo de hemodiálise), determinação dos efeitos e da pontuação de severidade, determinação das causas das falhas e da probabilidade de ocorrência destas, determinação das formas de controle existentes e do nível de detecção, cálculo do número de prioridade de risco (RPN), decisão e implantação do plano de ação e recálculo do RPN.

Ookalkar, A., Joshi e Ookalkar, D. (2009) utilizam escalas detalhadas, de dez níveis, para pontuação dos fatores "ocorrência" e "detecção" baseadas em escalas clássicas e propõem uma adaptação da escala de "severidade", conforme a Tabela 13. 
Tabela 13: Escala de severidade para processos de sistemas de saúde (adaptado de OOKALKAR, A., JOSHI E OOKALKAR, D.; 2009)

\begin{tabular}{|c|c|c|c|c|c|}
\hline Efeito & Critério: Severidade do Efeito & Pontuação & $\begin{array}{c}\text { Durante } \\
\text { tratamento }\end{array}$ & $\begin{array}{l}\text { Depois do } \\
\text { tratamento }\end{array}$ & Exemplo \\
\hline $\begin{array}{l}\text { Perigoso - sem } \\
\text { aviso }\end{array}$ & $\begin{array}{l}\text { A falha pode colocar o } \\
\text { paciente em perigo muito } \\
\text { sério }\end{array}$ & 10 & & & $\begin{array}{l}\text { A falha pode causar } \\
\text { morte do paciente ou } \\
\text { do staff }\end{array}$ \\
\hline $\begin{array}{l}\text { Perigoso - com } \\
\text { aviso }\end{array}$ & $\begin{array}{l}\text { A falha envolve não } \\
\text { atendimento a regulamento }\end{array}$ & 9 & & & $\begin{array}{l}\text { A falha pode causar } \\
\text { sequela permanente do } \\
\text { paciente ou do staff }\end{array}$ \\
\hline Muito alto & $\begin{array}{l}\text { A falha causa insatisfação alta } \\
\text { do paciente }\end{array}$ & 8 & & & $\begin{array}{l}\text { Saúde do paciente } \\
\text { seriamente impactada }\end{array}$ \\
\hline Alto & $\begin{array}{l}\text { A falha causa insatisfação do } \\
\text { paciente }\end{array}$ & 7 & & & $\begin{array}{l}\text { Saúde do paciente } \\
\text { impactada }\end{array}$ \\
\hline Moderado & $\begin{array}{l}\text { A falha causa insucesso no } \\
\text { process }\end{array}$ & 6 & & & $\begin{array}{l}\text { Paciente tem de voltar } \\
\text { para grande correção }\end{array}$ \\
\hline Baixo & $\begin{array}{l}\text { A falha causa insucesso no } \\
\text { process }\end{array}$ & 5 & & & $\begin{array}{l}\text { Falha descoberta em } \\
\text { outro provedor de } \\
\text { saúde }\end{array}$ \\
\hline Muito baixo & $\begin{array}{l}\text { Inconveniência na função } \\
\text { subsequente - retrabalho } \\
\text { mínimo }\end{array}$ & 4 & & & $\begin{array}{l}\text { Falha descoberta e } \\
\text { corrigida em alguma } \\
\text { função no local }\end{array}$ \\
\hline Insignificante & $\begin{array}{l}\text { Inconveniência pequena na } \\
\text { função subsequente - } \\
\text { retrabalho mínimo }\end{array}$ & 3 & & & $\begin{array}{l}\text { Falha descoberta e } \\
\text { corrigida na próxima } \\
\text { etapa }\end{array}$ \\
\hline \begin{tabular}{|l} 
Muito \\
insignificante
\end{tabular} & $\begin{array}{l}\text { Inconveniência pequena na } \\
\text { entrega - retrabalho mínimo }\end{array}$ & 2 & & & $\begin{array}{l}\text { Falha descoberta e } \\
\text { corrigida na entrega }\end{array}$ \\
\hline Nenhum & $\begin{array}{l}\text { Paciente provavelmente não } \\
\text { nota }\end{array}$ & 1 & & & Nenhum efeito \\
\hline
\end{tabular}

Ookalkar, A., Joshi e Ookalkar, D. (2009) aplicam o FMEA sem grandes adaptações e concluem que é uma ferramenta eficaz para melhoria de confiabilidade em sistemas de saúde. Os autores acrescentam, também, que grande parte dos ganhos se deve à conscientização das pessoas envolvidas na aplicação do FMEA e identificação de necessidade de treinamentos e procedimentos para os processos.

FMEA em desenvolvimento de produtos farmacêuticos (INOUE; YAMADA, 2010)

Inoue e Yamada (2010) propõem a utilização do FMEA para melhoria do desenvolvimento de produtos farmacêuticos, incorporando à análise tradicional do FMEA (das falhas) a questão de eficiência.

Para Inoue e Yamada (2010), muitas empresas farmacêuticas têm grande dificuldade em melhorar seus processos de desenvolvimento de produtos e acabam por perder produtividade 
em virtude de problemas comuns nestes ambientes como, por exemplo, dificuldade de prever e entender completamente as saídas dos processos. Os autores ainda acrescentam que o desenvolvimento de um produto farmacêutico é, geralmente, muito demorado e custoso.

Segundo Inoue e Yamada (2010) os fatores chave de sucesso identificados pelo trabalho que propuseram são comuns a outras empresas e indústrias que têm iniciativas de melhoria de qualidade e eficiência.

Inoue e Yamada (2010) adaptaram o formulário do FMEA tradicional para facilitar a visualização dos processos e incorporaram a análise de eficiência à de qualidade para utilizar o FMEA como ferramenta para melhoria do desempenho do desenvolvimento de produtos farmacêuticos.

Os autores propõem a análise de qualidade e eficiência criando dois tipos de RPN diferentes:

- Q-RPN: que é o valor que fornece a análise voltada para a qualidade, calculado a partir da multiplicação do impacto do efeito indesejável pela freqüência de ocorrência do mesmo; e

- E-RPN: que é o valor que fornece a análise voltada para a eficiência, calculado a partir da multiplicação do tempo utilizado para execução de determinada tarefa pela quantidade de mão-de-obra utilizada.

Para Inoue e Yamada (2010) a importância de medir a eficiência dos processos baseandose em tempo e mão-de-obra utilizada se deve ao fato de que, na maior parte das iniciativas de melhoria de processos, essa é principal medida de desempenho.

Inoue e Yamada (2010) ainda propõem a utilização de uma tabela (Tabela 14) que contém possíveis falhas relacionadas a eficiência e a qualidade, como ferramenta para auxiliar a equipe de aplicação do FMEA a enxergar mais facilmente essas possíveis falhas. 
Tabela 14: Possíveis falhas de eficiência e qualidade em pesquisa e desenvolvimento farmacêutico (adaptado de INOUE; YAMADA, 2010)

\begin{tabular}{|c|c|c|c|}
\hline Categoria & Exemplo de Ineficiência & Categoria & Exemplo de falta de qualidade \\
\hline \multirow{3}{*}{ Esperas } & $\begin{array}{l}\text { Espera por processos anteriores } \\
\text { completarem suas etapas }\end{array}$ & \multirow{5}{*}{ Operação ruim } & $\begin{array}{l}\text { A parato de laboratório e } \\
\text { equipamentos }\end{array}$ \\
\hline & Espera por compromissos agendados & & Injeção \\
\hline & $\begin{array}{l}\text { Entrega irregular de amostras e } \\
\text { reagentes }\end{array}$ & & Preparação de compostos \\
\hline \multirow{2}{*}{$\begin{array}{c}\text { Transporte no } \\
\text { ambiente de } \\
\text { trabalho }\end{array}$} & Distâncias longas de deslocamento & & Pesagem de compostos \\
\hline & Local de estoque não centralizado & & Digitação de erros no PC \\
\hline \multirow{2}{*}{ Movimentação } & Entrada manual de dados & \multirow{2}{*}{\begin{tabular}{|c|} 
Resultados \\
inconsistentes
\end{tabular}} & Dados incompatíveis com os estudos \\
\hline & Pesquisa demorada na literatura & & Quantidade para teste insuficiente \\
\hline $\begin{array}{c}\text { Estoque em } \\
\text { excesso }\end{array}$ & $\begin{array}{l}\text { Equipamentos e amostras de } \\
\text { laboratório desnecessárias }\end{array}$ & \multirow{2}{*}{$\begin{array}{l}\text { Falta de } \\
\text { padrão }\end{array}$} & $\begin{array}{l}\text { Falta de padrão na preparação de } \\
\text { compostos }\end{array}$ \\
\hline \multirow{2}{*}{$\begin{array}{c}\text { Qualidade em } \\
\text { excesso }\end{array}$} & Tamanho da amostra muito grande & & $\begin{array}{l}\text { Falta de padrão na preparação de } \\
\text { relatórios }\end{array}$ \\
\hline & Leituras não utilizadas depois & & \\
\hline
\end{tabular}

Inoue e Yamada (2010) conduzem a aplicação desta abordagem alternativa do FMEA e concluem que os resultados foram satisfatórios, mas destacam que, a primeira vista, o método é melhor se aplicado a fluxos de processos padronizados e repetitivos.

\section{FMEA para melhoria de confiabilidade de sistemas de Produção Enxuta (SAWHNEY et al.,}

No único trabalho identificado na literatura onde os conceitos de Lean e do método FMEA são usados em conjunto, os autores Sawhney et al. (2010) propõem a utilização de um FMEA modificado para melhoria de confiabilidade de sistemas de Produção Enxuta.

Sawhney et al. (2010) mencionam a crescente importância que as metodologias de melhoria contínua vêm tendo para as empresas, porém citam o fato de que grande parte das iniciativas Lean têm dado errado devido a uma má compreensão da metodologia por parte das empresas que aplicam os conceitos da Produção Enxuta. Os autores acreditam que as iniciativas Lean não são planejadas e, por vezes, são confundidas com um pacote de ferramentas. Sawhney et al. (2010) ainda acrescentam que, diferentemente do que é recomendado pela metodologia da Produção Enxuta, as empresas buscam ganhos rápidos de curto prazo que acabam por transferir os desperdícios de um local da empresa para outro. 
Sawhney et al. (2010) enumeram alguns fatores que contribuem para a falta de sustentabilidade e confiabilidade dos sistemas Lean como, por exemplo, resistência da média gerência, falta de conhecimento para as implantações, falta de crise e resistência dos funcionários.

Os autores propõem então um FMEA modificado para garantir a sustentabilidade e confiabilidade de sistemas de Produção Enxuta, que ajuda a evidenciar as condições reais do sistema em análise que divergem das condições ideais de acordo com os conceitos do Lean. O FMEA de Sawhney et al. (2010) possui um checklist dessas condições, de acordo com uma base de conhecimento dos autores e da literatura, divididos nos quatro recursos críticos para sustentabilidade de sistemas Lean:

- Pessoas: que consiste no papel das pessoas nestes sistemas. Desde a inclusão nos processos de tomada de decisão e desenvolvimento das estações de trabalho de acordo com padrões ergonômicos até a sistematização e monotonia do trabalho;

- Materiais: incluindo matéria-prima, work in process e produtos acabados. Consiste na manutenção de estoques mínimos para garantir que os processos não parem, mas que pode atrapalhar o sistema a lidar com imprevistos e situações não planejadas;

- Equipamentos: que consiste na aplicação de técnicas de manutenção preventiva com o objetivo de aumentar a capacidade e a confiabilidade dos equipamentos, mas que também pode aumentar as chances de quebra devido a utilização máxima da capacidade destes equipamentos; e

- Cronogramas ou programações: que consiste na habilidade de planejamento e previsão, tentando adequar o sistema a um sistema de produção de fazer sob encomenda. Porém, devido à volatilidade do ambiente de negócios, os cronogramas e programações podem se tornar bastante ineficientes.

De acordo com Sawhney et al. (2010) a maioria dos conceitos e ferramentas do Lean foram desenvolvidos com o objetivo de detectar e controlar várias condições do sistema, por exemplo, o 5S que consiste na organização e padronização da área de trabalho para pronta identificação de falta ou excesso de materiais e ferramentas, o supermercado que visa detectar e controlar a quantidade de estoque em determinado ponto do fluxo e a manutenção pró ativa que visa detectar falhas em equipamentos antes que estas ocorram e acarretem em paradas longas. 
Assim, Sawhney et al. (2010) propõem a utilização de um valor diferente do RPN tradicional, chamado pelos autores de Risk Assessmnet Value (RAV), ou em português, Valor de Avaliação de Risco. O RAV é calculado multiplicando-se o índice de ocorrência pelo de severidade e, então, dividindo-se o resultado pelo índice de detecção. Os autores acreditam que o fator detecção é o fator que os conceitos do Lean conseguem influenciar, e que um controle Lean é efetivo quando consegue detectar, controlar e lidar com a falha, impedindo que esta ocorra. Assim quando um controle é efetivo na detecção sua pontuação de detecção e de ocorrência são baixas, reduzindo o valor do RAV em comparação a uma falha que não tem um controle efetivo para detecção e controle. As escalas usadas para pontuar os índices de ocorrência, severidade e detecção são escalas comuns.

O FMEA modificado de Sawhney et al. (2010) possui listas padrão de possíveis falhas na sustentabilidade de sistemas Lean e de possíveis ações recomendadas para aumento da eficácia da detecção e do controle destas falhas.

Sawhney et al. (2010) concluem que a utilização do RAV conduz a uma priorização diferente da utilização do RPN tradicional, e que o RAV é mais adequado para análise de confiabilidade de sistemas de Produção Enxuta. Além disso, o FMEA modificado destes autores, segundo eles, auxilia a identificação de pontos críticos para a sustentabilidade de sistemas Lean em uma base de possíveis falhas nestes sistemas e ações recomendadas para eliminação destas.

A revisão da literatura feita neste trabalho, em especial o que consta nesta seção, não identificou nenhuma proposta de adaptação do FMEA para identificação, priorização e eliminação de todos os desperdícios propostos pela Produção Enxuta de uma forma estruturada. Os trabalhos que mais se aproximam da proposta deste trabalho são:

- O FMEA proposto por Sawhney et al. (2010), que tem como objetivo aumentar a confiabilidade e a sustentabilidade de um sistema de Produção Enxuta implantado; e

- O FMEA proposto por Inoue e Yamada (2010) tem como objetivo a melhora de qualidade e eficiência (através da redução de alguns desperdícios do Lean) em desenvolvimento e pesquisa farmacêutica. 


\section{PLANO DE DESENVOLVIMENTO}

Neste capítulo, serão abordados conceitos de pesquisa-ação para demonstrar qual foi o planejamento para desenvolvimento da proposta deste trabalho depois da fase de revisão da literatura. Nesta parte do trabalho, será apresentada a primeira versão da proposta conceitual do método, ainda em fase de desenvolvimento, além do planejamento de sua aplicação (pesquisa de campo).

No momento da elaboração do planejamento da aplicação e da proposta conceitual, surgiu a oportunidade de realização de um primeiro ciclo de aplicação do método para coleta de dados e resultados para aprimoramento do mesmo. Esse primeiro ciclo "piloto" também é apresentado neste capítulo, juntamente com alguns resultados observados e utilizados para um primeiro refinamento da proposta conceitual.

\subsection{Etapas da Pesquisa-ação}

Para Miguel et al. (2010), Kurt Lewin publicou um dos primeiros trabalhos sobre a metodologia de pesquisa chamada pesquisa-ação. Os autores mencionam este estudo de Lewin e definem pesquisa-ação como uma pesquisa que combina a geração de teoria com a mudança de um sistema por meio da ação do pesquisador.

Coughlan e Coghlan (2002) acrescentam que as principais características que definem uma pesquisa-ação são:

- Ocorre durante a ação, ao invés de ser sobre a ação;

- Participativa;

- Coincidente com a ação;

- Uma seqüência de eventos e uma abordagem para resolução de um problema;

- Pesquisadores fazem parte da ação;

- Tem dois objetivos: resolver um problema e contribuir para a ciência;

- É interativa entre o pesquisador e os envolvidos;

- Tem o objetivo de desenvolver entendimento holístico da situação; 
- É, fundamentalmente, baseada em mudança;

- Requer um entendimento da ética do framework;

- Pode incluir todos os métodos de coleta de dados;

- Requer um planejamento e pré-entendimento;

- Deve ser conduzida em tempo real; e

- Deve ter seu próprio critério de qualidade.

Miguel et al. (2010) e Coughlan e Coghlan (2002) denotam que a pesquisa-ação geralmente é conduzida em ciclos que compreendem as atividades de: planejar a pesquisaação, coletar dados, analisar dados e planejar ações, implantar ações e avaliar resultados e gerar relatórios. A Figura 10 mostra a seqüência dessas atividades de forma mais detalhada.



Figura 10: Etapas da pesquisa-ação (adaptado de MIGUEL et al., 2010) 
Para o planejamento de aplicação da proposta, foram concluídas as etapas de definição do contexto e de propósito (etapa 1), definição da estrutura conceitual (etapa 2) e seleção de unidade de análise (etapa 3). Como mencionado, uma pesquisa piloto começou a ser realizada, como relatado na seção seguinte.

\subsection{Ciclo Preliminar de Pesquisa}

Quando começou a ser formulada a idéia conceitual do método, decidiu-se por começar a primeira rodada de aplicação em paralelo à pesquisa da literatura, com o objetivo de coletar dados para desenvolver uma proposta mais robusta para a aplicação principal pretendida por este trabalho.

Foi definido um fluxo administrativo, relativamente simples, para servir como primeira experiência para aplicação do método. O fluxo definido foi o de reservas de hotel de uma empresa de consultoria situada em São Carlos, estado de São Paulo. Os processos deste fluxo são realizados tanto por uma pessoa do setor administrativo da empresa quanto pelos próprios consultores. Definiu-se como função do fluxo: fazer as reservas de hotel dos consultores da empresa que irão para projetos ou prospecções na semana seguinte sem gerar desperdícios como superprodução, esperas, movimentações, transporte, estoques, erros e defeitos.

O método começou a ser aplicado com apenas duas modificações em relação ao FMEA tradicional exposto no capítulo 3 deste trabalho:

- A substituição do conceito de modos de falha pelo conceito de modos de desperdício (aliado à utilização de um checklist de desperdícios compilado da literatura, que depois teve mais modos de desperdício adicionados - vide seção 4.3.2 a seguir); e

- A utilização de três modelos de priorização a serem comparados (o RPN tradicional (STAMATIS, 2003), (PALADY, 1997), o Gráfico de Áreas (PALADY, 1997) e o RAV (SAWHNEY et al., 2010)).

As escalas de pontuação para ocorrência, detecção e severidade usadas foram as propostas por Palady (1997), que consistem em escalas quantitativas (quando possível) e qualitativas de dez níveis. 
Antes de iniciar a aplicação do método, foram mapeadas as principais atividades realizadas neste fluxo. $\mathrm{O}$ objetivo deste mapeamento foi situar o pesquisador quanto ao objetivo e às expectativas de nível de serviço do fluxo para, assim, permitir que este fosse capaz de conduzir as entrevistas de preenchimento do formulário do método.

Os processos foram mapeados de forma simples apenas para o entendimento macro do pesquisador e as principais atividades do fluxo são:

1. Envio de email para os consultores com a solicitação da agenda da semana seguinte - atividade feita todas as terças-feiras pela secretária administrativa;

2. Depois de aguardar o recebimento das agendas dos consultores (até quinta-feira no máximo), ocorre o preenchimento de uma planilha com as informações destas agendas;

3. Neste ponto, o fluxo pode tomar três caminhos diferentes. Aproximadamente $70 \%$ das reservas são feitas por email, 20\% diretamente pelo website do hotel e $10 \%$ das reservas não podem ser realizadas por falta de informação;

a. As reservas feitas por email são feitas para o grupo todo que vai para o mesmo hotel, portanto, é necessário esperar as agendas de todos os consultores do grupo;

b. As reservas feitas pelo website do hotel são feitas individualmente à medida que as agendas são recebidas;

c. Para as reservas que não podem ser realizadas, a secretária administrativa entra em contato com os consultores para confirmar suas agendas e, então, efetuar as reservas.

4. Depois de solicitadas as reservas, assim que elas são confirmadas pelos hotéis, ocorre o preenchimento da planilha com os números das reservas;

5. Por fim, a parte da planilha que interessa a cada consultor é filtrada e enviada por email.

O lead time deste fluxo é de cinco dias e ele pode ser representado da seguinte forma (Figura 11): 


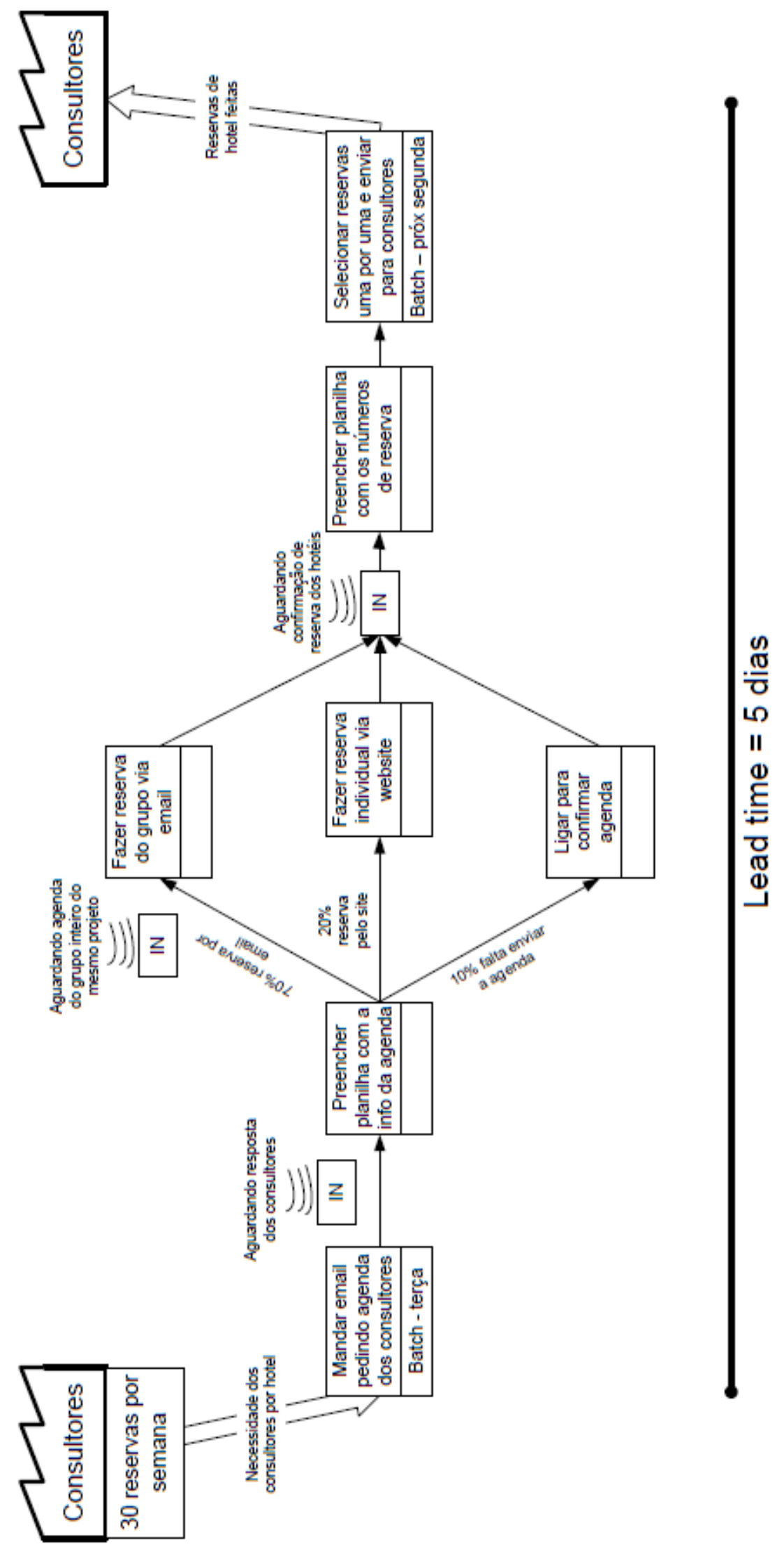

Figura 11: Fluxo de reservas de hotel em análise no clico preliminar de aplicação do método 
Com o mapeamento feito, iniciou-se a aplicação do método que, como proposta, apresentava a substituição dos modos de falha do FMEA tradicional pelos modos de desperdício (por meio da utilização da lista de desperdícios compilada da literatura) e a comparação entre o RPN o RAV e o Gráfico de Áreas.

O formulário foi preenchido pelo pesquisador com a secretária administrativa responsável pelas reservas de hotéis, na forma de entrevista. Com o checklist de desperdícios e as escalas de pontuação de severidade, ocorrência e detecção em mãos, o pesquisador conduziu o processo de preenchimento do formulário seguindo a recomendação de Palady (1997) de preencher uma coluna por vez.

Primeiramente foi apresentado o método FMEA para a entrevistada e, também, foram apresentados o checklist de desperdícios e as escalas de pontuação de severidade, ocorrência e detecção.

Após isso, foi preenchida primeiramente a coluna "Funções \#2" de acordo com o mapeamento realizado e com a percepção do pesquisador e da entrevistada. A segunda coluna, "Modos de Desperdício (MD) \#3", foi preenchida com o auxílio do checklist de desperdícios, por meio do questionamento de quais desperdícios desta lista eram observados no fluxo em análise. O pesquisador passou por todos os desperdícios da lista e usou como apoio o mapeamento feito previamente.

Com os desperdícios todos listados, foram preenchidas, concomitantemente, as colunas "Efeitos \#4" e "Severidade \#5" com o auxílio das escalas de severidade compiladas da literatura. O mesmo foi feito para as colunas "Causas \#6", "Ocorrência \#7", "Controle \#8" e "Detecção \#9".

Os dois índices de priorização calculados no formulário foram o RPN e o RAV, respectivamente nas duas colunas subsequentes. O Gráfico de Áreas de Palady (1997) também foi utilizado para análise dos modos de desperdício, considerando no eixo y a ocorrência e no eixo $\mathrm{x}$ a severidade.

O formulário preenchido (sem as ações recomendadas) é apresentado na Tabela 15 e o Gráfico de Áreas resultado desta aplicação é apresentado no Gráfico 5. 
Tabela 15: Formulário FMEA da aplicação piloto do método, sem ações recomendadas

Formulário FMEA (Análise de Efeitos e Modos de Falha) para análise dos modos de desperdício

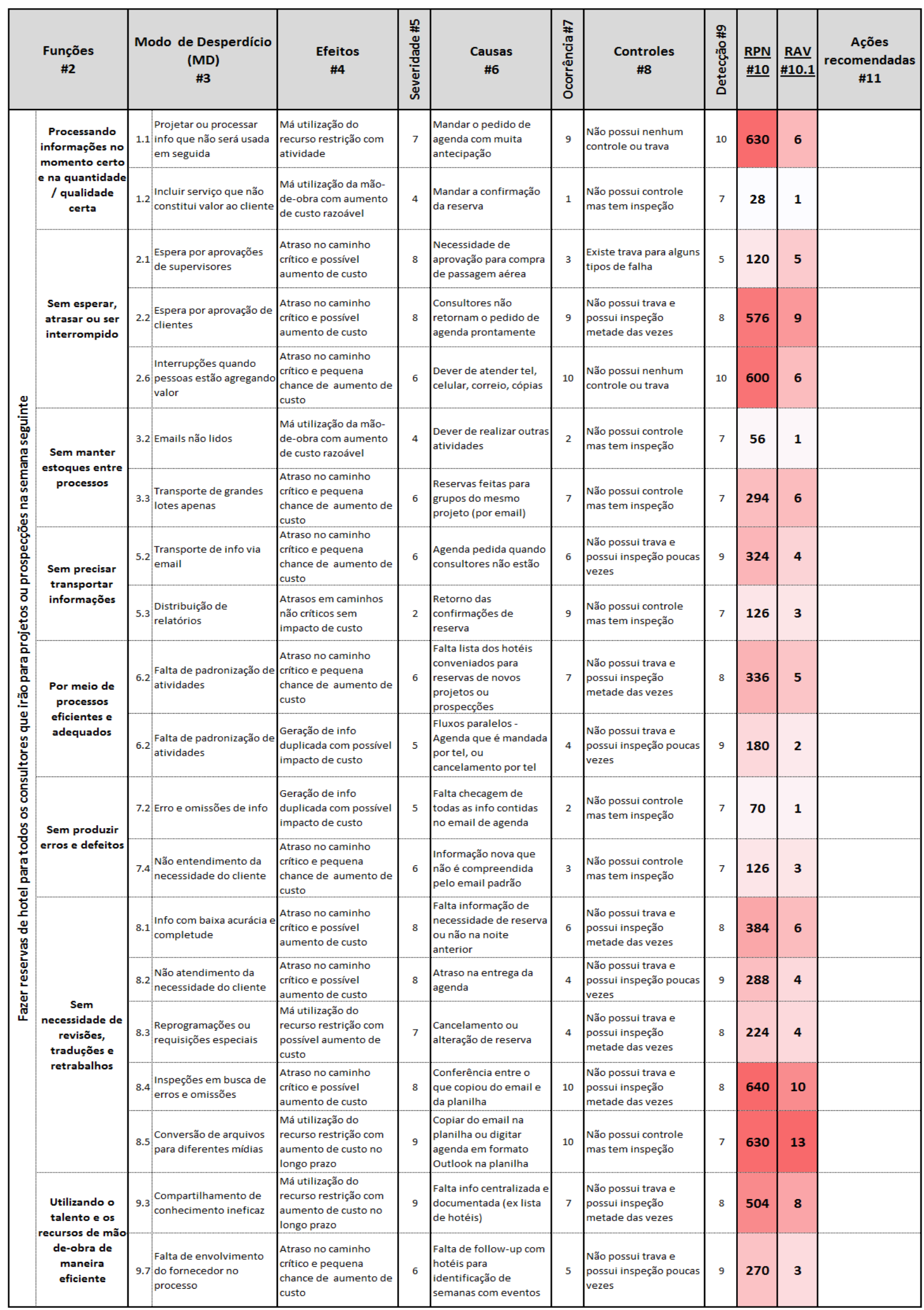




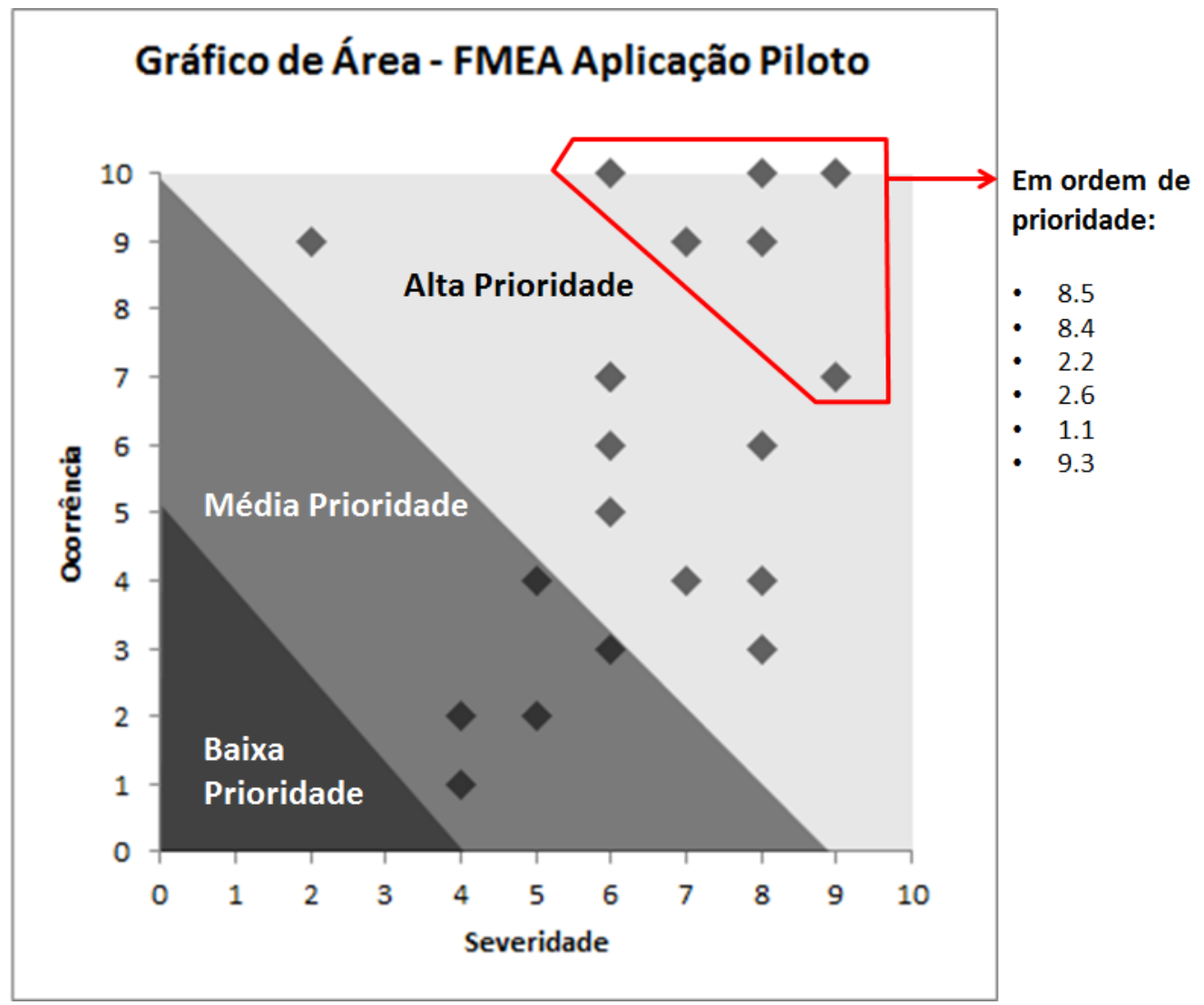

Gráfico 5: Gráfico de Áreas da Aplicação Piloto do Método

Comparando as três formas de priorização (RPN, RAV e Gráfico de Áreas), é possível notar que há pequenas diferenças entre elas, na ordem dos cinco modos de desperdício prioritários e, ainda, que apenas seis modos de desperdício diferentes aparecem analisando conjuntamente os cinco prioritários de cada forma (Tabela 16). A mesma análise para os cinco modos de desperdício menos prioritários evidencia a mesma situação (Tabela 17).

Tabela 16: Os cinco modos de desperdício prioritários de acordo com cada forma de priorização

\begin{tabular}{|c|c|c|c|c|c|c|}
\cline { 2 - 7 } \multicolumn{1}{c|}{} & \multicolumn{2}{c|}{ RPN } & \multicolumn{2}{c|}{ RAV } & \multicolumn{2}{c|}{ Gráfico de Áreas } \\
\hline $\mathbf{1}$ & Modo de Desperdício & Valor & Modo de Desperdício & Valor & Modo de Desperdício & Valor \\
\hline $\mathbf{2}$ & 8.4 & 640 & 8.5 & 13 & 8.5 & - \\
\hline $\mathbf{3}$ & 8.5 & 630 & 8.4 & 10 & 8.4 & - \\
\hline $\mathbf{4}$ & 1.1 & 630 & 2.2 & 9 & 2.2 & - \\
\hline $\mathbf{5}$ & 2.6 & 600 & 9.3 & 8 & 2.6 & - \\
\hline
\end{tabular}


Tabela 17: Os cinco modos de desperdício menos prioritários de acordo com cada forma de priorização

\begin{tabular}{|c|c|c|c|c|c|c|}
\cline { 2 - 7 } \multicolumn{1}{c|}{} & \multicolumn{2}{c|}{ RPN } & \multicolumn{2}{c|}{ RAV } & \multicolumn{2}{c|}{ Gráfico de Áreas } \\
\cline { 2 - 7 } \multicolumn{1}{c|}{} & Modo de Desperdício & Valor & Modo de Desperdício & Valor & Modo de Desperdício & Valor \\
\hline 16 & 7.4 & 126 & 7.4 & 3 & 7.4 & - \\
17 & 2.1 & 120 & 6.2 & 2 & 6.2 \\
18 & 7.2 & 70 & 7.2 & 1 & 7.2 & - \\
19 & 3.2 & 56 & 3.2 & 1 & 3.2 & - \\
\hline $\mathbf{1 0}$ & 1.2 & 28 & 1.2 & 1 & 1.2 & - \\
\hline
\end{tabular}

Pelo fato de que as três formas de priorização forneceram resultados parecidos e de que análise conjunta das três mostrou apenas seis modos de desperdício diferentes, foram geradas ações recomendadas para estes seis modos de desperdício (Tabela 18).

Tabela 18: Ações recomendas para os modos de desperdício prioritários

\begin{tabular}{|c|c|c|c|c|c|c|c|}
\hline \multicolumn{2}{|c|}{$\begin{array}{c}\text { Modo de Desperdício } \\
\text { (MD) } \\
\# 3\end{array}$} & $\begin{array}{c}\text { Efeitos } \\
\quad \# 4\end{array}$ & $\begin{array}{c}\text { Causas } \\
\# 6\end{array}$ & $\begin{array}{c}\text { Controles } \\
\text { \#8 }\end{array}$ & $\frac{\mathrm{RPN}}{\# 10}$ & $\frac{\text { RAV }}{\# 10.1}$ & $\begin{array}{c}\text { Ações recomendadas } \\
\# 11\end{array}$ \\
\hline 1.1 & $\begin{array}{l}\text { Projetar ou processar } \\
\text { info que não será usada } \\
\text { em seguida }\end{array}$ & $\begin{array}{l}\text { Má utilização do } \\
\text { recurso restrição com } \\
\text { atividade }\end{array}$ & $\begin{array}{l}\text { Mandar o pedido de } \\
\text { agenda com muita } \\
\text { antecipação }\end{array}$ & $\begin{array}{l}\text { Não possui nenhum } \\
\text { controle ou trava }\end{array}$ & 630 & 6 & $\begin{array}{l}\text { Procedimento para consultores } \\
\text { mandarem agenda em determinado dia } \\
\text { com ferramenta padrão }\end{array}$ \\
\hline 2.2 & $\begin{array}{l}\text { Espera por aprovação de } \\
\text { clientes }\end{array}$ & $\begin{array}{l}\text { Atraso no caminho } \\
\text { crítico e possível } \\
\text { aumento de custo }\end{array}$ & $\begin{array}{l}\text { Consultores não } \\
\text { retornam o pedido de } \\
\text { agenda prontamente }\end{array}$ & $\begin{array}{l}\text { Não possui trava e } \\
\text { possui inspeção } \\
\text { metade das vezes }\end{array}$ & 576 & 9 & $\begin{array}{l}\text { Ferramenta web para consultores de } \\
\text { agenda "fixa" que não precisa ser } \\
\text { alterada se a agenda não muda }\end{array}$ \\
\hline 2.6 & $\begin{array}{l}\text { Interrupções quando } \\
\text { pessoas estão agregando } \\
\text { valor }\end{array}$ & $\begin{array}{l}\text { Atraso no caminho } \\
\text { crítico e pequena } \\
\text { chance de aumento de } \\
\text { custo }\end{array}$ & $\begin{array}{l}\text { Dever de atender tel, } \\
\text { celular, correio, cópias }\end{array}$ & $\begin{array}{l}\text { Não possui nenhum } \\
\text { controle ou trava }\end{array}$ & 600 & 6 & $\begin{array}{l}\text { Horário fixo para realização da atividade } \\
\text { de reservas com revezamento das } \\
\text { outras atividades }\end{array}$ \\
\hline 8.4 & $\begin{array}{l}\text { Inspeções em busca de } \\
\text { erros e omissões }\end{array}$ & $\begin{array}{l}\text { Atraso no caminho } \\
\text { crítico e possível } \\
\text { aumento de custo }\end{array}$ & $\begin{array}{l}\text { Conferência entre o } \\
\text { que copiou do email e } \\
\text { da planilha }\end{array}$ & $\begin{array}{l}\text { Não possui trava e } \\
\text { possui inspeção } \\
\text { metade das vezes }\end{array}$ & 640 & 10 & $\begin{array}{l}\text { Ferramenta web para consultores de } \\
\text { agenda "fixa" que não precisa ser } \\
\text { alterada se a agenda não muda }\end{array}$ \\
\hline 8.5 & $\begin{array}{l}\text { Conversão de arquivos } \\
\text { para diferentes mídias }\end{array}$ & $\begin{array}{l}\text { Má utilização do } \\
\text { recurso restrição com } \\
\text { aumento de custo no } \\
\text { longo prazo }\end{array}$ & $\begin{array}{l}\text { Copiar do email na } \\
\text { planilha ou digitar } \\
\text { agenda em formato } \\
\text { Outlook na planilha }\end{array}$ & $\begin{array}{l}\text { Não possui controle } \\
\text { mas tem inspeção }\end{array}$ & 630 & 13 & $\begin{array}{l}\text { Ferramenta web para consultores de } \\
\text { agenda "fixa" que não precisa ser } \\
\text { alterada se a agenda não muda }\end{array}$ \\
\hline 9.3 & $\begin{array}{l}\text { Compartilhamento de } \\
\text { conhecimento ineficaz }\end{array}$ & $\begin{array}{l}\text { Má utilização do } \\
\text { recurso restrição com } \\
\text { aumento de custo no } \\
\text { longo prazo }\end{array}$ & \begin{tabular}{|l|} 
Falta info centralizada e \\
documentada (ex lista \\
de hotéis)
\end{tabular} & $\begin{array}{l}\text { Não possui trava e } \\
\text { possui inspeção } \\
\text { metade das vezes }\end{array}$ & 504 & 8 & $\begin{array}{l}\text { Criação de base de dados de } \\
\text { fornecedores (hotéis) por região e } \\
\text { categoria }\end{array}$ \\
\hline
\end{tabular}

Em resumo, as ações recomendadas são:

- Criar ou usar uma ferramenta web para preenchimento das agendas dos consultores onde eles possam preencher uma vez e alterar somente quando necessário. A secretária administrativa deve ser capaz de acessar periodicamente 
essa ferramenta e realizar as reservas de hotéis. A agenda não precisa ter somente a visão da próxima semana. $\mathrm{O}$ consultor que tem a agenda mais fixa pode colocar toda a agenda que já está confirmada nesta ferramenta;

- Criar uma base de dados de hotéis por região e por categoria para evitar perdas de tempo procurando alternativas de hotéis nos diferentes lugares que os consultores visitam; e

- Determinar um horário fixo na semana, de menor demanda para a secretária administrativa, para que sejam feitas todas as reservas de hotéis sem interrupção. Durante este horário pode haver um revezamento para atendimento dos telefones com outro funcionário do local.

No processo de discussão das ações recomendadas foi percebido que as ações são mais direcionadas à causa e devem ser pensadas analisando todas as causas em conjunto. Outro aspecto desta análise é o fato de que modos de desperdício diferentes e de categorias diferentes podem ter a mesma causa, o que faz com que a causa tenha um peso grande na análise e deva ser considerada tanto mais crítica quanto mais modos de desperdício ela gere.

Além disso, ficou aparente o fato de que a criação de travas e mecanismos para melhorar a detecção atua diretamente reduzindo a probabilidade de ocorrência como, por exemplo, a criação da ferramenta web mencionada que fica disponível para a secretária administrativa a todo momento e onde ela pode ver se o consultor já atualizou sua agenda.

A escala de severidade também foi discutida já que, para análise de processos internos de uma organização, os impactos dos efeitos nos custos são tão importantes quanto os impactos dos efeitos nos clientes.

Esta aplicação piloto do método forneceu resultados que acarretaram em algumas adaptações extras que foram adicionadas à proposta conceitual do método (discutida na próxima seção):

- A inclusão de outros modos de desperdício no checklist de modos de desperdício em ambientes administrativos;

- A percepção de que a detecção deve ser tratada de maneira mais contundente no que diz respeito à sua capacidade de influenciar diretamente a ocorrência. Ou seja, o nível de detecção deve ser enxergado como a capacidade que o sistema tem de evitar que as falhas e desperdícios ocorram; 
- A percepção de que a severidade dos desperdícios deve ser avaliada do ponto de vista dos custos que são gerados para a organização, já que alguns desperdícios que podem ocorrer não chegam a impactar o cliente, mas podem gerar custos altos para a empresa;

- A percepção de que o Gráfico de Áreas não seria a melhor maneira de priorizar os modos de desperdício, já que esta maneira desconsidera o fator detecção, e justamente este fator teve sua escala revista para se adequar mais ao conceito de reduzir ativamente a ocorrência dos desperdícios; e

- A criação de um novo número de prioridade de risco, que pondera a probabilidade de ocorrência de um desperdício e a capacidade do sistema impedir essa ocorrência pela severidade sob dois pontos de vista (interno e externo). Ainda, este novo número de prioridade de risco considera a quantidade de desperdícios relacionados a uma mesma causa.

\subsection{Proposta Conceitual do Método W-FMEA}

O método foi denominado Waste Mode, Failure Mode and Effect Analysis (W-FMEA), ou, em português, Análise dos Modos de Desperdícios, de Falhas e seus Efeitos. Nesta seção, será apresentada a proposta conceitual deste método e as tabelas de referência para enumeração dos modos de desperdício, as tabelas de referência para pontuação dos três fatores de análise (ocorrência, detecção e severidade) e as formas de priorização dos desperdícios.

\subsubsection{Objetivos e Formulação}

O W-FMEA é baseado em conceitos de Gestão da Qualidade e Lean e tem como objetivo servir de ferramenta para gestão de melhorias, por meio da identificação de desperdícios e suas causas e priorização de ações de melhoria em processos administrativos ou de manufatura. O W-FMEA fornece um ponto de vista derivado do método original do FMEA e dos conceitos de desperdícios do Lean.

Deve-se tratar o método como uma ferramenta de auxílio à tomada de decisão pelo fato de ser capaz de auxiliar o diagnóstico do nível de importância das causas e conseqüências dos 
desperdícios de um fluxo, e de ser capaz de auxiliar a gestão de ações de melhoria em fluxos previamente modelados. Para ser eficaz, o W-FMEA deve ser aplicado em um fluxo cujas pessoas participantes da aplicação tenham a visão holística da interface dos processos. No caso de o método ser aplicado para identificar possíveis desperdícios em um fluxo que está sendo projetado, ele deve ser aplicado por pessoas que tenham conhecimento de como o fluxo irá funcionar e quais resultados terá de gerar.

O W-FMEA, primeiramente, em um ciclo de melhoria, deve ser posicionado entre o mapeamento/modelagem da situação atual a definição do estado futuro. Assim, o método compreende a análise dos desperdícios e perdas da situação atual e fornece informações para o estágio de definição da situação futura.

Após a definição do estado futuro, a partir do momento em que começam a ser feitas as implantações e modificações no fluxo em análise, o método deve então ser tratado como ferramenta de acompanhamento e controle das melhorias e, com as informações coletadas durante as implantações, deve auxiliar a medição dos resultados das mudanças realizadas.

No caso de o método ser aplicado em um fluxo que está ainda na fase de projeto, a "situação atual" será entendida como o protótipo do fluxo e a "situação futura" o projeto definido do fluxo.

Essas interfaces do método são observadas na Figura 12. 




Figura 12: Posicionamento do W-FMEA no Ciclo de Melhoria

O método é formulado baseado em conceitos do Lean, principalmente nos desperdícios, e no método FMEA. Tem como base a análise dos desdobramentos dos desperdícios em três critérios de classificação a serem abordados no decorrer deste capítulo: nível de detecção, probabilidade de ocorrência e severidade financeira.

A partir dos conceitos pesquisados na literatura e da necessidade de criação de um método eficaz para gerir melhorias por meio da redução de desperdícios e falhas em processos (de manufatura ou administrativos), o método foi formulado para aliar conceitos das teorias de Gestão da Qualidade e Lean e auxiliar no processo contínuo de melhoria.

O formulário básico do W-FMEA é apresentado a seguir (Tabela 19) e é composto pelas seguintes colunas:

- Fluxo: onde deve ser descrito qual é o fluxo que será analisado;

- Função do Fluxo: onde são escritas as funções do fluxo, ou seja, o que é esperado que este fluxo produza de resultados. As funções são descritas de modo a respeitar os conceitos de não se produzir os desperdícios categorizados pelo Lean. 
- Modo de Desperdício (MD): onde é escrito o modo de desperdício identificado no fluxo, com o auxílio de um checklist de desperdícios.

- Causa do Modo de Desperdício: onde é descrita a causa de cada modo de desperdício, ou de um conjunto de MDs. Essa causa é identificada pela equipe de aplicação do W-FMEA com a utilização de técnicas como o Diagrama de Ishikawa ou o 5 Por-quês.

- Probabilidade de Ocorrência (PO): onde é pontuada a probabilidade de ocorrência de determinada causa de um MD.

- Nível de Detecção (ND): onde é pontuado o nível de detecção de determinada causa de um MD.

- Consequência/Efeito: onde é descrita a consequência ou o efeito de um MD.

- Severidade Financeira (SF): onde é pontuada a severidade financeira de determinada consequência de um MD.

- GINC: onde é calculado o índice de prioridade de risco, a partir das pontuações de $\mathrm{PO}, \mathrm{ND}$ e SF.

- Ações Recomendadas: onde são descritas as recomendações para eliminação das causas dos desperdícios identificados.

Tabela 19: Formulário do W-FMEA não preenchido

Waste FMEA - Análise dos Modos de Desperdícios, de Falhas e seus Efeitos



\subsubsection{Checklists dos desperdícios}

Dois recursos fundamentais do W-FMEA são os checklists de desperdícios. Existem duas versões do checklist, uma para os desperdícios em ambientes administrativos e outra para os desperdícios em ambientes de manufatura. 
Como Teng e Ho (1996), Von Ashen (2008) e Inoue e Yamada (2010) comentam, a aplicação do FMEA, geralmente, requer grande quantidade de tempo e de esforço. Como meio para minimizar a necessidade de tempo e esforço na aplicação do W-FMEA, este trabalho propõe a utilização de checklists de modos de desperdícios, sendo um para desperdícios de fluxos administrativos e outro para desperdícios de fluxos de manufatura.

Os checklists foram compilados a partir da literatura pesquisada sobre o assunto e a partir do início da aplicação piloto, relatada resumidamente na seção 4.2. A Tabela 20 e a Tabela 21 representam o checklist dos modos de desperdício em ambientes administrativos e a Tabela 22 e a Tabela 23 representam o checklist dos modos de desperdício na manufatura. Os modos de desperdício que não possuem referências nas tabelas são propostas deste trabalho, e como nenhuma aplicação foi feita em manufatura o checklist dos desperdícios de manufatura é totalmente baseado na literatura. 
Tabela 20: Checklist dos modos de desperdício em ambientes administrativos (categorias de 1 a 5)

\begin{tabular}{|c|c|c|}
\hline Categoria de Desperdício & Modo/Causa do Desperdício & Referências \\
\hline \multirow{2}{*}{$\begin{array}{l}\text { 1. Superprodução ou excesso de } \\
\text { produção }\end{array}$} & $\begin{array}{l}\text { 1.1. Projetar ou processar informações que não serão } \\
\text { usados em seguida }\end{array}$ & \multirow{2}{*}{$\begin{array}{l}\text { (LAREAU, 2002) (LOCHER, 2008) (CUATRECASAS, } \\
\text { 2004) (RASTEIRO, NAZARENO, SILVA, 2010) }\end{array}$} \\
\hline & $\begin{array}{l}\text { 1.2. Incluir serviços e características que não } \\
\text { constituem valor na ótica do cliente }\end{array}$ & \\
\hline \multirow{7}{*}{ 2. Esperas, interrupções ou atrasos } & 2.1. Esperas por aprovaçốes de supervisores & \multirow{6}{*}{$\begin{array}{l}\text { (LAREAU, 2002) (LOCHER, 2008) (CUATRECASAS, } \\
\text { 2004) (RASTEIRO, NAZARENO, SILVA, 2010) } \\
\text { (PIERCY; RICH, 2009) (FARIA, 2011) (SILVA et al, } \\
\text { 2007) (FRANCISCHINI; MIYAKE; GIANNINI, 2006) } \\
\text { (LAGO; CARVALHO; RIBEIRO, 2008) }\end{array}$} \\
\hline & 2.2. Espera por aprovação de clientes & \\
\hline & 2.3. Espera por informaçőes dos processos anteriores & \\
\hline & 2.4. Espera por manutenção de equipamentos & \\
\hline & 2.5. Espera por geração de relatórios & \\
\hline & $\begin{array}{l}\text { 2.6. Interrupçốes das pessoas quando estas estão } \\
\text { realizando atividades que agregam valor }\end{array}$ & \\
\hline & $\begin{array}{l}\text { 2.7. Excesso de reuniốes para alinhamento dos } \\
\text { envolvidos no fluxo. Retrabalhos de reuniôes. }\end{array}$ & - \\
\hline \multirow{5}{*}{$\begin{array}{l}\text { 3. Estoques intermediários e finais e } \\
\text { armazenamento }\end{array}$} & 3.1. Caixas cheias de documentos e papéis & \multirow{5}{*}{$\begin{array}{l}\text { (LAREAU, 2002) (LOCHER, 2008) (CUATRECASAS, } \\
\text { 2004) (RASTEIRO, NAZARENO, SILVA, 2010), } \\
\text { (FRANCISCHINI; MIYAKE; GIANNINI, 2006) }\end{array}$} \\
\hline & 3.2. Caixas de email cheias de emails não lidos & \\
\hline & $\begin{array}{l}\text { 3.3. Transporte apenas de grandes lotes que são } \\
\text { acumulados }\end{array}$ & \\
\hline & $\begin{array}{l}\text { 3.4. Retenção de documentos por maior tempo que o } \\
\text { necessário }\end{array}$ & \\
\hline & $\begin{array}{l}\text { 3.5. Recursos gastos para controle de filas entre } \\
\text { processos e de produtos prontos }\end{array}$ & \\
\hline \multirow{7}{*}{ 4. Movimentação ou deslocamento } & 4.1. Movimentação entre escritórios & \multirow{7}{*}{$\begin{array}{c}\text { (LAREAU, 2002) (LOCHER, 2008) (CUATRECASAS, } \\
\text { 2004) (RASTEIRO, NAZARENO, SILVA, 2010), } \\
\text { (PIERCY; RICH, 2009) (FARIA, 2011) (FRANCISCHINI; } \\
\text { MIYAKE; GIANNINI, 2006) (LAGO; CARVALHO; } \\
\text { RIBEIRO, 2008) }\end{array}$} \\
\hline & 4.2. Movimentação dentro dos escritórios & \\
\hline & 4.3. Movimentação entre atividades subseqüentes & \\
\hline & 4.4. Movimentação excessiva de pessoas & \\
\hline & 4.5. Movimentação para imprimir documentos & \\
\hline & 4.6. Movimentação para uso de fax & \\
\hline & $\begin{array}{l}\text { 4.7. Deslocamento para reuniôes desnecessárias em } \\
\text { outros locais }\end{array}$ & \\
\hline \multirow{5}{*}{ 5. Transporte } & 5.1. Transporte de documentos & \multirow{5}{*}{$\begin{array}{l}\text { (LAREAU, 2002) (LOCHER, 2008) (CUATRECASAS, } \\
\text { 2004) (RASTEIRO, NAZARENO, SILVA, 2010) } \\
\text { (PIERCY; RICH, 2009) (FRANCISCHINI; MIYAKE; } \\
\text { GIANNINI, 2006) (LAGO; CARVALHO; RIBEIRO, 2008) }\end{array}$} \\
\hline & 5.2. Transporte de informações via email & \\
\hline & 5.3. Distribuição de relatórios & \\
\hline & 5.4. Circulação de papéis para pessoas assinarem & \\
\hline & $\begin{array}{l}\text { 5.5 Qualquer transporte de informações que não } \\
\text { estejam integradas em sistema único e acessível a } \\
\text { todos os envolvidos }\end{array}$ & \\
\hline
\end{tabular}


Tabela 21: Checklist dos modos de desperdício em ambientes administrativos (categorias de 6 a 10)

\begin{tabular}{|c|c|c|}
\hline Categoria de Desperdício & Modo/Causa do Desperdício & Referências \\
\hline \multirow{9}{*}{$\begin{array}{l}\text { 6. Processos inadequados ou } \\
\text { ineficientes e falta de comunicação }\end{array}$} & $\begin{array}{l}\text { 6.1. Má utilização dos recursos na condução das } \\
\text { atividades }\end{array}$ & \multirow{4}{*}{$\begin{array}{l}\text { (LAREAU, 2002) (LOCHER, 2008) (CUATRECASAS, } \\
\text { 2004) (RASTEIRO; NAZARENO; SILVA, 2010) } \\
\text { (PIERCY; RICH, 2009) (FRANCISCHINI; MIYAKE; } \\
\text { GIANNINI, 2006) (LAGO; CARVALHO; RIBEIRO, 2008) }\end{array}$} \\
\hline & 6.2. Falta de padronização das atividades & \\
\hline & 6.3. Geração de cópias extras de documentos & \\
\hline & $\begin{array}{l}\text { 6.4. Falta ou dificuldade de comunicação entre os } \\
\text { envolvidos no fluxo }\end{array}$ & \\
\hline & $\begin{array}{l}\text { 6.5. Generalização dos fluxos e tratamento igual para } \\
\text { diferentes tipos de informação }\end{array}$ & \multirow[b]{2}{*}{ (HAMMER; CHAMPY, 1994) } \\
\hline & $\begin{array}{l}\text { 6.6. Excesso de departamentalização na organização } \\
\text { dos fluxos de informção e falta de estrutura } \\
\text { organizacional por fluxo de processos }\end{array}$ & \\
\hline & $\begin{array}{l}\text { 6.7. Determinação incorreta dos preços/custos dos } \\
\text { serviços/processos }\end{array}$ & - \\
\hline & $\begin{array}{l}\text { 6.8. Aceite de configurações de serviços/produtos } \\
\text { infactíveis }\end{array}$ & - \\
\hline & $\begin{array}{l}\text { 6.9. Existência de caminhos paralelos e incorretos } \\
\text { para a informação acarretanto perda da informação }\end{array}$ & - \\
\hline \multirow{5}{*}{ 7. Defeitos, erros e imperfeições } & 7.1. Processamento de informaçōes com defeitos & \multirow{5}{*}{$\begin{array}{l}\text { (LAREAU, 2002) (LOCHER, 2008) (CUATRECASAS, } \\
\text { 2004) (PIERCY; RICH, 2009) (FARIA, 2011) } \\
\text { (FRANCISCHINI; MIYAKE; GIANNINI, 2006) }\end{array}$} \\
\hline & 7.2. Omissőes de informações & \\
\hline & 7.3. Erros nos projetos, produtos ou serviços & \\
\hline & 7.4. Geração de informações erradas na primeira vez & \\
\hline & $\begin{array}{l}\text { 7.5. Não entendimento das necessidades dos } \\
\text { clientes }\end{array}$ & \\
\hline \multirow{6}{*}{ 8. Revisões, traduções e retrabalhos } & 8.1. Informações com baixa acurácia e completude & \multirow{6}{*}{$\begin{array}{c}\text { (LAREAU, 2002) (RASTEIRO; NAZARENO; SILVA, } \\
\text { 2010) (PIERCY; RICH, 2009) (FARIA, 2011) (LAGO; } \\
\text { CARVALHO; RIBEIRO, 2008) }\end{array}$} \\
\hline & 8.2. Não atendimento das necessidades dos clientes & \\
\hline & 8.3. Reprogramações e requisiçőes especiais & \\
\hline & 8.4. Inspeçőes em busca de erros e omissôes & \\
\hline & $\begin{array}{l}\text { 8.5. Conversão de arquivos para uso em diferentes } \\
\text { tipos de mídia ou softwares }\end{array}$ & \\
\hline & $\begin{array}{l}\text { 8.6. Atividades feitas para corrigir erros ou } \\
\text { ineficiências dos processos }\end{array}$ & \\
\hline \multirow{6}{*}{$\begin{array}{l}\text { 9. Sub-utlização da mão-de-obra, do } \\
\text { talento e dos recursos }\end{array}$} & 9.1. Limitação de autonomia para questões básicas & \multirow{6}{*}{$\begin{array}{l}\text { (LOCHER, 2008) (PIERCY; RICH, 2009) (RASTEIRO; } \\
\text { NAZARENO; SILVA, 2010) (FARIA, 2011) }\end{array}$} \\
\hline & 9.2. Potencial subestimado das pessoas & \\
\hline & 9.3. Compartilhamento de conhecimento ineficaz & \\
\hline & 9.4. Mau gerenciamento dos recursos de pessoas & \\
\hline & \begin{tabular}{|l} 
9.5. Mau gerenciamento dos recursos de materiais \\
9.6. Mau gerenciamento dos equipamentos
\end{tabular} & \\
\hline & $\begin{array}{l}\text { 9.7. Falta de envolvimento de fornecedor e do cliente } \\
\text { em etapas necessárias }\end{array}$ & \\
\hline \multirow[t]{2}{*}{ 10. Excesso de capacidade instalada } & $\begin{array}{l}\text { 10.1. Capacidade instalada para absorver picos de } \\
\text { demanda, que fica ociosa em períodos de demanda } \\
\text { menor }\end{array}$ & $\begin{array}{l}\text { (LAREAU, 2002) (FRANCISCHINI; MIYAKE; } \\
\text { GIANNINI, 2006) (LAGO; CARVALHO; RIBEIRO, 2008) }\end{array}$ \\
\hline & 10.2. Desnivelamento dos processos do fluxo & - \\
\hline
\end{tabular}


Tabela 22: Checklist dos modos de desperdício em ambientes de manufatura (categorias de 1 a 4)

\begin{tabular}{|c|c|c|}
\hline Categoria de Desperdício & Modo do Desperdício & Referências \\
\hline \multirow{7}{*}{ 1. Superprodução } & $\begin{array}{l}\text { 1.1. Falta de coordenação entre a produção e o ritmo } \\
\text { de consumo da demanda }\end{array}$ & \multirow{7}{*}{$\begin{array}{c}\text { (SHINGO, 1996) (WOMACK; JONES, 2003) (OHNO, 1988) } \\
\text { (LIKER, 2004) (CORRÊA; GIANESI; CAON, 2001) (RENTES; } \\
\text { SILVA, A; SILVA, V, 2003) (SANCHÉZ; PERÉZ, 2001) (SILVEIRA } \\
\text { COUTINHO, 2008) (NAZARENO, 2003) }\end{array}$} \\
\hline & $\begin{array}{l}\text { 1.2. Ter incerteza na ocorrência de defeitos nos } \\
\text { produtos e nos processos }\end{array}$ & \\
\hline & 1.3. Possuir grandes áreas de depósito & \\
\hline & 1.4. Custos de transporte elevados & \\
\hline & 1.5. Falhas na programação da produção & \\
\hline & 1.6. Tempos altos de setup das máquinas & \\
\hline & 1.7. Antecipação da produção das peças e produtos & \\
\hline \multirow{2}{*}{ 2. Excesso de invetário } & $\begin{array}{l}\text { 2.1. Peças em estoque esperando por causa de } \\
\text { desbalanceamento dos processos de produção }\end{array}$ & \multirow{2}{*}{$\begin{array}{l}\text { (SHINGO, 1996) (WOMACK; JONES, 2003) (OHNO, 1988) } \\
\text { (LIKER, 2004) (CORRÊA; GIANESI; CAON, 2001) (RENTES; } \\
\text { SILVA, A; SILVA, V, 2003) (SANCHÉZ; PERÉZ, 2001) (SILVEIRA } \\
\text { COUTINHO, 2008) (NAZARENO, 2003) (ALMEIDA, 2009) }\end{array}$} \\
\hline & $\begin{array}{l}\text { 2.2. Dificuldade e ineficiência em lidar com flutuação } \\
\text { de demanda }\end{array}$ & \\
\hline \multirow{2}{*}{ 3. Transporte desnecessário } & 3.1. Necessidade de produção em grandes volumes & \multirow{2}{*}{$\begin{array}{c}\text { (SHINGO, 1996) (WOMACK; JONES, 2003) (OHNO, 1988) } \\
\text { (LIKER, 2004) (CORRÊA; GIANESI; CAON, 2001) (RENTES; } \\
\text { SILVA, A; SILVA, V, 2003) (SANCHÉZ; PERÉZ, 2001) (SILVEIRA } \\
\text { COUTINHO, 2008) (NAZARENO, 2003) }\end{array}$} \\
\hline & $\begin{array}{l}\text { 3.2. Layouts inadequados com grande distanciamento } \\
\text { entre os processos }\end{array}$ & \\
\hline \multirow{3}{*}{ 4. Defeitos } & 4.1. Falta de treinamento dos operadores & \multirow{3}{*}{$\begin{array}{l}\text { (SHINGO, 1996) (WOMACK; JONES, 2003) (OHNO, 1988) } \\
\text { (LIKER, 2004) (CORRÊA; GIANESI; CAON, 2001) (RENTES; } \\
\text { SILVA, A; SILVA, V, 2003) (SANCHÉZ; PERÉZ, 2001) (SILVEIRA; } \\
\text { COUTINHO, 2008) (NAZARENO, 2003) }\end{array}$} \\
\hline & 4.2. Matéria-prima do processo defeituosa & \\
\hline & 4.3. Processos de fabricação inadequados & \\
\hline
\end{tabular}

Tabela 23: Checklist dos modos de desperdício em ambientes de manufatura (categorias de 5 a 8 )

\begin{tabular}{|c|c|c|}
\hline Categoria de Desperdício & Modo do Desperdício & Referências \\
\hline \multirow{4}{*}{ 5. Esperas } & 5.1. Interrupções em processos anteriores & \multirow{4}{*}{$\begin{array}{l}\text { (SHINGO, 1996) (WOMACK; JONES, 2003) (OHNO, 1988) } \\
\text { (LIKER, 2004) (CORREAA; GIANESI; CAON, 2001) (RENTES; } \\
\text { SILVA, A; SILVA, V, 2003) (SANCHÉZ; PERÉZ, 2001) (SILVEIRA } \\
\text { COUTINHO, 2008) (NAZARENO, 2003) }\end{array}$} \\
\hline & 5.2. Falta de materiais, ferramentas ou informações & \\
\hline & 5.3. Ocorrência de imprevistos na produção & \\
\hline & 5.4. Mau gerenciamentos dos gargalos de capacidade & \\
\hline \multirow{4}{*}{$\begin{array}{l}\text { 6. Superprocessamento ou } \\
\text { processamento incorreto }\end{array}$} & 6.1. Utilização de mais recursos que o necessário & \multirow{4}{*}{$\begin{array}{c}\text { (SHINGO, 1996) (WOMACK; JONES, 2003) (OHNO, 1988) } \\
\text { (LIKER, 2004) (CORRÊA; GIANESI; CAON, 2001) (RENTES; } \\
\text { SILVA, A; SILVA, V, 2003) (SANCHÉZ; PERÉZ, 2001) (SILVEIRA } \\
\text { COUTINHO, 2008) (NAZARENO, 2003) }\end{array}$} \\
\hline & $\begin{array}{l}\text { 6.2. Produção de itens com qualidade superior à } \\
\text { necessária }\end{array}$ & \\
\hline & $\begin{array}{l}\text { 6.3. Utilização de ferramentas inadequadas ao } \\
\text { processo }\end{array}$ & \\
\hline & $\begin{array}{l}\text { 6.4. Problemas nas cartas de processo e/ou no } \\
\text { seqüenciamentos dos mesmos }\end{array}$ & \\
\hline \multirow{4}{*}{ 7. Movimentação desnecessária } & 7.1. Falta de procedimentos padrão de trabalho & \multirow{4}{*}{$\begin{array}{l}\text { (SHINGO, 1996) (WOMACK; JONES, 2003) (OHNO, 1988) } \\
\text { (LIKER, 2004) (CORRÊA; GIANESI; CAON, 2001) (RENTES; } \\
\text { SILVA, A; SILVA, V, 2003) (SANCHÉZ; PERÉZ, 2001) (SILVEIRA; } \\
\quad \text { COUTINHO, 2008) (WEBER, 2005) (NAZARENO, 2003) }\end{array}$} \\
\hline & $\begin{array}{l}\text { 7.2. Movimentos para alcançar objetos, insumos e } \\
\text { ferramentas }\end{array}$ & \\
\hline & 7.3. Má organização do posto de trabalho & \\
\hline & $\begin{array}{l}\text { 7.4. Busca de objetos, insumos e ferramentas } \\
\text { perdidos }\end{array}$ & \\
\hline $\begin{array}{l}\text { 8. Desperdício de talento e } \\
\text { criatividade dos funcionários }\end{array}$ & 8.1. Falta de tempo para realizar melhorias & (LIKER, 2004) \\
\hline
\end{tabular}

Sabe-se que estes modos de desperdício podem não representar todos os tipos possíveis, porém acredita-se que representem grande parte deles. É esperado que estes checklists sejam eficazes, já que de acordo com Palady (1997), não se deve considerar todos os modos de falha possíveis na aplicação do FMEA.

Estes checklists devem ser usados durante a fase de mapeamento/modelagem da situação atual e preenchimento dos modos de desperdício no formulário do W-FMEA. 


\subsubsection{Escalas de Probabilidade de Ocorrência, Nível de Detecção e Severidade Financeira}

As escalas de Probabilidade de Ocorrência (PO), Nível de Detecção (ND) e Severidade Financeira (SF) foram elaboradas baseadas em compilações das escalas encontradas na literatura. Este trabalho procurou, também, deixar mais claras as descrições qualitativas referentes a cada nível de pontuação.

A Tabela 24 é uma referência para a determinação de qual pontuação representará cada nível de probabilidade de ocorrência, e é baseada na pesquisa dos autores (PALADY, 1997), (INOUE; YAMADA, 2010), (KUMAR; CHATURVEDI, 2011), (OOKALKAR, A; JOSHI; OOKALKAR， D, 2009), (BEN-DAYA; RAOUF, 1996), (ROTONDARO, 2008), (CAPALDO; TOLEDO; ROZENFELD, 1999), (CARPINETTI, 2010), (PINHO et al., 2008), (MCCAIN, 2007), (ROOS et al., 2007) e (TOLEDO; AMARAL, 199-) além de contribuições do autor deste trabalho.

Também é apresentada a seguir uma tabela (Tabela 25) que pode servir como referência para a pontuação de Nível de Detecção, também baseada na pesquisa dos autores (PALADY, 1997), (INOUE; YAMADA, 2010), (KUMAR; CHATURVEDI, 2011), (OOKALKAR, A; JOSHI; OOKALKAR, D, 2009), (BEN-DAYA; RAOUF, 1996), (ROTONDARO, 2008), (CAPALDO; TOLEDO; ROZENFELD, 1999), (CARPINETTI, 2010), (PINHO et al., 2008), (MCCAIN, 2007), (ROOS et al., 2007) e (TOLEDO; AMARAL, 199-) além de contribuições do autor deste trabalho. A escala de detecção apresentada nesta seção foi incrementada, após a aplicação piloto do W-FMEA mencionada na seção 4.2, de acordo com os conceitos da Produção Enxuta, que consistem no fato de que uma detecção boa é aquela que evita que o erro aconteça. Para que um processo tenha um nível de detecção ótimo, é preciso que este processo possua um mecanismo à prova de falhas, que impeça a ocorrência de qualquer falha. Esses conceitos também são apresentados por Sawhney et al. (2010) e influenciaram a elaboração desta escala de nível de detecção.

A Tabela 26 a seguir é um modelo de referência para a pontuação de "Severidade Financeira" e, como mencionada anteriormente é uma das adaptações propostas pelo WFMEA. A coluna que analisa a severidade do ponto de vista da empresa é influenciada, principalmente, pelos estudos de Inoue e Yamada (2010) e Von Ashen (2008) e a coluna de severidade do ponto de vista do cliente é baseada na pesquisa dos autores (PALADY, 1997), (KUMAR; CHATURVEDI, 2011), (OOKALKAR, A; JOSHI; OOKALKAR, D, 2009), 
(BEN-DAYA; RAOUF, 1996), (ROTONDARO, 2008), (CAPALDO; TOLEDO; ROZENFELD, 1999), (CARPINETTI, 2010), (PINHO et al., 2008), (MCCAIN, 2007), (ROOS et al., 2007) e (TOLEDO; AMARAL, 199-) além de contribuições do autor deste trabalho. Para pontuar a Severidade Financeira, a consequiência do modo de desperdício deve ser analisada sob os pontos de vista interno e externo. O valor a ser atribuído deve ser o maior entre os dois tipos de análise. 
Tabela 24: Escala de referência para pontuação da Probabilidade de Ocorrência (PO)

\begin{tabular}{|c|c|c|}
\hline \multicolumn{3}{|c|}{ Pontuação de Probabilidade de Ocorrência } \\
\hline Pontuação & $\begin{array}{l}\text { Descrição Qualitativa da } \\
\text { Pontuação }\end{array}$ & $\begin{array}{l}\text { Descrição Quantitativa } \\
\text { da Pontuação }\end{array}$ \\
\hline 1 & $\begin{array}{c}\text { Bastante remota, muito improvável - } \\
\text { até pessoas experientes no fluxo não } \\
\text { se recordam de quando ocorreu da } \\
\text { útlima vez } \\
\end{array}$ & $\begin{array}{l}\text { Chance quase zero de } \\
\text { ocorrer }(0,1 \%)\end{array}$ \\
\hline 2 & $\begin{array}{c}\text { Improvável - as pessoas mais } \\
\text { experientes se recordam, com } \\
\text { dificuldade, uma vez em que ocorreu }\end{array}$ & $\begin{array}{c}\text { Chance menor que } 1 \% \text { de } \\
\text { ocorrer }\end{array}$ \\
\hline 3 & $\begin{array}{c}\text { Chance pequena de ocorrer - pessoas } \\
\text { mais experientes conseguem lembrar, } \\
\text { com dificuldade, de poucas vezes em } \\
\text { que ocorreu }\end{array}$ & $\begin{array}{c}\text { Chance de } 1 \text { a } 3 \% \text { de } \\
\text { ocorrer }\end{array}$ \\
\hline 4 & $\begin{array}{l}\text { Alguma chance de ocorrer - pessoas } \\
\text { mais experientes no fluxo apontam } \\
\text { poucos casos }\end{array}$ & $\begin{array}{c}\text { Chance de } 3 \text { a } 5 \% \text { de } \\
\text { ocorrer }\end{array}$ \\
\hline 5 & $\begin{array}{l}\text { Poucas ocorrências - todos envolvidos } \\
\text { no fluxo se lembram de poucos casos }\end{array}$ & $\begin{array}{l}\text { Chance de } 5 \text { a } 8 \% \text { de } \\
\text { ocorrer }\end{array}$ \\
\hline 6 & $\begin{array}{c}\text { Número considerável de ocorrências - } \\
\text { pessoas mais experientes no fluxo } \\
\text { apontam alguns casos }\end{array}$ & $\begin{array}{l}\text { Chance de } 8 \text { a } 15 \% \text { de } \\
\text { ocorrer }\end{array}$ \\
\hline 7 & $\begin{array}{c}\text { Ocorre com alguma frequência - todos } \\
\text { envolvidos no fluxo lembram de } \\
\text { alguns casos }\end{array}$ & $\begin{array}{l}\text { Chance de } 15 \text { a } 25 \% \text { de } \\
\text { ocorrer }\end{array}$ \\
\hline 8 & $\begin{array}{c}\text { Ocorre com muita frequência - pessoas } \\
\text { mais experientes no fluxo conseguem } \\
\text { apontar muitos casos }\end{array}$ & $\begin{array}{l}\text { Chance de } 25 \text { a } 35 \% \text { de } \\
\text { ocorrer }\end{array}$ \\
\hline 9 & $\begin{array}{c}\begin{array}{c}\text { Ocorre muito provavelmente - todos } \\
\text { envolvidos no fluxo se lembram de } \\
\text { muitos casos }\end{array} \\
\end{array}$ & $\begin{array}{l}\text { Chance de } 35 \text { a } 50 \% \text { de } \\
\text { ocorrer }\end{array}$ \\
\hline 10 & $\begin{array}{c}\text { Ocorre quase certamente (diversas } \\
\text { vezes) - todos da empresa conseguem } \\
\text { apontar muitos casos }\end{array}$ & $\begin{array}{l}\text { Chance maior de } 50 \% \text { de } \\
\text { ocorrer }\end{array}$ \\
\hline
\end{tabular}


Tabela 25: Escala de referência para pontuação do Nível de Detecção (ND)

\begin{tabular}{|c|c|c|}
\hline \multicolumn{3}{|c|}{ Pontuação de Nível de Detecção } \\
\hline Pontuação & $\begin{array}{c}\text { Descrição Qualitativa da } \\
\text { Pontuação }\end{array}$ & $\begin{array}{c}\text { Descrição Quantitativa } \\
\text { da Pontuação }\end{array}$ \\
\hline 1 & $\begin{array}{c}\text { Com certeza será detectado antes que } \\
\text { ocorra a falha - existem mecanismos à } \\
\text { prova de falha que evitam todo tipo de } \\
\text { falha }\end{array}$ & $\begin{array}{c}\text { Detecta e impede a } \\
\text { ocorrência em } 100 \% \text { das } \\
\text { vezes }\end{array}$ \\
\hline 2 & $\begin{array}{c}\text { Probabilidade muito alta de ser } \\
\text { detectado antes que ocorra a falha - } \\
\text { existem mecanismos à prova de falha } \\
\text { que evitam quase todo o tipo de falha }\end{array}$ & $\begin{array}{c}\text { Detecta e impede a } \\
\text { ocorrência em } 85 \% \text { das } \\
\text { vezes e apenas detecta o } \\
\text { restante }\end{array}$ \\
\hline 3 & $\begin{array}{l}\text { É provável que seja detectado antes } \\
\text { que a falha ocorra - existem } \\
\text { mecanismos à prova de falhas para } \\
\text { grande parte dos tipos de falha }\end{array}$ & $\begin{array}{c}\text { Detecta e impede a } \\
\text { ocorrência em } 70 \% \text { das } \\
\text { vezes e apenas detecta o } \\
\text { restante }\end{array}$ \\
\hline 4 & $\begin{array}{c}\text { Tem boa chance de ser detectado antes } \\
\text { que a falha ocorra - existem } \\
\text { mecanismos à prova de falhas para } \\
\text { cerca de metade dos tipos de falha }\end{array}$ & $\begin{array}{c}\text { Detecta e impede a } \\
\text { ocorrência em } 50 \% \text { das } \\
\text { vezes e apenas detecta o } \\
\text { restante }\end{array}$ \\
\hline 5 & $\begin{array}{c}\text { Tem pequena chance de ser detectado } \\
\text { antes que a falha ocorra - existem } \\
\text { mecanismos à prova de falhas para } \\
\text { poucos tipos de falha }\end{array}$ & $\begin{array}{c}\text { Detecta e impede a } \\
\text { ocorrência em } 30 \% \text { das } \\
\text { vezes e apenas detecta o } \\
\text { restante }\end{array}$ \\
\hline 6 & $\begin{array}{l}\text { Tem chance mínima de ser detectado } \\
\text { antes que a falha ocorra - existem } \\
\text { mecanismos à prova de falhas para } \\
\text { quase nenhum tipo de falha }\end{array}$ & $\begin{array}{c}\text { Detecta e impede a } \\
\text { ocorrência em } 10 \% \text { das } \\
\text { vezes e apenas detecta o } \\
\text { restante } \\
\end{array}$ \\
\hline 7 & $\begin{array}{c}\text { Não possui mecanismo à prova de } \\
\text { falhas e possui inspeção de tudo após o } \\
\text { processo }\end{array}$ & $\begin{array}{c}\text { Não impede a ocorrência } \\
\text { e detecta } 90 \% \text { das falhas } \\
\text { após a ocorrência, antes } \\
\text { de chegar no cliente }\end{array}$ \\
\hline 8 & $\begin{array}{l}\text { Não possui mecanismo à prova de } \\
\text { falhas e possui inspeção após o } \\
\text { processo cerca de metade das vezes }\end{array}$ & $\begin{array}{c}\text { Não impede a ocorrência } \\
\text { e detecta } 50 \% \text { das falhas } \\
\text { após a ocorrência, antes } \\
\text { de chegar no cliente }\end{array}$ \\
\hline 9 & $\begin{array}{l}\text { Não possui mecanismo à prova de } \\
\text { falhas e possui inspeção após o } \\
\text { processo cerca poucas vezes }\end{array}$ & $\begin{array}{c}\text { Não impede a ocorrência } \\
\text { e detecta } 10 \% \text { das falhas } \\
\text { após a ocorrência, antes } \\
\text { de chegar no cliente }\end{array}$ \\
\hline 10 & $\begin{array}{l}\text { Não possui mecanismo à prova de } \\
\text { falhas e nem possui inspeção após o } \\
\text { processo }\end{array}$ & $\begin{array}{c}\text { Detecta menos de } 1 \% \text { das } \\
\text { vezes e as falhas } \\
\text { geralmente atingem os } \\
\text { clientes }\end{array}$ \\
\hline
\end{tabular}


Tabela 26: Escala de referência para pontuação da Severidade Financeira (SF)

\begin{tabular}{|c|c|c|}
\hline \multicolumn{3}{|c|}{ Pontuação de Severidade Financeira } \\
\hline Pontuação & $\begin{array}{l}\text { Descrição Qualitativa da } \\
\text { Pontuação (ponto de vista } \\
\text { interno) }\end{array}$ & \begin{tabular}{|c} 
Descrição Qualitativa da \\
Pontuação (ponto de vista do \\
cliente)
\end{tabular} \\
\hline 1 & $\begin{array}{l}\text { Má utilização ou sub-utilização de } \\
\text { recurso não restrição do fluxo com } \\
\text { aumento de custo pequeno no curto } \\
\text { prazo }\end{array}$ & $\begin{array}{c}\text { Serviço não impõe nenhuma } \\
\text { difuldade ou restrição para o } \\
\text { cliente }\end{array}$ \\
\hline 2 & $\begin{array}{c}\text { Atrasos em caminhos não críticos que } \\
\text { não impactam prazo final de entrega } \\
\text { do serviço com aumento de custo no } \\
\text { curto prazo }\end{array}$ & $\begin{array}{l}\text { Serviço impõe pequenos } \\
\text { problemas para o cliente porém } \\
\text { não afetam sua característica }\end{array}$ \\
\hline 3 & $\begin{array}{c}\text { Geração de informações duplicadas } \\
\text { que demande algum tempo e custo } \\
\text { para determinar a correta }\end{array}$ & $\begin{array}{c}\text { Dificuldade em utilizar o serviço, } \\
\text { porém fácil de consertar pelo } \\
\text { próprio cliente }\end{array}$ \\
\hline 4 & $\begin{array}{c}\text { Atrasos em caminhos não críticos que } \\
\text { não impactam prazo final de entrega } \\
\text { do serviço mas aumentam o custo no } \\
\text { médio prazo }\end{array}$ & $\begin{array}{c}\text { Dificuldade em utilizar o serviço e } \\
\text { cliente precisa de ajuda para } \\
\text { consertar }\end{array}$ \\
\hline 5 & $\begin{array}{c}\text { Geração de informações duplicadas } \\
\text { com demanda de tempo e aumento de } \\
\text { custo no médio prazo para determinar } \\
\text { informação correta }\end{array}$ & $\begin{array}{c}\text { Impossibilidade de utilização do } \\
\text { serviços na primeira vez, mas com } \\
\text { possibilidade de consertar sem } \\
\text { custo para o cliente } \\
\end{array}$ \\
\hline 6 & $\begin{array}{c}\text { Atrasos no caminho crítico que } \\
\text { impactam data final de entrega do } \\
\text { serviço mas aumentam custo apenas } \\
\text { no curto prazo }\end{array}$ & $\begin{array}{c}\text { Impossibilidade de utilização do } \\
\text { serviço na primeira vez, mas com } \\
\text { possibilidade de consertar com } \\
\text { pequeno custo do cliente }\end{array}$ \\
\hline 7 & $\begin{array}{l}\text { Má utilização ou sub-utilização do } \\
\text { recurso restrição com aumento de } \\
\text { custo no médio prazo }\end{array}$ & $\begin{array}{l}\text { Perda temporária do cliente } \\
\text { porém sem perda de marketshare } \\
\text { imediata }\end{array}$ \\
\hline 8 & $\begin{array}{c}\text { Atrasos no caminho crítico que } \\
\text { impactam data final de entrega do } \\
\text { serviço e aumento de custo no médio } \\
\text { prazo }\end{array}$ & $\begin{array}{l}\text { Impossibilidade de utilização do } \\
\text { serviço sem possibilidade de } \\
\text { conserto e perda definitiva do } \\
\text { cliente mas não de marketshare }\end{array}$ \\
\hline 9 & $\begin{array}{l}\text { Má utilização ou sub-utilização do } \\
\text { recurso restrição com aumento de } \\
\text { custo no longo prazo }\end{array}$ & $\begin{array}{l}\text { Perda temporária do cliente com } \\
\text { impacto temporário no } \\
\text { marketshare }\end{array}$ \\
\hline 10 & $\begin{array}{c}\text { Atrasos no caminho crítico que } \\
\text { impactam data final de entrega do } \\
\text { serviço e aumento de custo no longo } \\
\text { prazo }\end{array}$ & $\begin{array}{c}\text { Perda definitiva do cliente e } \\
\text { marketing negativo por parte } \\
\text { deste com perda efetiva de } \\
\text { marketshare }\end{array}$ \\
\hline
\end{tabular}




\subsubsection{Resultados e Interpretação do W-FMEA}

Como mencionado anteriormente, no início da seção 4.3, o valor obtido, depois da atribuição de pontuações para os fatores de probabilidade de ocorrência, nível de detecção e severidade financeira, será tratado de três maneiras diferentes.

A primeira maneira será calcular o resultado dos níveis de ocorrência, detecção e severidade de acordo com o RPN tradicional, ou seja, multiplicar as pontuações destes três fatores para gerar o número de prioridade de risco. O RPN é calculado conforme a equação a seguir:

$R P N=P O \times N D \times S F$ ..Equação 1

Existem algumas limitações na utilização do RPN tradicional para priorização de ações de melhoria, conforme já foi descrito na seção 3.1. A principal limitação é em relação ao peso do fator detecção, que na escala tradicional representa uma maneira reativa de intervir nos problemas. Como a escala de nível de detecção proposta neste trabalho tem forte correlação com a diminuição direta da probabilidade de ocorrência de um desperdício, o RPN pode ser um índice de prioridade de risco satisfatório.

A segunda maneira de obter os resultados da combinação dos fatores PO, ND e SF será por meio do cálculo do RAV, de acordo com a proposta de Sawhney et al. (2010) descrito na seção 3.2. Sawhney et al. (2010) propõem a utilização do FMEA para aumentar a confiabilidade de sistemas de produção enxuta, e afirmam que a proposta do RAV tem como principal motivo priorizar o fator detecção, que deve ser considerado bom (ou seja, deve ter um número baixo na escala) quando influencia diretamente a ocorrência. Para Sawhney et al. (2010), as principais ferramentas do Lean acrescentam ao sistema a capacidade de identificar e tratar as causas dos problemas. O RAV é calculado conforme a equação a seguir:

$R A V=\frac{P O \times S F}{N D}$ Equação 2

A terceira maneira para obtenção dos resultados da combinação de PO, ND e SF é a proposta deste trabalho a ser testada na aplicação principal. O índice proposto será denominado Grau de Impacto Negativo da Causa (GINC) e, ao invés de ser um valor para 
cada modo de desperdício, será calculado um valor para cada causa identificada na coluna de "Causa do Modo de Desperdício". O cálculo do GINC considerará os fatores PO, ND e SF e, também, a quantidade de modos de desperdício atrelados a cada causa, para que uma causa que resulte em mais desperdícios que outra tenha prioridade maior. Outra diferença do cálculo do GINC é a determinação da combinação dos fatores PO, ND e SF. Como a escala de Nível de Detecção foi elaborada com base nos conceitos de mecanismos à prova de falhas, que implicam diretamente na redução da ocorrência das falhas, propõe-se o cálculo dos três fatores de forma a multiplicar o valor de Severidade Financeira pela média aritmética dos valores de Probabilidade de Ocorrência e Nível de Detecção. Dessa forma, o GINC é calculado a partir do somatório das combinações dos três fatores de análise para cada MD resultante da mesma causa. A equação que define o GINC é a seguinte:

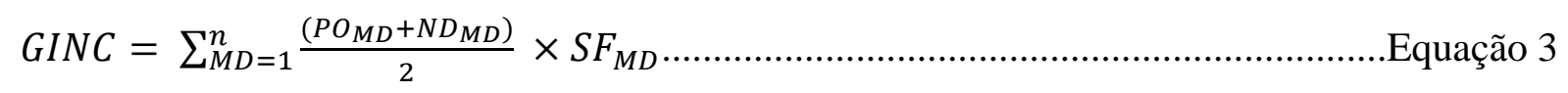

Onde "MD" é cada Modo de Desperdício resultante da causa cujo GINC está sendo calculado e " $n$ " é a quantidade de Modos de Desperdício atrelados à mesma causa.

Em resumo, as principais diferenças entre o FMEA tradicional e a proposta conceitual do W-FMEA, como já pôde ser observado no decorrer desta seção (4.3), são:

- A determinação da função do fluxo (que seria a função do produto ou processo no FMEA tradicional) deve levar em consideração a necessidade de o fluxo produzir os resultados esperados sem gerar nenhum dos tipos de desperdício;

- Os "Modos de Falha" do FMEA tradicional são incorporados aos "Modos de Desperdício" do W-FMEA e, assim, as causas potenciais da falha passam a ser as causas potenciais do desperdício, e as consequiências das falhas, as conseqüências dos desperdícios;

- A escala de "Nível de Detecção" é profundamente baseada nos conceitos de mecanismos à prova de falhas, que colaboram ativamente para a redução da ocorrência de falhas e desperdícios;

- A "Severidade Financeira" passa a ser analisada sob dois aspectos: severidade do ponto de vista do cliente (análise tradicional do FMEA) e severidade do ponto de vista da empresa (relacionada aos custos); e 
- O índice de prioridade de risco, ainda a ser validado, pode ser calculado de forma diferente. Este novo índice será denominado Grau de Impacto Negativo da Causa (GINC) e seus resultados ainda serão comparados aos da utilização do RPN e do RAV, na aplicação principal do método.

\subsection{Planejamento da Aplicação}

A aplicação principal do método foi planejada para ocorrer em outro fluxo administrativo, porque é observado que a literatura sobre melhoria de processos e redução de desperdícios em ambientes de escritório é mais carente que a literatura deste assunto para ambientes de manufatura. Além disso, observa-se, também, que os desperdícios de fluxos administrativos são mais difíceis de serem enxergados e há maior dificuldade na determinação de atividades que realmente agregam valor nestes fluxos.

A aplicação de métodos para gestão de melhorias em processos administrativos e fluxos de informação vem ganhando cada vez mais importância no cenário atual, principalmente pelo fato de que, cada vez mais, há um movimento de desindustrialização do Brasil. Em contrapartida, ainda não existem métodos tão consagrados para otimização de fluxos de informação quanto os que existem para gestão de melhorias em manufatura. Essa nova fronteira vem sendo explorada e, por isso, o objeto da aplicação deste trabalho teve como objetivo contribuir para aumentar os exemplos de aplicação de métodos de melhoria em ambientes administrativos.

O método foi aplicado para identificação, priorização e eliminação de desperdícios e suas causas em um fluxo de informação de análise de orçamentos, geração de pedidos e geração de ordens de produção. Este fluxo ocorre na interface entre os departamentos Comercial, Financeiro, Técnico e de Planejamento e Controle de Produção de uma indústria do setor madeireiro, fornecedora de produtos para o ramo da construção civil. Por motivos contratuais e para preservar as informações da empresa, os termos e nomes serão modificados para termos genéricos. A empresa será denominada Fornecedora de Produtos de Madeira para a Construção Civil, ou simplesmente Fornecedora de Madeira daqui em diante, e a família de itens a ser contemplada na análise será denominada Produtos de Madeira. Apenas para contextualização, trata-se de uma empresa de grande porte que atua no mercado interno e no mercado externo. 
A técnica de coleta de dados utilizada consiste no apontamento dos dados, por parte dos envolvidos da empresa na aplicação, em planilhas preparadas. As medidas de resultado para aplicação do método estão definidas na próxima seção, e são baseadas em lead time do fluxo e quantidade de desperdícios eliminados ou reduzidos.

Os primeiros passos para aplicação do método foram: definição da equipe de aplicação e mapeamento/modelagem dos processos para entendimento das relações entre eles. Após essas etapas completadas, foi iniciado o preenchimento do formulário proposto pelo método.

O detalhamento da aplicação, bem como os resultados e adaptações do método estão descritos no próximo capítulo deste trabalho. 


\section{W-FMEA: APLICAÇÃO E RESULTADOS}

Este é o capítulo onde será apresentada a aplicação da proposta do método, chamado Waste Mode, Failure Mode and Effect Analysis (W-FMEA) e. também, onde serão mostrados os resultados da aplicação e as adaptações feitas para elaboração da proposta final deste trabalho.

Com a proposta conceitual desenvolvida, a aplicação piloto realizada e o local e fluxo de aplicação do método escolhidos, os próximos passos seriam aa definições da equipe da aplicação do método e dos indicadores de resultados a serem usados.

Após essas definições e antes da aplicação do método em si, a equipe mapeou os processos do fluxo de informação escolhido com o intuito de entender as atividades realizadas e os produtos deste fluxo. Concomitantemente, por meio das entrevistas para mapeamento das atividades, o pesquisador iniciou o levantamento dos principais problemas e das principais oportunidades de melhoria do fluxo, com o auxílio do checklist de desperdícios de ambientes administrativos (Tabela 20 e Tabela 21).

O mapeamento do fluxo foi seguido do preenchimento do formulário do método, porém a aplicação do método começou com o levantamento de problemas feito paralelamente ao mapeamento, com o auxílio do checklist de desperdícios.

Para medição de eficácia das ações recomendadas pelo W-FMEA e do índice GINC, proposto por este trabalho, foram compilados indicadores de lead time do fluxo e de somatório dos GINCs de todas as causas identificadas.

Por fim, este capítulo apresenta as adaptações feitas na proposta conceitual do método para geração da proposta final do W-FMEA. 


\subsection{Definição da Equipe e dos Indicadores de Resultado}

O fluxo definido para aplicação do método possui interface entre os departamentos Comercial, Financeiro, Técnico e de Planejamento e Controle de Produção (PCP) da Fornecedora de Madeira e consiste na análise de orçamentos, geração de pedidos e geração de ordens de produção para a fábrica. Sendo assim, existe grande participação das áreas Comercial e de PCP neste processo.

Em reuniões com a diretoria da Fornecedora de Madeira, ficou evidente que este fluxo era importante para a empresa, por se tratar do fluxo por onde passam as informações para fechamento de negócios e geração de ordens de produção para o produto de maior valor agregado da empresa e responsável por boa parte do faturamento. Vale ressaltar, também, que havia um ambiente propício para a aplicação do método, e havia confiança de geraria resultados satisfatórios e possíveis de serem implantados.

A equipe de aplicação do método começou a ser definida, então, a partir da identificação das pessoas mais familiarizadas com os processos nos departamentos Comercial e de PCP. O principal pré-requisito para que a pessoa participasse da equipe era que esta fosse capaz de ter uma visão dos principais problemas do fluxo.

As pessoas da Fornecedora de Madeira escolhidas para compor a equipe de aplicação do método junto com o pesquisador foram o Gerente do PCP e o Vendedor mais experiente do Comercial. Essas duas pessoas da empresa seriam responsáveis por auxiliar o pesquisador no preenchimento do formulário do W-FMEA e, também, por fornecer as informações para o mapeamento das atividades das áreas a que pertenciam.

Em uma reunião de lançamento deste processo, o pesquisador apresentou para os envolvidos o método de mapeamento usado (descrito na próxima seção) e a proposta do método W-FMEA. Este método foi apresentado de acordo com a proposta adaptada depois da aplicação piloto que, por sua vez, também foi apresentada.

Antes do mapeamento, também foram definidos os indicadores de resultado que seriam usados neste processo. O indicador mais usado para medir resultado de aplicações de conceitos da produção enxuta foi escolhido, o lead time do fluxo, bem como foi definido que seria usado um indicador de comparação entre os índices de priorização antes das implantações e os índices depois das implantações.

O lead time do fluxo é calculado somando o tempo de realização de cada atividade com os tempos de espera entre as atividades do fluxo, o que é o mesmo que dizer que o lead time é a diferença entre a data e hora de término da última atividade do fluxo e a data e hora de 
começo da primeira, descontando as horas não disponíveis (descontando as horas entre $18 \mathrm{~h}$ e $8 \mathrm{~h}$, para horário comercial, por exemplo). Os tempos de espera podem ser medidos ou podem ser calculados pela divisão da quantidade de informação parada entre duas atividades pela quantidade demandada dessa informação. Por exemplo, se existem 10 orçamentos para serem aprovados entre a atividade 1 e a atividade 2 de um fluxo e a demanda é de 5 orçamentos por dia, há um estoque ou espera de 2 dias entre a atividade 1 e a atividade 2. A Figura 13 mostra como pode ser entendido o lead time para um fluxo de três atividades em um local que trabalha 8 horas por dia.

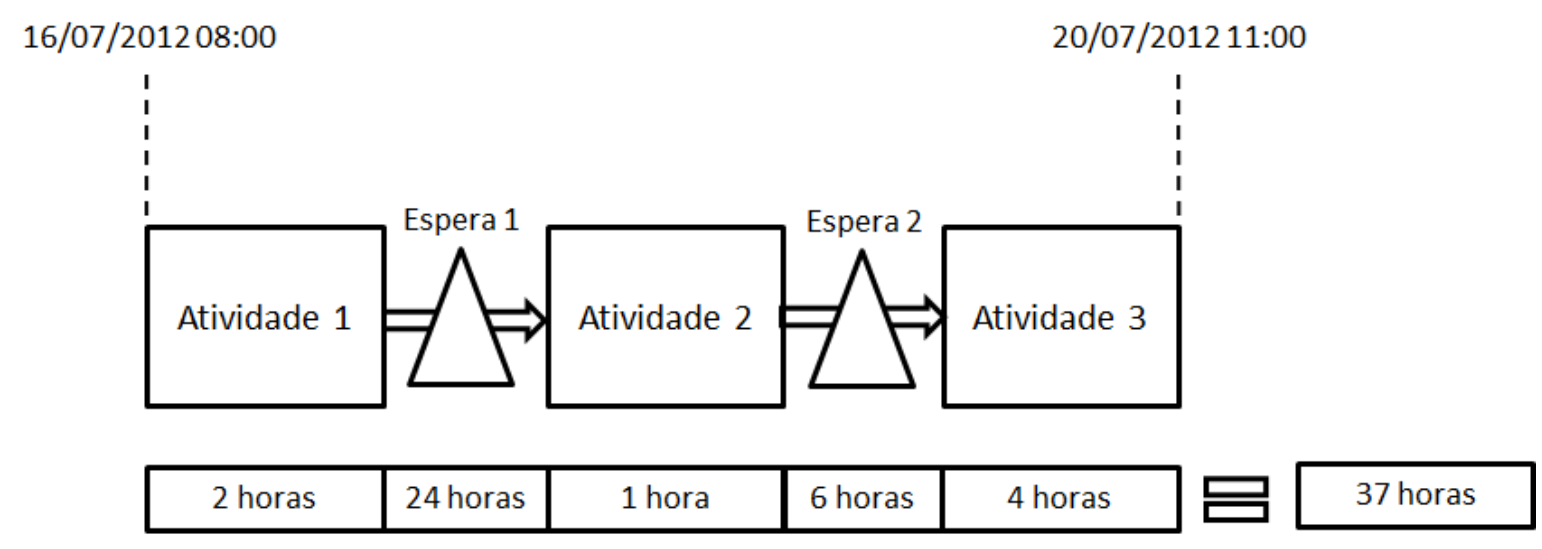

Figura 13: Exemplo de cálculo do lead time de um fluxo hipotético

Para a compilação do lead time do fluxo em análise da Fornecedora de Madeira foram levantadas e subtraídas as datas de recebimento da solicitação de orçamento e de geração da ordem de produção (primeira e última atividade do fluxo, respectivamente) de cada produto. Foi calculada uma média semanal para o lead time do fluxo para cada semana nos períodos de maio a agostos dos anos de 2010 e 2011.

O outro indicador de resultado utilizado foi a comparação do somatório do GINC antes e depois da implantação. Esse indicador, diferentemente do lead time, não compõe uma série histórica, é apenas uma comparação entre dois números, um antes e um depois.

Depois das definições da equipe de aplicação e dos indicadores de resultado iniciou-se o mapeamento do fluxo e, como mencionado, o levantamento dos principais problemas deste fluxo. Essa fase é descrita na próxima seção. 


\subsection{Mapeamento do Fluxo}

O mapeamento do fluxo foi realizado em três fases. Primeiramente, todos os envolvidos no fluxo (dos departamentos Comercial, Financeiro, Técnico e de Planejamento e Controle de Produção) foram entrevistados, depois o fluxo foi desenhado e, por fim, houve uma etapa de validação com os envolvidos e com a diretoria da Fornecedora de Madeira.

O método usado para o mapeamento do fluxo foi o proposto por Locher (2008) para mapeamento de fluxos de desenvolvimento de produtos, porque é um método de simples compreensão e pelo fato de que fluxos de desenvolvimento de produtos são essencialmente fluxos de informação que em alguns momentos são paralelos com um fluxo de produção.

As principais considerações de Locher (2008) para o mapeamento de um fluxo de informação são:

- Os processos fazem várias atividades e atividades bem diferentes ao mesmo tempo;

- Para o fluxo de informação devem ser considerados os phase gates de validação, ou batch como chamado pelo autor;

- Entre dois processos, sendo que o segundo é realizado em batch assume-se a existência de filas;

- Existem refluxos em fluxos de informação; e

- Geralmente não há padrão de trabalho e planejamento suficiente.

Locher (2008) propõe a utilização de alguns símbolos diferentes de um mapa de fluxo de valor tradicional, porém as caixas de dados dos processos não diferem no conteúdo. A Figura 14 mostra um exemplo de um mapa de fluxo de informação retirado do livro Value Stream Mapping for Lean Development: A How-To Guide for Streamlining Time to Market, de Locher (2008). 


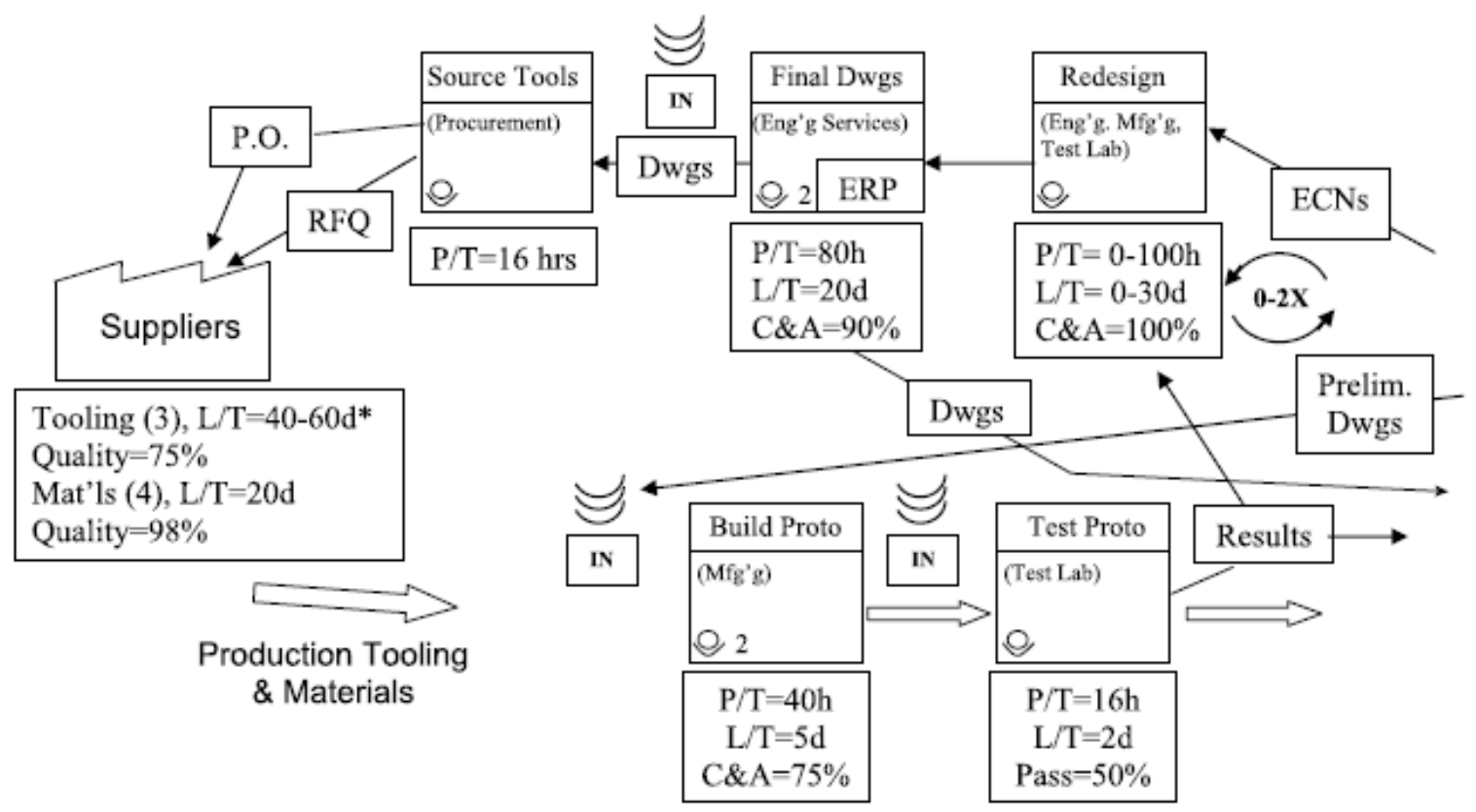

Figura 14: Exemplo de mapa de fluxo de informação (LOCHER, 2008)

A primeira fase do mapeamento - a fase de entrevistas - foi conduzida pelo pesquisador e consistiu no levantamento direto das atividades realizadas em cada departamento envolvido no fluxo, as entradas e saídas de cada atividade, bem como os tempos de processamento e de fila estimados. Em paralelo, com o auxílio do checklist de desperdícios em ambientes administrativos (Tabela 20 e Tabela 21) o pesquisador iniciou o levantamento dos problemas do fluxo. O produto dessas entrevistas é o levantamento das informações necessárias para o desenvolvimento da segunda fase do mapeamento e o desenho do fluxo, que pode ser observado no Apêndice 8.1, de forma detalhada, e na Figura 15 de forma macro. 


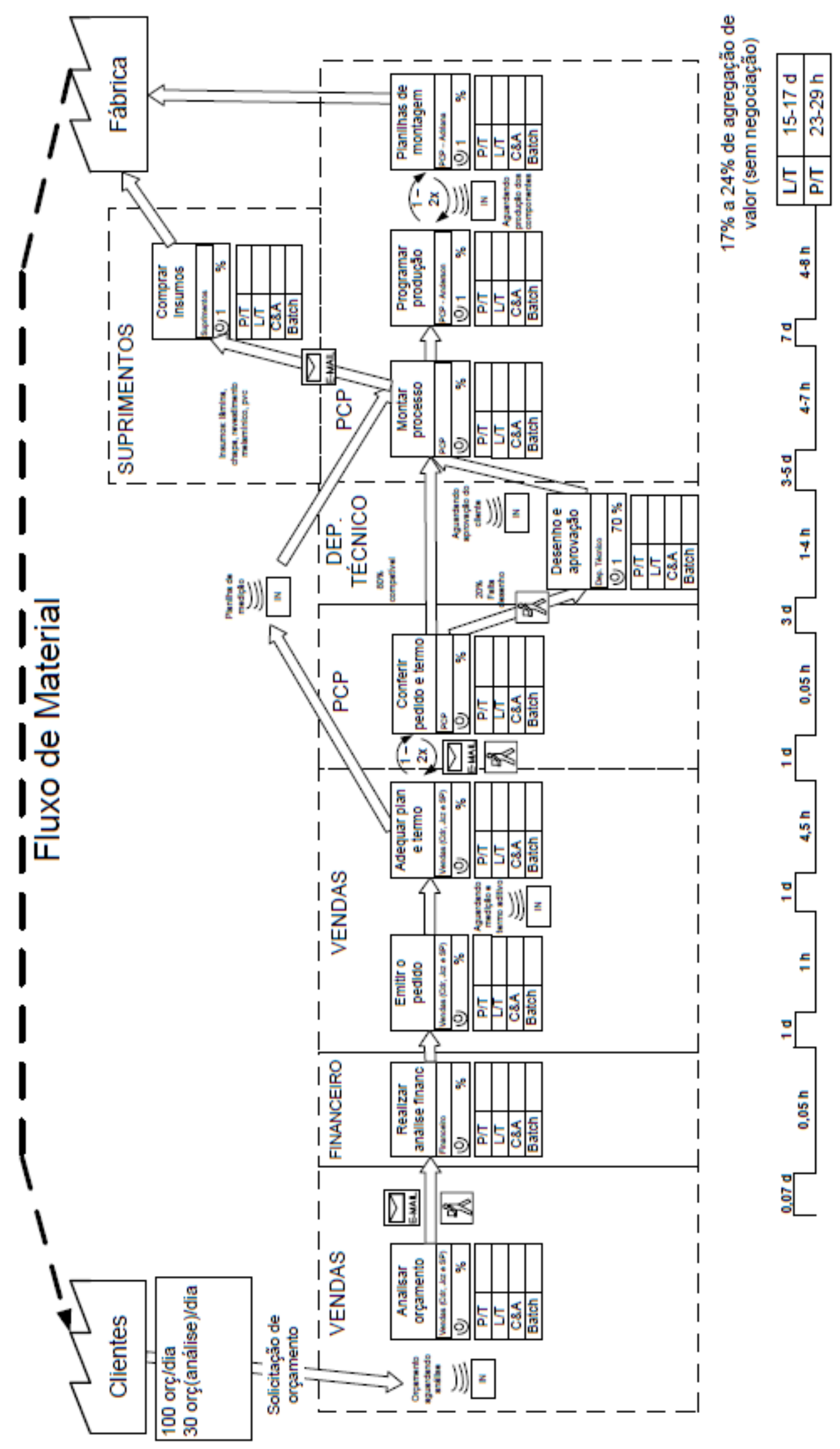

Figura 15: Mapa macro do fluxo de informação dos Produtos de Madeira 
Os principais problemas levantados durante essa fase de entrevistas foram:

- Aceite do orçamento é via email e pode demorar para ser visto;

- A documentação para análise do Financeiro é levada impressa e em mãos para o responsável;

- Os códigos e nomenclaturas dos produtos, usados pelos representantes de venda, são diferentes dos padrões de inserção no sistema, gerando retrabalho;

- Alguns representantes de venda aguardam a finalização de um pedido muito grande ao invés de quebrá-lo em lotes, como poderia ser feito;

- Todos os pedidos e termos aditivos devem ser impressos para análise do PCP;

- A planilha (planilha de medição) na qual são enviados os dados do pedido exigem muitas conferências e adequações;

- Todos os desenhos de novos produtos requerem aprovação do diretor industrial;

- Todos novos produtos, independente da quantidade de modificações em relação a um produto comum, devem ser desenhados;

- Existe um estoque de desenhos para serem feitos;

- Os desenhos devem ser submetidos à aprovação do cliente pelo departamento Comercial, que recebe o desenho do PCP que, por sua vez, recebe o desenho feito pelo departamento Técnico;

- O cliente pode demorar a aprovar o desenho;

- Existe estoque de pedidos para serem inseridos no cronograma de produção;

- O sistema de geração de ordens de produção necessita de muitas intervenções manuais por não ter algumas funcionalidades básicas automatizadas; e

- Eventualmente, faltam páginas nas ordens de produção enviadas à fábrica.

Depois de realizadas as fases de entrevista e desenho do fluxo, foi marcada uma reunião com os envolvidos e com a diretoria da Fornecedora de Madeira para validação do fluxo desenhado.

A partir disso, teve início a fase de aplicação do W-FMEA propriamente dita. Essa fase é descrita a seguir. 


\subsection{Aplicação do Método W-FMEA}

O preenchimento do formulário do W-FMEA foi feito em duas reuniões de trabalho entre o pesquisador (autor deste trabalho), o gerente do PCP e o vendedor do Comercial, os três elementos chave da aplicação do método. Para estas reuniões foram distribuídos o checklist de desperdícios de escritório (Tabela 20 e Tabela 21) e as escalas de pontuação de severidade (Tabela 26), probabilidade de ocorrência (Tabela 24) e nível de detecção (Tabela 25).

Com os problemas levantados nas entrevistas de mapeamento o pesquisador conduziu a primeira reunião que foi baseada na análise do checklist de desperdícios e atribuição das causas de cada modo de desperdício identificado no fluxo.

Os integrantes da equipe já estavam familiarizados com o W-FMEA, uma vez que o método já tinha sido apresentado para eles. Assim, o início do preenchimento do formulário do W-FMEA aconteceu, então, durante a primeira reunião sendo que cada coluna do formulário era preenchida completamente antes de se iniciar o preenchimento da próxima. Primeiramente foi preenchida a coluna "Função do Fluxo" e depois a coluna "Modo de Desperdício", seguindo a ordem do checklist de desperdícios.

Para preenchimento da coluna "Causa do Modo de Desperdício", na Tabela 27 e na Tabela 28, foi utilizada a técnica de 5 Por-quês, que consiste em perguntar "por quê" até que seja identificada a causa de determinado problema. À medida que essa coluna ia sendo preenchida, ficava mais claro que existia um agrupamento dos modos de desperdício em função das causas, ou seja, poucas causas geravam diversos modos de desperdício.

Essa constatação sustentou ainda mais a utilização do índice GINC de priorização, proposto por este trabalho.

$\mathrm{Na}$ segunda reunião realizada, as pontuações de PO, ND e SF foram preenchidas conforme as escalas distribuídas, assim como a coluna "Consequência/Efeito", decorrência da escala de severidade. De acordo com a recomendação de Palady (1997), sobre análise de extremos e cisão (Tabela 2), alguns modos de desperdício eram discutidos com mais profundidade pelo fato de que, por vezes, alguma pontuação de algum integrante da equipe diferia muito das demais opiniões. Em todos os casos de cisão, a pessoa que causava a discussão expunha argumentos suficientes para alterar a pontuação dos demais.

Algumas ações recomendadas também foram sendo levantadas durante o preenchimento do formulário e indicadas na tabela do W-FMEA, ao passo que as discussões sobre as consequências de cada modo de desperdício surgiam e as causas eram observadas. Essa antecipação do preenchimento de uma coluna não é recomendado por Palady (1997), porém 
como as discussões surgiam naturalmente, os resultados delas já eram documentados no próprio formulário do método.

Após a atribuição de notas, que depois das análises das cisões foram consensuais, o passo seguinte foi analisar como calcular o índice de risco. Como mencionado anteriormente, a análise das relações entre causas e desperdícios revelou que uma mesma causa poderia gerar diversos modos de desperdício, portanto o primeiro índice de priorização calculado e analisado foi o GINC. Para o cálculo do GINC, deveriam ser calculados os GINDs de cada modo de desperdício, para assim calcular os GINCs de cada causa relacionada a alguns modos de desperdício, conforme as equações 4 e 5.

$G I N C=\sum_{M D=1}^{n} G I N D_{M D}$ Equação 4

$G I N D=\frac{N D+P O}{2} \times S F$ Equação 5

A Tabela 27 e a Tabela 28 apresentam os resultados da aplicação do W-FMEA, para o fluxo de processo da família de produtos definida, incluindo o cálculo do índice GIND para os diferentes modos de desperdício. Algumas ações recomendadas já são mostradas também. A compilação do GINC, com o agrupamento dos modos de desperdício de mesmas causas, é apresentada na Tabela 29, já classificada das causas mais relevantes de modos de desperdício para as menos relevantes, segundo o índice GINC.

Observou-se que todo o processo de análise dos desperdícios, pontuação dos índices de Probabilidade de Ocorrência, Nível de Detecção e Severidade Financeira, cálculo dos índices de priorização (GIND e GINC) e levantamento de ações recomendadas foi eficiente e auxiliado pelo checklist de desperdícios. Ao todo, essas atividades consumiram dois dias inteiros de trabalho dos três envolvidos, ou seja, 48 horas de trabalho. 
Tabela 27: Formulário do W-FMEA preenchido (parte 1)

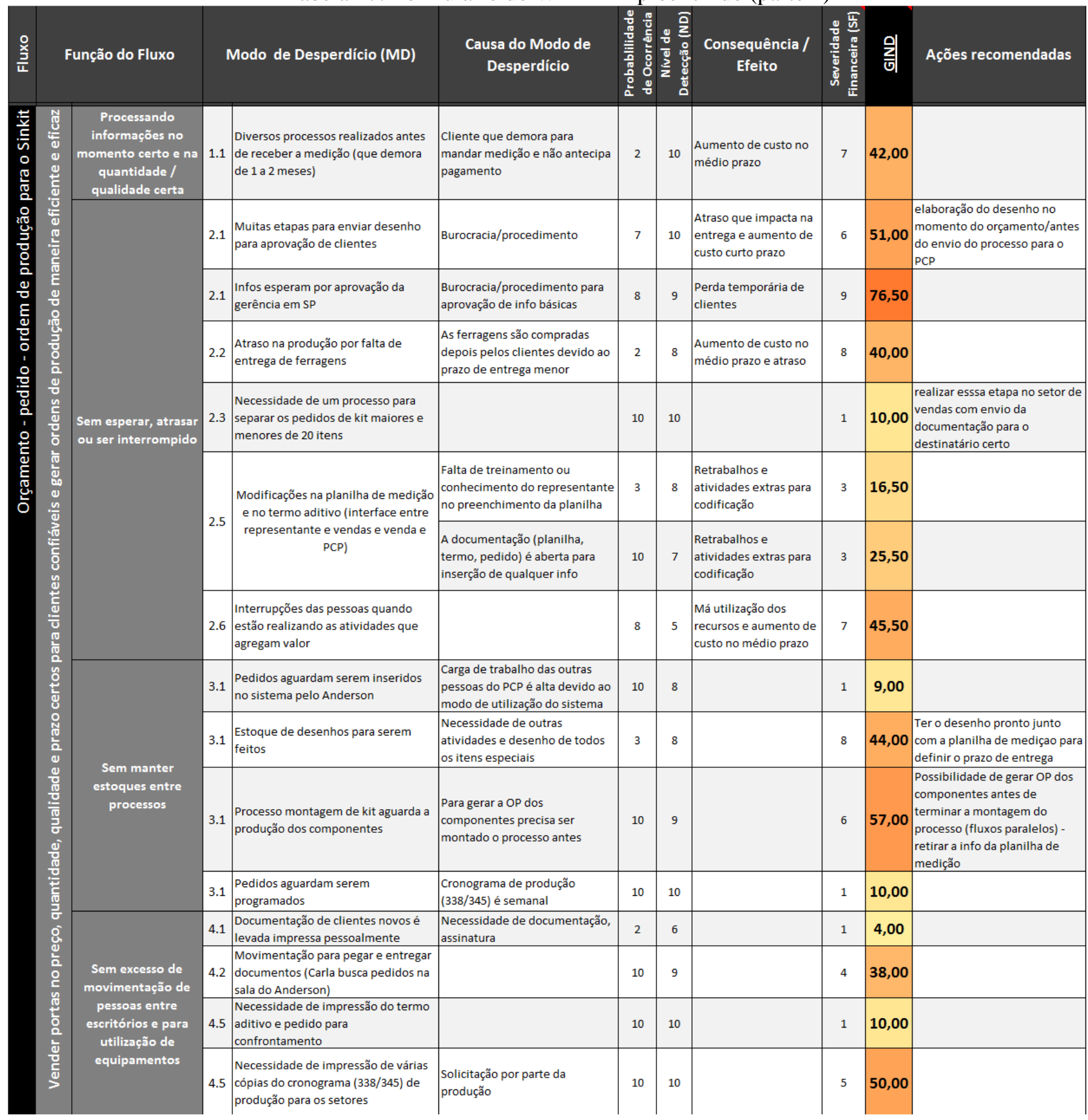


Tabela 28: Formulário do W-FMEA preenchido (parte 1)

\begin{tabular}{|c|c|c|c|c|c|c|c|c|c|}
\hline Função do Fluxo & & Modo de Desperdício (MD) & $\begin{array}{l}\text { Causa do Modo de } \\
\text { Desperdício }\end{array}$ &  & 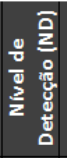 & $\begin{array}{c}\text { Consequência / } \\
\text { Efeito }\end{array}$ & 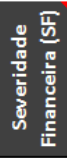 & 윈 & Ações recomendadas \\
\hline \multirow{4}{*}{$\begin{array}{l}\text { Sem precisar } \\
\text { transportar } \\
\text { informações }\end{array}$} & 5.1 & $\begin{array}{l}\text { Vendas Cdr transporta pedido } \\
\text { impresso para o PCP }\end{array}$ & Burocracia/procedimento & 6 & 10 & & 1 & 8,00 & \\
\hline & 5.2 & $\begin{array}{l}\text { Várias infos transportadas por email } \\
\text { internamente }\end{array}$ & $\begin{array}{l}\text { Informação percorre setores } \\
\text { diferentes em locais diferente }\end{array}$ & 8 & 8 & & 1 & 8,00 & $\begin{array}{l}\text { Utilizar MSN para transmissão } \\
\text { de info }\end{array}$ \\
\hline & 5.3 & $\begin{array}{l}\text { Impressão e transporte de um } \\
\text { checklist de embraque }\end{array}$ & Controle de embarque de carga & 10 & 9 & & 1 & 9,50 & $\begin{array}{l}\text { Implantar sistema de código de } \\
\text { barras }\end{array}$ \\
\hline & 5.4 & \begin{tabular}{|l|}
$\begin{array}{l}\text { Necessidade de diretor e } \\
\text { coordenador assinar para aprovar } \\
\text { requisição e o desenho em si }\end{array}$ \\
\end{tabular} & Burocracia/procedimento & 5 & 9 & & 6 & 42,00 & \\
\hline \multirow{5}{*}{$\begin{array}{l}\text { Por meio de } \\
\text { processos } \\
\text { adequados e } \\
\text { padronizados }\end{array}$} & 6.1 & $\begin{array}{l}\text { Não existe a funcionalidade de } \\
\text { quebra de pág para itens que vão ou } \\
\text { para Sinkit ou para Montados }\end{array}$ & \multirow{3}{*}{$\begin{array}{l}\text { O sistema não possui essas } \\
\text { funcionalidades }\end{array}$} & 8 & 10 & & 9 & 81,00 & \\
\hline & 6.1 & $\begin{array}{l}\text { Sistema não processa } \\
\text { automaticamente as info de portas } \\
\text { de correr e pivotantes }\end{array}$ & & 8 & 10 & & 9 & $81,00 \mid$ & \\
\hline & 6.1 & $\begin{array}{l}\text { Aceite do orçamento não é via } \\
\text { sistema (é via email ou telefone) }\end{array}$ & & 8 & 10 & & 9 & 81,00 & \\
\hline & 6.3 & $\begin{array}{l}\text { Cópia extra do processo de kit para } \\
\text { supervisão fáb } 2\end{array}$ & $\begin{array}{l}\text { Solicitação por parte da } \\
\text { produção }\end{array}$ & 10 & 9 & & 5 & 47,50 & \\
\hline & 6.5 & $\begin{array}{l}\text { Aceite de portas que não podem ser } \\
\text { produzidas }\end{array}$ & $\begin{array}{l}\text { A documentação (planilha, } \\
\text { termo, pedido) é aberta para } \\
\text { inserção de qualquer info }\end{array}$ & 3 & 6 & & 7 & 31,50 & \\
\hline \multirow{5}{*}{$\begin{array}{c}\text { Sem produzir erros e } \\
\text { defeitos }\end{array}$} & 7.1 & $\begin{array}{l}\text { Erro na inserção do afastamento da } \\
\text { guarnição }\end{array}$ & $\begin{array}{l}\text { Não existe um alerta/bloqueio } \\
\text { para pedido faltando info }\end{array}$ & 2 & 8 & & 5 & 25,00 & $\begin{array}{l}\text { Criar um padrão para a relação } \\
\text { entre afastamento da } \\
\text { guarnição e sinclick }\end{array}$ \\
\hline & 7.2 & $\begin{array}{l}\text { Falta de informação de sentido da } \\
\text { abertura e altura da furação }\end{array}$ & $\begin{array}{l}\text { Falta de atenção quanto a } \\
\text { questão de altura de furação }\end{array}$ & 3 & 8 & $\begin{array}{l}\text { Dificuldade em utilizar } \\
\text { o serviço }\end{array}$ & 4 & 22,00 & \\
\hline & 7.2 & Falta de informação de ferragem & $\begin{array}{l}\text { Indefinição do cliente de qual } \\
\text { ferragem usar (as ferragens são } \\
\text { compradas depois devido a } \\
\text { prazo de entrega menor) }\end{array}$ & 6 & 7 & & 8 & 52,00 & \\
\hline & 7.3 & $\begin{array}{l}\text { Pode faltar documento impresso no } \\
\text { processo de kit }\end{array}$ & & 1 & 8 & & 8 & 36,00 & \\
\hline & 7.6 & $\begin{array}{l}\text { Determinação incorreta de preços de } \\
\text { portas especiais }\end{array}$ & $\begin{array}{l}\text { Falta um sistema e um padrão } \\
\text { de custeio }\end{array}$ & 5 & 7 & & 9 & 54,00 & $\begin{array}{l}\text { Ter e utilizar uma sistema, uma } \\
\text { tabela de preços padrão }\end{array}$ \\
\hline \multirow{5}{*}{$\left|\begin{array}{c}\text { Sem necessidade de } \\
\text { revisões, traduções e } \\
\text { retrabalhos }\end{array}\right|$} & 8.1 & $\begin{array}{l}\text { Falta de informação no pedido e no } \\
\text { termo aditivo }\end{array}$ & $\begin{array}{l}\text { Não existe um alerta/bloqueio } \\
\text { para pedido faltando info }\end{array}$ & 2 & 7 & & 3 & 13,50 & \\
\hline & 8.3 & $\begin{array}{l}\text { Representante/cliente solicita } \\
\text { modificação nas dimensões da } \\
\text { planilha de medição }\end{array}$ & $\begin{array}{l}\text { - Solicitação do cliente } \\
\text { - Troca/confusão de informação } \\
\text { inserida na planilha }\end{array}$ & 7 & 10 & & 8 & 68,00 & \\
\hline & 8.3 & $\begin{array}{l}\text { Representante/cliente solicita } \\
\text { modificação nas dimensões da } \\
\text { planilha de medição }\end{array}$ & $\begin{array}{l}\text { - Inserção incorreta com valor } \\
\text { não existente na planilha de } \\
\text { medição }\end{array}$ & 5 & 10 & & 8 & 60,00 & \\
\hline & 8.4 & Conferência da planilha de medição & $\begin{array}{l}\text { A documentação (planilha, } \\
\text { termo, pedido) é aberta para } \\
\text { inserção de qualquer info }\end{array}$ & 10 & 10 & & 5 & 50,00 & \\
\hline & 8.5 & $\begin{array}{l}\text { Envio de info de planilha ou print } \\
\text { screen por email (ferragens) }\end{array}$ & & 10 & 8 & & 1 & 9,00 & \\
\hline \multirow{4}{*}{$\begin{array}{c}\text { Utilizando o talento } \\
\text { e os recursos de mão- } \\
\text { de-obra de maneira } \\
\text { eficiente }\end{array}$} & 9.1 & $\begin{array}{l}\text { Excesso de etapas para envio de } \\
\text { desenho para aprovação de cliente }\end{array}$ & Burocracia/procedimento & 7 & 7 & & 6 & 42,00 & \\
\hline & 9.1 & $\begin{array}{l}\text { Diretor comercial deve assinar todos } \\
\text { os pedidos }\end{array}$ & $\begin{array}{l}\text { Burocracia para liberação de } \\
\text { pedido }\end{array}$ & 10 & 8 & & 2 & 18,00 & \\
\hline & 9.7 & $\begin{array}{l}\text { Falta de envolvimento do cliente } \\
\text { para aprovação de desenho }\end{array}$ & & 3 & 6 & & 8 & 36,00 & \\
\hline & 9.7 & $\begin{array}{l}\text { Falta comprometimento com } \\
\text { questões prioritárias de } \\
\text { fornecimento de info }\end{array}$ & & 4 & 9 & & 8 & 52,00 & \\
\hline $\begin{array}{l}\text { Em um fluxo } \\
\text { harmonioso de } \\
\text { processos }\end{array}$ & 10.1 & $\begin{array}{l}\text { Existe capacidade instalada maior } \\
\text { para poder trabalhar com o sistema } \\
\text { existente }\end{array}$ & $\begin{array}{l}\text { O sistema não possui } \\
\text { funcionalidades para deixar o } \\
\text { fluxo mais automatizado }\end{array}$ & 8 & 10 & & 9 & $81,00 \mid$ & \\
\hline
\end{tabular}


Tabela 29: Resultado compilado da aplicação do W-FMEA com a utilização do GINC

\begin{tabular}{|c|c|c|c|c|}
\hline Causa do Modo de Desperdício & $\frac{U}{\mathrm{z}}$ & Ações recomendadas & $\begin{array}{l}\% \text { Acumulada } \\
\text { da causa }\end{array}$ & $\begin{array}{c}\text { Classificação } \\
\text { da causa }\end{array}$ \\
\hline $\begin{array}{l}\text { O sistema não possui funcionalidades para deixar o } \\
\text { fluxo mais automatizado }\end{array}$ & 369,0 & $\begin{array}{l}\text { adequar sistema para importação dos dados do sistema de } \\
\text { medição }\end{array}$ & $25,4 \%$ & A \\
\hline $\begin{array}{l}\text { Burocracia exagerada nos procedimentos ou falta de } \\
\text { padrão nos procedimentos }\end{array}$ & 263,5 & $\begin{array}{l}\text { elaboração do desenho no momento do orçamento/antes do } \\
\text { envio do processo para o PCP, realizar etapa de separar os } \\
\text { dois produtos no setor de vendas com envio da } \\
\text { documentação para o destinatário certo, criar regras para } \\
\text { quando é necessário supervisor assinar pedidos ou definir } \\
\text { prazo de entrega (em SP também), possibilitar o envio de } \\
\text { desenho para o cliente diretamente pelo Dep. Técnico, } \\
\text { incorporar termo aditivo no sistema de medição }\end{array}$ & $43,5 \%$ & A \\
\hline $\begin{array}{l}\text { A documentação (planilha, termo, pedido) é aberta } \\
\text { para inserção de qualquer info }\end{array}$ & 227,5 & $\begin{array}{l}\text { Criar um padrão para a relação entre afastamento dos } \\
\text { componentes do produto, criar bloqueios no sistema para } \\
\text { evitar inserção de dados errados, criar funcionalidade no } \\
\text { sistema para relacionar apenas características possiveis de } \\
\text { serem relacionadas (configurador) }\end{array}$ & $59,2 \%$ & A \\
\hline $\begin{array}{c}\text { Cópias extras das ordens de produção e do cronograma } \\
\text { de produção: Solicitação por parte da produção }\end{array}$ & 97,5 & & $65,9 \%$ & A \\
\hline $\begin{array}{l}\text { Alguns componentes são compradas depois pelos } \\
\text { clientes devido ao prazo de entrega menor }\end{array}$ & 92,0 & & $72,2 \%$ & A \\
\hline $\begin{array}{l}\text { Mudança na medição: Solicitação do cliente, } \\
\text { Troca/confusão de informação inserida na planilha }\end{array}$ & 68,0 & & $76,9 \%$ & B \\
\hline $\begin{array}{c}\text { Para gerar a OP dos componentes precisa ser montado } \\
\text { o processo antes }\end{array}$ & 57,0 & $\begin{array}{c}\text { Possibilidade de gerar OP dos componentes antes de } \\
\text { terminar a montagem do processo (fluxos paralelos) - retirar } \\
\text { a info da planilha de medição }\end{array}$ & $80,8 \%$ & B \\
\hline Falta um sistema e um padrão de custeio & 54,0 & Ter e utilizar uma sistema, uma tabela de preços padrão & $84,5 \%$ & B \\
\hline \begin{tabular}{|c|} 
Interrupções das pessoas quando estão realizando as \\
atividades que agregam valor \\
\end{tabular} & 45,5 & & $87,7 \%$ & B \\
\hline $\begin{array}{l}\text { Necessidade de outras atividades a serem feitas e } \\
\text { desenho de todos os itens especiais }\end{array}$ & 44,0 & $\begin{array}{c}\text { Ter o desenho pronto junto com a planilha de mediçao para } \\
\text { definir o prazo de entrega }\end{array}$ & $90,7 \%$ & C \\
\hline $\begin{array}{l}\text { Cliente que demora para mandar medição e não } \\
\text { antecipa pagamento }\end{array}$ & 42,0 & & $93,6 \%$ & C \\
\hline $\begin{array}{l}\begin{array}{l}\text { Falta de envolvimento do cliente para aprovação de } \\
\text { desenho }\end{array} \\
\end{array}$ & 36,0 & & $96,1 \%$ & C \\
\hline $\begin{array}{l}\text { Falta de treinamento ou conhecimento do } \\
\text { representante no preenchimento da planilha }\end{array}$ & 16,5 & & $97,2 \%$ & C \\
\hline Cronograma de produção (338/345) é semanal & 10,0 & & $97,9 \%$ & $\mathrm{C}$ \\
\hline Controle de embarque de carga & 9,5 & Implantar sistema de código de barras & $98,6 \%$ & C \\
\hline $\begin{array}{l}\text { Envio de info de planilha ou print screen por email } \\
\text { (ferragens) }\end{array}$ & 9,0 & & $99,2 \%$ & C \\
\hline $\begin{array}{c}\text { Informação percorre setores diferentes em locais } \\
\text { diferentes }\end{array}$ & 8,0 & Utilizar MSN para transmissão de info & $99,7 \%$ & C \\
\hline $\begin{array}{l}\text { Necessidade de documentação, assinatura para } \\
\text { processos de análise financeira de clientes novos }\end{array}$ & 4,0 & & $100,0 \%$ & C \\
\hline
\end{tabular}

O resultado da aplicação do W-FMEA mostrou que apenas três causas, dentre todas as levantadas, eram responsáveis por boa parte dos desperdícios e dos problemas do fluxo analisado. Ainda, a causa com maior índice GINC (o sistema não possui funcionalidades para deixar o fluxo mais automatizado) é fortemente relacionada com a terceira causa mais prioritária (a documentação é aberta para inserção de qualquer informação), uma vez que dados gerados incorretamente na documentação (etapa do começo do fluxo) carregam erros 
para o sistema de geração de ordens de produção que, por não ser automatizado e receber muitos erros, é responsável por boa parte do elevado lead time do fluxo.

Os modos de desperdício foram analisados também de acordo com os índices de priorização RPN e RAV, com o objetivo de identificar se os resultados desses três índices seriam parecidos e se as ações recomendadas geradas a partir da priorização seriam as mesmas. Os resultados, por modo de desperdício, dos índices RPN e RAV são observados na Tabela 30 e na Tabela 31.

Tabela 30: W-FMEA com índices de priorização RPN e RAV (parte 1)

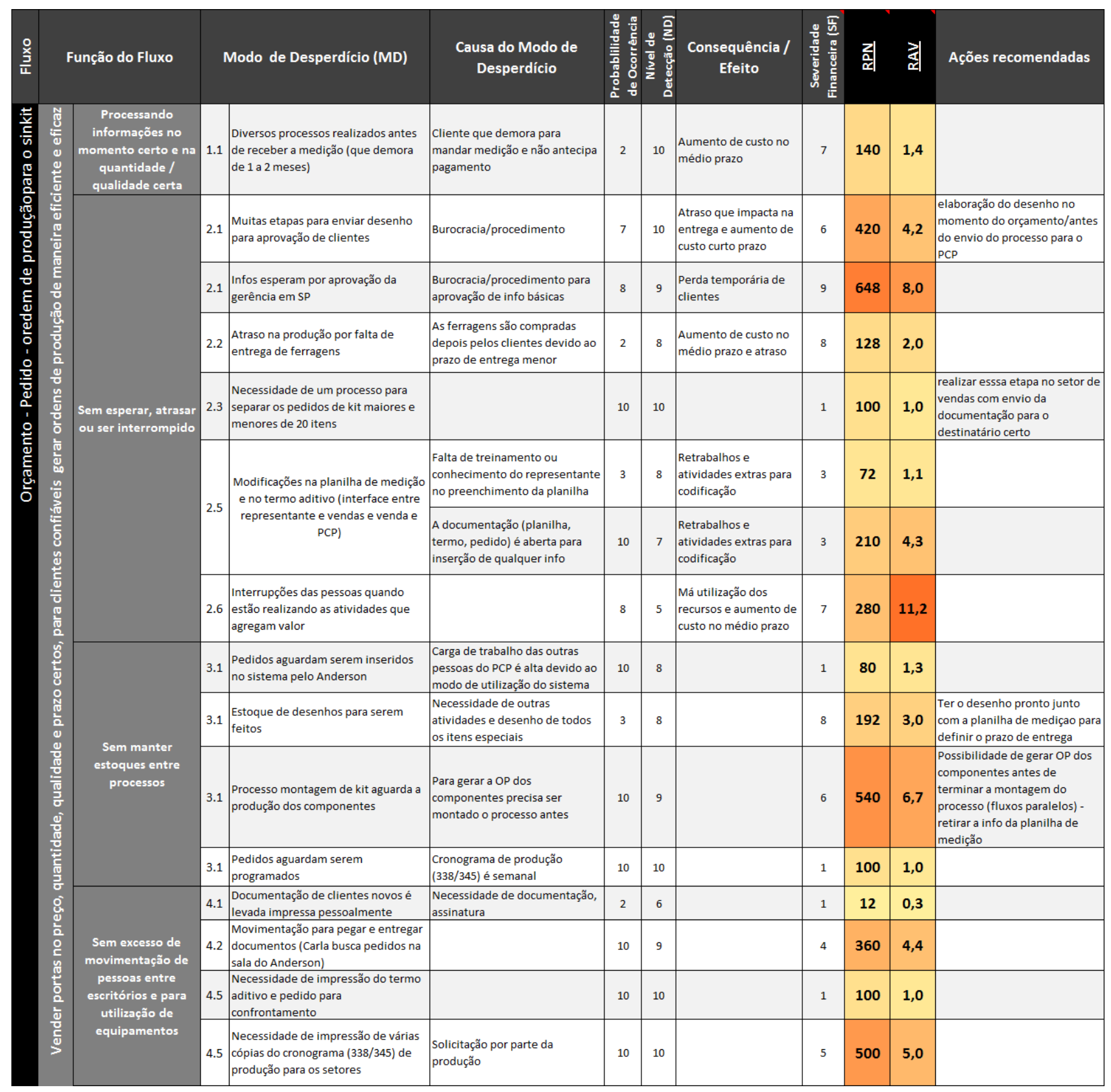


Tabela 31: W-FMEA com índices de priorização RPN e RAV (parte 2)

\begin{tabular}{|c|c|c|c|c|c|c|c|c|c|c|}
\hline Função do Fluxo & & Modo de Desperdício (MD) & $\begin{array}{l}\text { Causa do Modo de } \\
\text { Desperdício }\end{array}$ & 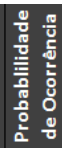 & 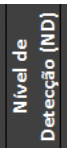 & $\begin{array}{c}\text { Consequência / } \\
\text { Efeito }\end{array}$ &  & 깅 & 쳥| & Ações recomendadas \\
\hline \multirow{4}{*}{$\begin{array}{l}\text { Sem precisar } \\
\text { transportar } \\
\text { informações }\end{array}$} & 5.1 & $\begin{array}{l}\text { Vendas Cdr transporta pedido } \\
\text { impresso para o PCP }\end{array}$ & Burocracia/procedimento & 6 & 10 & & 1 & 60 & 0,6 & \\
\hline & 5.2 & $\begin{array}{l}\text { Várias infos transportadas por email } \\
\text { internamente }\end{array}$ & $\begin{array}{l}\text { Informação percorre setores } \\
\text { diferentes em locais diferente }\end{array}$ & 8 & 8 & & 1 & 64 & 1,0 & $\begin{array}{l}\text { Utilizar MSN para transmissão } \\
\text { de info }\end{array}$ \\
\hline & 5.3 & $\begin{array}{l}\text { Impressão e transporte de um } \\
\text { checklist de embraque }\end{array}$ & Controle de embarque de carga & 10 & 9 & & 1 & 90 & 1,1 & $\begin{array}{l}\text { Implantar sistema de código de } \\
\text { barras }\end{array}$ \\
\hline & 5.4 & $\begin{array}{l}\text { Necessidade de diretor e } \\
\text { coordenador assinar para aprovar } \\
\text { requisição e o desenho em si }\end{array}$ & Burocracia/procedimento & 5 & 9 & & 6 & 270 & 3,3 & \\
\hline \multirow{5}{*}{$\begin{array}{l}\text { Por meio de } \\
\text { processos } \\
\text { adequados e } \\
\text { padronizados }\end{array}$} & 6.1 & $\begin{array}{l}\text { Não existe a funcionalidade de } \\
\text { quebra de pág para itens que vão ou } \\
\text { para Sinkit ou para Montados }\end{array}$ & \multirow{3}{*}{$\begin{array}{l}\text { O sistema não possui essas } \\
\text { funcionalidades }\end{array}$} & 8 & 10 & & 9 & 720 & 7,2 & \\
\hline & 6.1 & $\begin{array}{l}\text { Sistema não processa } \\
\text { automaticamente as info de portas } \\
\text { de correr e pivotantes }\end{array}$ & & 8 & 10 & & 9 & 720 & 7,2 & \\
\hline & 6.1 & $\begin{array}{l}\text { Aceite do orçamento não é via } \\
\text { sistema (é via email ou telefone) }\end{array}$ & & 8 & 10 & & 9 & 720 & 7,2 & \\
\hline & 6.3 & $\begin{array}{l}\text { Cópia extra do processo de kit para } \\
\text { supervisão fáb } 2\end{array}$ & $\begin{array}{l}\text { Solicitação por parte da } \\
\text { produção }\end{array}$ & 10 & 9 & & 5 & 450 & 5,6 & \\
\hline & 6.5 & $\begin{array}{l}\text { Aceite de portas que não podem ser } \\
\text { produzidas }\end{array}$ & $\begin{array}{l}\text { A documentação (planilha, } \\
\text { termo, pedido) é aberta para } \\
\text { inserção de qualquer info }\end{array}$ & 3 & 6 & & 7 & 126 & 3,5 & \\
\hline \multirow{5}{*}{$\begin{array}{c}\text { Sem produzir erros e } \\
\text { defeitos }\end{array}$} & 7.1 & $\begin{array}{l}\text { Erro na inserção do afastamento da } \\
\text { guarnição }\end{array}$ & $\begin{array}{l}\text { Não existe um alerta/bloqueio } \\
\text { para pedido faltando info }\end{array}$ & 2 & 8 & & 5 & 80 & 1,3 & $\begin{array}{l}\text { Criar um padrão para a relação } \\
\text { entre afastamento da } \\
\text { guarnição e sinclick }\end{array}$ \\
\hline & 7.2 & $\begin{array}{l}\text { Falta de informação de sentido da } \\
\text { abertura e altura da furação }\end{array}$ & $\begin{array}{l}\text { Falta de atenção quanto a } \\
\text { questão de altura de furação }\end{array}$ & 3 & 8 & $\begin{array}{l}\text { Dificuldade em utilizar } \\
\text { o serviço }\end{array}$ & 4 & 96 & 1,5 & \\
\hline & 7.2 & Falta de informação de ferragem & $\begin{array}{l}\text { Indefinição do cliente de qual } \\
\text { ferragem usar (as ferragens são } \\
\text { compradas depois devido a } \\
\text { prazo de entrega menor) }\end{array}$ & 6 & 7 & & 8 & 336 & 6,9 & \\
\hline & 7.3 & $\begin{array}{l}\text { Pode faltar documento impresso no } \\
\text { processo de kit }\end{array}$ & & 1 & 8 & & 8 & 64 & 1,0 & \\
\hline & 7.6 & $\begin{array}{l}\text { Determinação incorreta de preços de } \\
\text { portas especiais }\end{array}$ & $\begin{array}{l}\text { Falta um sistema e um padrão } \\
\text { de custeio }\end{array}$ & 5 & 7 & & 9 & 315 & 6,4 & $\begin{array}{l}\text { Ter e utilizar uma sistema, uma } \\
\text { tabela de preços padrão }\end{array}$ \\
\hline \multirow{5}{*}{$\left|\begin{array}{c}\text { Sem necessidade de } \\
\text { revisões, traduções e } \\
\text { retrabalhos }\end{array}\right|$} & 8.1 & $\begin{array}{l}\text { Falta de informação no pedido e no } \\
\text { termo aditivo }\end{array}$ & $\begin{array}{l}\text { Não existe um alerta/bloqueio } \\
\text { para pedido faltando info }\end{array}$ & 2 & 7 & & 3 & 42 & 0,9 & \\
\hline & 8.3 & $\begin{array}{l}\text { Representante/cliente solicita } \\
\text { modificação nas dimensões da } \\
\text { planilha de medição }\end{array}$ & $\begin{array}{l}\text { - Solicitação do cliente } \\
\text { - Troca/confusão de informação } \\
\text { inserida na planilha }\end{array}$ & 7 & 10 & & 8 & 560 & 5,6 & \\
\hline & 8.3 & $\begin{array}{l}\text { Representante/cliente solicita } \\
\text { modificação nas dimensões da } \\
\text { planilha de medição }\end{array}$ & $\begin{array}{l}\text { - Inserção incorreta com valor } \\
\text { não existente na planilha de } \\
\text { medição }\end{array}$ & 5 & 10 & & 8 & 400 & 4,0 & \\
\hline & 8.4 & Conferência da planilha de medição & $\begin{array}{l}\text { A documentação (planilha, } \\
\text { termo, pedido) é aberta para } \\
\text { inserção de qualquer info }\end{array}$ & 10 & 10 & & 5 & 500 & 5,0 & \\
\hline & 8.5 & $\begin{array}{l}\text { Envio de info de planilha ou print } \\
\text { screen por email (ferragens) }\end{array}$ & & 10 & 8 & & 1 & 80 & 1,3 & \\
\hline \multirow{4}{*}{$\begin{array}{c}\text { Utilizando o talento } \\
\text { e os recursos de mão- } \\
\text { de-obra de maneira } \\
\text { eficiente }\end{array}$} & 9.1 & $\begin{array}{l}\text { Excesso de etapas para envio de } \\
\text { desenho para aprovação de cliente }\end{array}$ & Burocracia/procedimento & 7 & 7 & & 6 & 294 & 6,0 & \\
\hline & 9.1 & $\begin{array}{l}\text { Diretor comercial deve assinar todos } \\
\text { os pedidos }\end{array}$ & $\begin{array}{l}\text { Burocracia para liberação de } \\
\text { pedido }\end{array}$ & 10 & 8 & & 2 & 160 & 2,5 & \\
\hline & 9.7 & $\begin{array}{l}\text { Falta de envolvimento do cliente } \\
\text { para aprovação de desenho }\end{array}$ & & 3 & 6 & & 8 & 144 & 4,0 & \\
\hline & 9.7 & $\begin{array}{l}\text { Falta comprometimento com } \\
\text { questốes prioritárias de } \\
\text { fornecimento de info }\end{array}$ & & 4 & 9 & & 8 & 288 & 3,6 & \\
\hline $\begin{array}{l}\text { Em um fluxo } \\
\text { harmonioso de } \\
\text { processos }\end{array}$ & 10.1 & $\begin{array}{l}\text { Existe capacidade instalada maior } \\
\text { para poder trabalhar com o sistema } \\
\text { existente }\end{array}$ & $\begin{array}{l}\text { O sistema não possui } \\
\text { funcionalidades para deixar o } \\
\text { fluxo mais automatizado }\end{array}$ & 8 & 10 & & 9 & 720 & 7,2 & \\
\hline
\end{tabular}

Os índices de priorização RPN e RAV forneceram resultados diferentes para o fluxo da Fornecedora de Madeira.

Os modos de desperdício mais relevantes segundo o RAV foram mais pulverizados em relação a causas comuns e foram mais concentrados na causa "Burocracia exagerada ou falta de padrão nos procedimentos", segunda colocada de acordo com o GINC. 
Os modos de desperdício segundo o RPN foram mais concentrados na causa "O sistema não possui funcionalidades para deixar o fluxo mais automatizado", primeira colocada de acordo com o GINC. Porém, o RPN desconsiderou, entre os dez MDs mais relevantes, alguns MDs com ações recomendadas claras e, também, a maioria dos MDs relacionados à causa "Burocracia exagerada ou falta de padrão nos procedimentos".

O GINC forneceu o resultado mais abrangente, e considerou o agrupamento dos MDs em causas e a importância dos MDs com ações recomendadas claras. Em virtude disso e da discrepância entre os três índices, foi decidido que seriam implantadas as ações recomendadas por meio da priorização utilizando o GINC.

As ações implantadas são descritas na próxima seção, assim como os resultados obtidos com essas implantações.

\subsection{Ações Implantadas e Compilação dos Indicadores}

As três (3) principais causas de desperdício (o sistema não possui funcionalidades para deixar o fluxo mais automatizado, burocracia exagerada ou falta de padrão nos procedimentos e a documentação é aberta para inserção de qualquer informação) tiveram as ações recomendadas implantadas. Essas três principais causas representavam 59,2\% do GINC acumulado de todas as causas (dezoito no total).

As grandes contribuições do método W-FMEA são no processo de mapeamento e levantamento de dados da situação atual e na priorização de quais causas de desperdícios e problemas são mais relevantes. A partir dessas informações, é necessário combinar a aplicação do W-FMEA com outras ferramentas e técnicas para eliminação dos desperdícios, como, por exemplo, as técnicas da produção enxuta e da gestão da qualidade. Para as implantações descritas nesta seção, foram usadas técnicas de criação de padrões e procedimentos enxutos, mecanismos a prova de falhas (poka-yokes) para o sistema de inserção das informações dos pedidos e automatização de sistemas.

As implantações foram divididas em três frentes de trabalho. A primeira frente foi referente à revisão dos procedimentos do fluxo, eliminando aprovações desnecessárias e agrupando etapas possíveis de serem realizadas pela mesma pessoa. A segunda frente compreendeu a elaboração de um sistema web de inserção das informações do pedido, 
eliminando informações imprecisas e não padronizadas. Por fim, a terceira frente de trabalho compreendeu a adequação/padronização do sistema de geração de ordens de produção.

A Fornecedora de Madeira já possuía procedimentos de trabalho para as atividades compreendidas pelo fluxo mapeado, e esses procedimentos eram detalhados ao ponto de mencionar que tipos de desenhos necessitavam de aprovações de diretores e quais eram os documentos onde deveriam ser inseridas as informações da ordem de produção, por exemplo.

Assim, depois de analisar os procedimentos existentes na empresa, o mapeamento do fluxo (Apêndice 8.2) e os modos de desperdício relacionados à causa "Burocracia exagerada ou falta de padrão nos procedimentos", foi elaborado um documento com os novos procedimentos, que foi submetido à aprovação da diretoria da Fornecedora de Madeira, foi implantado no manual da qualidade da empresa e foi replicado aos envolvidos via treinamentos.

O novo procedimento contemplava as etapas a seguir, com as seguintes modificações em relação ao procedimento original:

- Etapa 1 - Análises de Orçamentos e Negociações: elaboração do desenho (esboço) passou a ser feito nesta etapa, para antecipar a análise e aprovação dos diretores quanto à possibilidade de fabricação do produto;

- Etapa 2 - Análise Financeira dos Clientes: esta etapa não sofreu modificações;

- Etapa 3 - Emissão dos Pedidos e Preenchimento do Sistema de Inserção das Informações do Pedido: nesta etapa do procedimento foi descrito o modo de utilização do sistema de inserção de informações do pedido, que foi a segunda ação implantada. Além disso, foram definidas regras para quando é necessário aprovação do diretor comercial para um pedido (antes a aprovação era necessária para todos os pedidos);

- Etapa 4 - Elaboração e Aprovação de Desenhos de Produtos Novos: modificação do formulário padrão do desenho, permitindo que os desenhos fossem enviados diretamente do departamento Comercial para o Técnico e do Técnico para o cliente, para aprovação; e

- Etapa 5 - Manutenção do Cronograma de Produção e Geração das Ordens de Produção e de Montagem: criação de regras para quando é necessário intervenção do gerente do PCP na manutenção do Cronograma de Produção (em função dos prazos e estoques disponíveis) e paralelização do fluxo para elaboração 
de ordens de produção dos diferentes componentes (possibilitando a produção em paralelo dos componentes na fábrica, também).

A segunda frente de implantação compreendeu o desenvolvimento de um sistema web para inserção das informações do pedido, criando travas para bloquear a inserção de informações incorretas ou para envio do pedido com ausência de informações imprescindíveis para o PCP e para a fábrica.

O sistema foi desenvolvido pela área de tecnologia da própria empresa, com auxílio do pesquisador quanto às travas que o sistema deveria ter para minimizar os modos de desperdício mais impactantes.

Em virtude da forte correlação entre a primeira e a terceira causas mais prioritárias, um sistema web a prova de erros, para inserção das informações necessárias para a produção, além de deixar a própria atividade mais rápida, deixaria o fluxo dali para frente mais ágil, evitando a propagação de erros do começo do fluxo.

Após o desenvolvimento do sistema, foi realizada uma comunicação corporativa para os representantes de venda, por parte do Diretor Comercial da empresa e, posteriormente, foram realizados treinamentos sobre a utilização desta ferramenta.

Por fim, a terceira frente de implantação se referiu à adequação do sistema de geração de ordens de produção, utilizado pelo PCP, para que as informações inseridas no sistema web dos pedidos fossem compiladas automaticamente.

Durante essas implantações, foi identificada outra oportunidade de melhoria do controle deste fluxo, que era a implantação de um sistema de workflow para auxiliar os gestores a terem a visão dos pontos onde estariam parados cada pedido. Essa ação não foi implantada até a finalização deste trabalho.

As implantações começaram em abril de 2011 e para calcular as medidas de resultado das implantações, foram coletados dados de lead time do fluxo e comparados os valores do GINC obtidos antes e depois das implantações definidas a partir da aplicação do W-FMEA.

O Gráfico 6 apresenta a comparação semanal dos lead times médios do fluxo de processamento de pedidos do período de maio a agosto de 2010 contra o mesmo período de 2011 (período de alta demanda). O patamar de quantidade de pedidos se manteve o mesmo comparando 2010 e 2011 (Gráfico 7), o que prova que houve redução de lead time depois das implantações apesar de o volume de pedidos ter se mantido. A redução do lead time de 2010 
para 2011 foi da ordem de 28\% (de 18 para 12,9 dias), comparando a média de lead time do fluxo no período de maio a agosto dos dois anos.

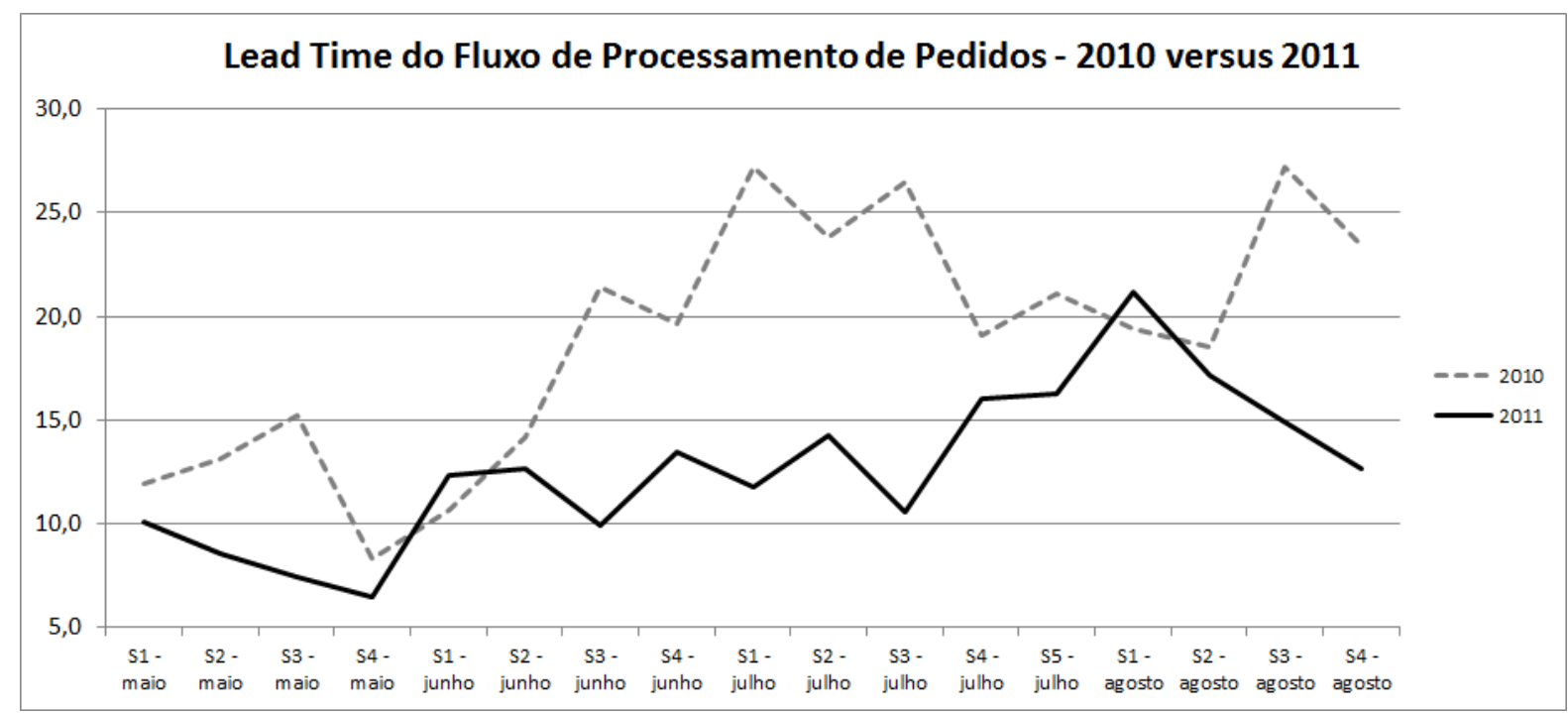

Gráfico 6: Comparação do lead time médio do fluxo de processamento de pedidos no período de maio a agosto dos anos de 2010 e 2011



Gráfico 7: Comparação da quantidade de pedidos processados por semana entre maio e agosto de 2010 e de 2011

Além disso, nota-se que a curva de lead time de 2010 apresenta tendência de alta mais acentuada neste período de alta demanda, enquanto a curva de 2011 se mostra mais constante. E mais, a equipe do PCP que antes era composta por sete pessoas (incluindo o gerente) que se dividiam para realizar as atividades do fluxo de informação dos Produtos de Madeira, passou a ter seis pessoas para atender ao mesmo volume de demanda de pedidos por semana.

A outra forma de comparação do resultado das implantações se deu por meio do recálculo dos índices GIND e GINC dos modos de desperdício. Para isso, foi realizada uma reunião de 
revisão das pontuações de probabilidade de ocorrência, nível de detecção e severidade financeira dos modos de desperdício relacionados às causas com ações recomendadas implantadas. Os formulários do W-FMEA com as pontuações revisadas podem ser observados na Tabela 32, na Tabela 33 e na Tabela 34.

Tabela 32: W-FMEA revisado depois das implantações (parte 1)

Waste FMEA - Análise dos Modos de Desperdícios, de Falhas e seus Efeitos

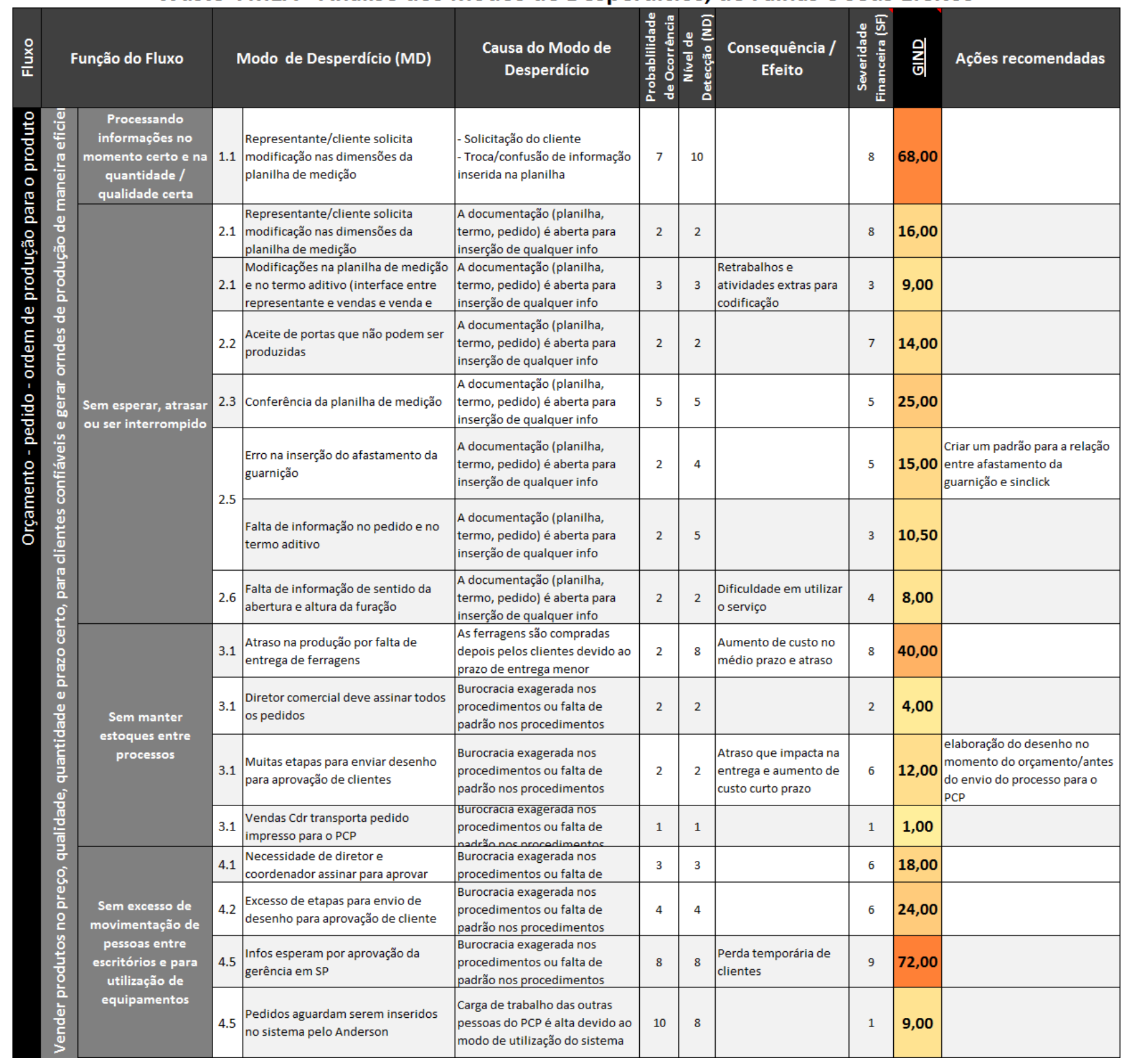


Tabela 33: W-FMEA revisado depois das implantações (parte 2)

Waste FMEA - Análise dos Modos de Desperdícios, de Falhas e seus Efeitos

\begin{tabular}{|c|c|c|c|c|c|c|c|c|c|}
\hline Função do Fluxo & & Modo de Desperdício (MD) & $\begin{array}{l}\text { Causa do Modo de } \\
\text { Desperdício }\end{array}$ & 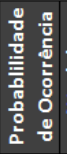 & 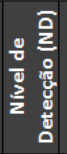 & $\begin{array}{c}\text { Consequência / } \\
\text { Efeito }\end{array}$ & 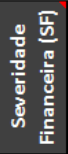 & 이 히 & Ações recomendadas \\
\hline \multirow{4}{*}{$\begin{array}{l}\text { Sem precisar } \\
\text { transportar } \\
\text { informações }\end{array}$} & 5.1 & $\begin{array}{l}\text { Diversos processos realizados antes } \\
\text { de receber a medição (que demora }\end{array}$ & \begin{tabular}{|l|} 
Cliente que demora para \\
mandar medição e não antecipa
\end{tabular} & 2 & 10 & $\begin{array}{l}\text { Aumento de custo no } \\
\text { médio prazo }\end{array}$ & 7 & 42,00 & \\
\hline & 5.2 & $\begin{array}{l}\text { Impressão e transporte de um } \\
\text { checklist de embraque }\end{array}$ & Controle de embarque de carga & 10 & 9 & & 1 & 9,50 & \begin{tabular}{|l|} 
Implantar sistema de código de \\
barras
\end{tabular} \\
\hline & 5.3 & $\begin{array}{l}\text { Pedidos aguardam serem } \\
\text { programados }\end{array}$ & $\begin{array}{l}\text { Cronograma de produção } \\
\text { (338/345) é semanal }\end{array}$ & 10 & 10 & & 1 & 10,00 & \\
\hline & 5.4 & $\begin{array}{l}\text { Modificações na planilha de medição } \\
\text { e no termo aditivo (interface entre } \\
\text { representante e vendas e venda e }\end{array}$ & \begin{tabular}{|l|}
$\begin{array}{l}\text { Falta de treinamento ou } \\
\text { conhecimento do representante } \\
\text { no preenchimento da planilha }\end{array}$ \\
\end{tabular} & 3 & 8 & \begin{tabular}{|l|}
$\begin{array}{l}\text { Retrabalhos e } \\
\text { atividades extras para } \\
\text { codificação }\end{array}$ \\
\end{tabular} & 3 & 16,50 & \\
\hline \multirow{5}{*}{$\begin{array}{l}\text { Por meio de } \\
\text { processos } \\
\text { adequados e } \\
\text { padronizados }\end{array}$} & 6.1 & $\begin{array}{l}\text { Determinação incorreta de preços de } \\
\text { portas especiais }\end{array}$ & $\begin{array}{l}\text { Falta um sistema e um padrão } \\
\text { de custeio }\end{array}$ & 5 & 7 & & 9 & 54,00 & $\begin{array}{l}\text { Ter e utilizar uma sistema, uma } \\
\text { tabela de preços padrão }\end{array}$ \\
\hline & 6.1 & Falta de informação de ferragem & \begin{tabular}{|l|} 
Indefinição do cliente de qual \\
ferragem usar (as ferragens são \\
compradas depois devido a \\
prazo de entrega menor)
\end{tabular} & 6 & 7 & & 8 & 52,00 & \\
\hline & 6.1 & $\begin{array}{l}\text { Várias infos transportadas por email } \\
\text { internamente }\end{array}$ & \begin{tabular}{|l|} 
Informação percorre setores \\
diferentes em locais diferente
\end{tabular} & 8 & 8 & & 1 & 8,00 & $\begin{array}{l}\text { Utilizar MSN para transmissão } \\
\text { de info }\end{array}$ \\
\hline & 6.3 & $\begin{array}{l}\text { Documentação de clientes novos é } \\
\text { levada impressa pessoalmente }\end{array}$ & \begin{tabular}{|l|}
$\begin{array}{l}\text { Necessidade de documentação, } \\
\text { assinatura }\end{array}$ \\
\end{tabular} & 2 & 6 & & 1 & 4,00 & \\
\hline & 6.5 & $\begin{array}{l}\text { Estoque de desenhos para serem } \\
\text { feitos }\end{array}$ & $\begin{array}{l}\text { Necessidade de outras } \\
\text { atividades e desenho de todos } \\
\text { os itens especiais }\end{array}$ & 3 & 8 & & 8 & 44,00 & $\begin{array}{l}\text { Ter o desenho pronto junto } \\
\text { com a planilha de mediçao para } \\
\text { definir o prazo de entrega }\end{array}$ \\
\hline \multirow{5}{*}{$\begin{array}{c}\text { Sem produzir erros e } \\
\text { defeitos }\end{array}$} & 7.1 & $\begin{array}{l}\text { Não existe a funcionalidade de } \\
\text { quebra de pág para itens que vão ou } \\
\text { para Sinkit ou para Montados }\end{array}$ & $\begin{array}{l}\text { O sistema não possui } \\
\text { funcionalidades para deixar o } \\
\text { fluxo mais automatizado }\end{array}$ & 4 & 4 & & 9 & 36,00 & \\
\hline & 7.2 & $\begin{array}{l}\text { Sistema não processa } \\
\text { automaticamente as info de portas } \\
\text { de correr e pivotantes }\end{array}$ & $\begin{array}{l}\text { O sistema não possui } \\
\text { funcionalidades para deixar o } \\
\text { fluxo mais automatizado }\end{array}$ & 6 & 6 & & 9 & 54,00 & \\
\hline & 7.2 & $\begin{array}{l}\text { Aceite do orçamento não é via } \\
\text { sistema (é via email ou telefone) }\end{array}$ & $\begin{array}{l}\text { O sistema não possui } \\
\text { funcionalidades para deixar o } \\
\text { fluxo mais automatizado }\end{array}$ & 8 & 10 & & 9 & $81,00 \mid$ & \\
\hline & 7.3 & $\begin{array}{l}\text { Existe capacidade instalada maior } \\
\text { para poder trabalhar com o sistema } \\
\text { existente }\end{array}$ & $\begin{array}{l}\text { O sistema não possui } \\
\text { funcionalidades para deixar o } \\
\text { fluxo mais automatizado }\end{array}$ & 4 & 4 & & 9 & 36,00 & \\
\hline & 7.6 & $\begin{array}{l}\text { Pode faltar documento impresso no } \\
\text { processo de kit }\end{array}$ & $\begin{array}{l}\text { O sistema não possui } \\
\text { funcionalidades para deixar o } \\
\text { fluxo mais automatizado }\end{array}$ & 1 & 5 & & 8 & 24,00 & \\
\hline \multirow{5}{*}{$\begin{array}{c}\text { Sem necessidade de } \\
\text { revisões, traduçóes e } \\
\text { retrabalhos }\end{array}$} & 8.1 & $\begin{array}{l}\text { Envio de info de planilha ou print } \\
\text { screen por email (ferragens) }\end{array}$ & $\begin{array}{l}\text { O sistema não possui } \\
\text { funcionalidades para deixar o }\end{array}$ & 10 & 8 & & 1 & 9,00 & \\
\hline & 8.3 & $\begin{array}{l}\text { Processo montagem de kit aguarda a } \\
\text { produção dos componentes }\end{array}$ & $\begin{array}{l}\text { Para gerar a OP dos } \\
\text { componentes precisa ser } \\
\text { montado o processo antes }\end{array}$ & 10 & 9 & & 6 & 57,00 & \begin{tabular}{|l|} 
Possibilidade de gerar OP dos \\
componentes antes de \\
terminar a montagem do \\
processo (fluxos paralelos) -
\end{tabular} \\
\hline & 8.3 & $\begin{array}{l}\text { Necessidade de impressão de várias } \\
\text { cópias do cronograma (338/345) de } \\
\text { produção para os setores }\end{array}$ & $\begin{array}{l}\text { Solicitação por parte da } \\
\text { produção }\end{array}$ & 10 & 10 & & 5 & 50,00 & \\
\hline & 8.4 & $\begin{array}{l}\text { Cópia extra do processo de kit para } \\
\text { supervisão fáb } 2\end{array}$ & $\begin{array}{l}\text { Solicitação por parte da } \\
\text { produção }\end{array}$ & 10 & 9 & & 5 & 47,50 & \\
\hline & 8.5 & $\begin{array}{l}\text { Necessidade de um processo para } \\
\text { separar os pedidos de kit maiores e } \\
\text { menores de } 20 \text { itens }\end{array}$ & & 10 & 10 & & 1 & 10,00 & \begin{tabular}{|l|} 
realizar esssa etapa no setor de \\
vendas com envio da \\
documentação para o \\
destinatário certo
\end{tabular} \\
\hline \multirow{4}{*}{$\begin{array}{l}\text { Utilizando o talento } \\
\text { e os recursos de mão- } \\
\text { de-obra de maneira } \\
\text { eficiente }\end{array}$} & 9.1 & $\begin{array}{l}\text { Interrupções das pessoas quando } \\
\text { estão realizando as atividades que }\end{array}$ & & 8 & 5 & \begin{tabular}{|l|} 
Má utilização dos \\
recursos e aumento de
\end{tabular} & 7 & 45,50 & \\
\hline & 9.1 & $\begin{array}{l}\text { Movimentação para pegar e entregar } \\
\text { documentos (Carla busca pedidos na } \\
\text { sala do Anderson) }\end{array}$ & & 10 & 9 & & 4 & 38,00 & \\
\hline & 9.7 & $\begin{array}{l}\text { Necessidade de impressão do termo } \\
\text { aditivo e pedido para } \\
\text { confrontamento }\end{array}$ & & 10 & 10 & & 1 & 10,00 & \\
\hline & 9.7 & $\begin{array}{l}\text { Falta de envolvimento do cliente } \\
\text { para aprovação de desenho }\end{array}$ & & 3 & 6 & & 8 & 36,00 & \\
\hline $\begin{array}{l}\text { Em um fluxo } \\
\text { harmonioso de } \\
\text { processos }\end{array}$ & 10.1 & $\begin{array}{l}\text { Falta comprometimento com } \\
\text { questốes prioritárias de } \\
\text { fornecimento de info }\end{array}$ & & 4 & 9 & & 8 & 52,00 & \\
\hline
\end{tabular}


Tabela 34: W-FMEA resultado depois das implantações

\begin{tabular}{|c|c|c|c|c|}
\hline Causa do Modo de Desperdício & $\frac{3}{\frac{1}{6}}$ & Ações recomendadas & $\begin{array}{l}\% \text { Acumulada } \\
\text { da causa }\end{array}$ & $\begin{array}{l}\text { Classifícação } \\
\text { da causa }\end{array}$ \\
\hline $\begin{array}{c}\text { O sistema não possui funcionalidades para deixar o fluxo } \\
\text { mais automatizado }\end{array}$ & 240,0 & $\begin{array}{l}\text { adequar sistema para importação dos dados do sistema de } \\
\text { medição }\end{array}$ & $22,6 \%$ & A \\
\hline $\begin{array}{l}\text { Burocracia exagerada nos procedimentos ou falta de } \\
\text { padrão nos procedimentos }\end{array}$ & 131,0 & $\begin{array}{l}\text { elaboração do desenho no momento do orçamento/antes do } \\
\text { envio do processo para o PCP, realizar etapa de separar os } \\
\text { dois produtos no setor de vendas com envio da } \\
\text { documentação para o destinatário certo, criar regras para } \\
\text { quando é necessário supervisor assinar pedidos ou definir } \\
\text { prazo de entrega (em SP também), possibilitar o envio de } \\
\text { desenho para o cliente diretamente pelo Dep. Técnico, } \\
\text { incorporar termo aditivo no sistema de medição }\end{array}$ & $35,0 \%$ & $\mathbf{A}$ \\
\hline $\begin{array}{c}\text { A documentação (planilha, termo, pedido) é aberta para } \\
\text { inserção de qualquer info }\end{array}$ & 97,5 & $\begin{array}{l}\text { Criar um padrão para a relação entre afastamento dos } \\
\text { componentes do produto, criar bloqueios no sistema para } \\
\text { evitar inserção de dados errados, criar funcionalidade no } \\
\text { sistema para relacionar apenas características possiveis de } \\
\text { serem relacionadas (configurador) }\end{array}$ & $44,1 \%$ & A \\
\hline $\begin{array}{c}\text { Cópias extras das ordens de produção e do cronograma } \\
\text { de produção: Solicitação por parte da produção }\end{array}$ & 97,5 & & $53,3 \%$ & A \\
\hline $\begin{array}{l}\text { Alguns componentes são compradas depois pelos } \\
\text { clientes devido ao prazo de entrega menor }\end{array}$ & 92,0 & & $62,0 \%$ & $\mathbf{A}$ \\
\hline $\begin{array}{l}\text { Mudança na medição: Solicitação do cliente, } \\
\text { Troca/confusão de informação inserida na planilha }\end{array}$ & 68,0 & & $68,4 \%$ & A \\
\hline $\begin{array}{c}\text { Para gerar a OP dos componentes precisa ser montado o } \\
\text { processo antes }\end{array}$ & 57,0 & $\begin{array}{c}\text { Possibilidade de gerar OP dos componentes antes de } \\
\text { terminar a montagem do processo (fluxos paralelos) - retirar } \\
\text { a info da planilha de medição }\end{array}$ & $73,8 \%$ & A \\
\hline Falta um sistema e um padrão de custeio & 54,0 & Ter e utilizar uma sistema, uma tabela de preços padrão & $78,9 \%$ & B \\
\hline $\begin{array}{l}\text { Interrupções das pessoas quando estão realizando as } \\
\text { atividades que agregam valor }\end{array}$ & 45,5 & & $83,1 \%$ & B \\
\hline $\begin{array}{l}\text { Necessidade de outras atividades a serem feitas e } \\
\text { desenho de todos os itens especiais }\end{array}$ & 44,0 & $\begin{array}{c}\text { Ter o desenho pronto junto com a planilha de mediçao para } \\
\text { definir o prazo de entrega }\end{array}$ & $87,3 \%$ & B \\
\hline \begin{tabular}{|c|} 
Cliente que demora para mandar medição e não antecipa \\
pagamento
\end{tabular} & 42,0 & & $91,2 \%$ & $\mathrm{C}$ \\
\hline $\begin{array}{l}\text { Falta de envolvimento do cliente para aprovação de } \\
\text { desenho }\end{array}$ & 36,0 & & $94,6 \%$ & $\mathrm{C}$ \\
\hline \begin{tabular}{|c|} 
Falta de treinamento ou conhecimento do representante \\
no preenchimento da planilha
\end{tabular} & 16,5 & & $96,2 \%$ & $\mathrm{C}$ \\
\hline Cronograma de produção (338/345) é semanal & 10,0 & & $97,1 \%$ & $\mathbf{C}$ \\
\hline Controle de embarque de carga & 9,5 & Implantar sistema de código de barras & $98,0 \%$ & C \\
\hline $\begin{array}{l}\text { Envio de info de planilha ou print screen por email } \\
\text { (ferragens) }\end{array}$ & 9,0 & & $98,9 \%$ & $\mathrm{C}$ \\
\hline $\begin{array}{l}\text { Informação percorre setores diferentes em locais } \\
\text { diferentes }\end{array}$ & 8,0 & Utilizar MSN para transmissão de info & $99,6 \%$ & $\mathrm{C}$ \\
\hline $\begin{array}{l}\text { Necessidade de documentação, assinatura para } \\
\text { processos de análise financeira de clientes novos }\end{array}$ & 4,0 & & $100,0 \%$ & C \\
\hline
\end{tabular}

Após o primeiro ciclo de aplicação da proposta, foram revistos os GINDs e recalculados os GINCs, como mostrado. As três principais causas (com maiores valores de GINC) continuaram as mesmas, o que significa que o foco de melhoria ainda deve ser o mesmo. Entretanto, essas causas passaram a representar 44,1\% do GINC acumulado, frente aos 59,2\% anteriores. O GINC acumulado diminuiu de 1.453 para 1.061 pontos, ou seja, redução de $27 \%$. 


\subsection{Adaptações da Proposta Inicial}

A proposta conceitual, elaborada depois da aplicação piloto e descrita na seção 4.3 deste trabalho é baseada em uma mistura dos conceitos do FMEA tradicional com os conceitos da Produção Enxuta. Como mencionado, o W-FMEA tem como objetivo servir de ferramenta para gestão de melhorias, por meio da identificação de desperdícios e suas causas e priorização de ações de melhoria em processos administrativos ou de manufatura. Tanto a aplicação piloto deste trabalho, quanto a aplicação principal mostram que este método pode ser bastante útil para identificação de oportunidades de melhoria. $\mathrm{Na}$ aplicação principal, as oportunidades identificadas e implantadas, com o auxílio de outras ferramentas e outros métodos, acarretaram em redução de desperdícios no fluxo de informação analisado.

Porém, durante essas aplicações algumas outras adaptações foram acrescentadas à proposta conceitual do método. Essas adaptações são basicamente duas:

- Adição de novos modos de desperdício ao checklist de desperdícios em ambientes administrativos. Estes modos de desperdício foram adicionados por serem considerados tipos de desperdício que não se encaixam em nenhum outro modo existente do checklist;

- Criação de um formulário de apoio ao formulário do W-FMEA para análise do resultado compilado do GINC, ordenado do maior para o menor valor e com a informação de porcentagem acumulada da causa em relação ao total.

Os modos de desperdício acrescentados ao checklist proposto inicialmente (Tabela 20 e Tabela 21) são dez e apareceram principalmente na aplicação principal do W-FMEA, no fluxo de informação dos Produtos de Madeira da Fornecedora de Madeira. Esses novos modos de desperdício foram claramente identificados neste fluxo, por serem mais relacionados a desperdícios de escritório e serem mais presentes em fluxos mais complexos e detalhados. Eles não puderam ser observados na aplicação piloto. A Tabela 35 apresenta os modos de desperdício acrescentados ao checklist. 
Tabela 35: Modos de desperdício incluídos no checklist de desperdícios de escritório

\begin{tabular}{|c|c|}
\hline Categoria de Desperdício & Tipo do Desperdício \\
\hline \multirow{2}{*}{ 1. Superprodução ou excesso de produção } & 1.3. Compra de itens de consumo antes do necessário \\
\hline & 1.4. Impressão de relatórios antes do necessário \\
\hline 2. Esperas, interrupções ou atrasos & 2.7. Muitas reuniões para alinhamento dos participantes do fluxo \\
\hline $\begin{array}{l}\text { 3. Estoques intermediários e finais e } \\
\text { armazenamento }\end{array}$ & $\begin{array}{l}\text { 3.3. Processar informações (relatórios, transações, documentos) em } \\
\text { lotes }\end{array}$ \\
\hline \multirow{3}{*}{$\begin{array}{l}\text { 6. Processos inadequados ou ineficientes } \\
\text { e falta de comunicação }\end{array}$} & 6.6. Aceite de configuraçôes de serviços/produtos infactíveis \\
\hline & 6.8. Sistema de informática não confiável e sujeito à muitas "quedas" \\
\hline & $\begin{array}{l}\text { 6.9. Falta de alinhamento de objetivos e recursos gastos com } \\
\text { atividades feitas não condizentes com os objetivos }\end{array}$ \\
\hline 7. Defeitos, erros e imperfeições & 7.6. Determinação incorreta dos preços/custos dos serviços/processos \\
\hline $\begin{array}{l}\text { 9. Sub-utlização da mão-de-obra, do } \\
\text { talento e dos recursos }\end{array}$ & $\begin{array}{l}\text { 9,8. Falta de senso de urgência para questôes prioritárias por parte dos } \\
\text { envolvidos no fluxo }\end{array}$ \\
\hline 10. Excesso de capacidade instalada & 10.2. Desbalanceamento dos processos do fluxo \\
\hline
\end{tabular}

A segunda grande adaptação da proposta conceitual do W-FMEA para a proposta final deste trabalho é a criação do formulário de apoio para cálculo do GINC. Sem este formulário o cálculo deste índice não seria metódico.

O formulário de apoio do W-FMEA contém apenas cinco colunas, sendo que a primeira é a coluna que repete as causas identificadas no primeiro formulário do W-FMEA. A diferença é que, no formulário de apoio para o cálculo do GINC, as causas não aparecem mais de uma vez cada e, assim, a segunda coluna (GINC) contempla a soma dos índices GIND de todos os modos de desperdício relacionados a cada causa. As ações recomendadas também são agrupadas conforme a causa na terceira coluna. A quarta e a quinta coluna são as colunas que apresentam a representatividade de cada causa no total do GINC somado de todas as causas. Essas colunas mostram o quão importante é uma causa no total de causas identificadas.

A utilização deste formulário de apoio também auxilia no cálculo do total do GINC para comparação entre antes e depois das implantações de ações recomendadas, bem como auxilia na comparação da representatividade das causas antes e depois de ações de melhoria.

O formulário de apoio do W-FMEA não preenchido é observado na Tabela 36. 
Tabela 36: Formulário de apoio para cálculo do GINC do W-FMEA não preenchido

\begin{tabular}{|l|l|l|l|l|l|}
\hline \multicolumn{6}{|c|}{ Waste FMEA - Análise dos Modos de Desperdícios, de Falhas e seus Efeitos } \\
\hline Causa do Modo de Desperdício & $\begin{array}{l}\text { \% Acumulada } \\
\text { da causa }\end{array}$ & $\begin{array}{c}\text { Classificação } \\
\text { da causa }\end{array}$ \\
\hline & & & & & \\
\hline & & & & & \\
\hline & & & & \\
\hline & & & & & \\
\hline & & & & \\
\hline & & & & \\
\hline & & & & \\
\hline & & & & \\
\hline & & & & \\
\hline
\end{tabular}




\section{CONSIDERAÇÕES FINAIS}

Este trabalho apresentou uma forma de alinhar os conceitos da Produção Enxuta com os conceitos do FMEA, de gestão de qualidade e confiabilidade de produtos, por meio da adaptação do FMEA tradicional para análise, não só de falhas, mas também de outros tipos de desperdícios em fluxos de processos, e não somente em processos.

A idéia que acarretou no objetivo deste trabalho era contribuir para a literatura de gestão de melhorias em Produção Enxuta, por meio da criação de um método estruturado para análise e eliminação de desperdícios, principalmente em fluxos de informação.

Os principais conceitos pesquisados na literatura foram os conceitos de desperdícios sob a ótica do Lean, tanto para ambientes de manufatura quanto para ambientes de escritório, e os conceitos do método FMEA. A possibilidade de juntar esses dois conceitos para elaboração de um método para auxiliar a gestão de melhorias surgiu da dificuldade de identificação e eliminação de desperdícios em iniciativas de melhorias em fluxos de informação, observada pelo autor e sentida em experiências próprias.

A elaboração de uma proposta inicial de método simples e aliada a aplicação piloto foi de suma importância para criação de uma capacidade de análise crítica do próprio método que, posteriormente submetido a outra aplicação, apresentou resultados bem satisfatórios.

\subsection{Questão de Pesquisa e Objetivos}

Ao invés de uma discussão muito mais abrangente sobre métodos, melhores práticas e comparação entre diversas técnicas para gestão de melhorias e redução de desperdícios em sistemas produtivos de manufatura ou de informação, este trabalho perseguiu uma questão de pesquisa mais direta e objetiva: "Como usar o FMEA para analisar os desperdícios de fluxos de processos (de acordo com a classificação da Produção Enxuta) e priorizar ações de melhoria?". 
Pelo fato de que os conceitos consolidados da Produção Enxuta são relevantes e que uma ferramenta tradicional e largamente aplicada para priorização de ações de melhoria como o FMEA é eficaz, o autor optou por desenvolver um método pela junção destes conceitos. As principais contribuições deste método deveriam ser o aumento da eficácia e da rapidez para identificação de desperdícios em fluxos de processos (isso foi percebido no momento em que o processo todo consumiu dois dias de trabalho de três pessoas) e o aumento da assertividade e da capacidade de priorização de ações que trouxessem melhoria de eficiência para fluxos de processos (isso foi percebido pelo fato de que as implantações de outras técnicas decorrentes da priorização do W-FMEA trouxeram bons resultados de redução de lead time). Por isso, as duas principais adaptações do W-FMEA em relação ao FMEA tradicional foram: a criação de checklists de desperdícios e a elaboração de um índice de priorização mais robusto. Os checklists de desperdícios tinham como função proporcionar uma identificação mais rápida, padronizada e eficaz dos possíveis desperdícios existentes em um fluxo e, o índice de priorização GINC, abranger uma quantidade mais relevante e impactante de causas e ações de melhoria na escala de priorização.

O objetivo principal do trabalho, que era Desenvolver uma adaptação do método FMEA para gestão de melhoria em manufatura e processos administrativos baseada na análise dos desperdícios classificados pelas teorias da Produção Enxuta, foi completado, como mostram os resultados obtidos durante e após as aplicações do método. Para completar o objetivo principal do trabalho, foram enumerados quatro objetivos secundários a serem atingidos durante a realização da pesquisa:

- Identificar, na literatura, teorias do Lean para os conceitos de desperdícios e suas fontes, em processos de manufatura e administrativos;

- Identificar, também na literatura, as formas alternativas de aplicação do FMEA em manufatura, serviços e aliado aos conceitos de Lean;

- Desenvolver dois checklists de fontes de desperdícios (um para manufatura e um para processos administrativos) para servir de guia para identificação das causas dos desperdícios durante a aplicação do método; e

- Estruturar uma proposta do método a partir de uma aplicação do mesmo.

Os objetivos secundários foram todos cumpridos, uma vez que: 
- A revisão da literatura abrangeu todas as teorias existentes sobre desperdícios de manufatura e administrativos sob a ótica do Lean (mais de vinte autores e diversos trabalhos nacionais e internacionais sobre o assunto foram pesquisados);

- A revisão da literatura também abrangeu todos os conceitos tradicionais do FMEA e diversas adaptações e aplicações alternativas da ferramenta (cerca de quinze autores de trabalhos internacionais pesquisados sobre os conceitos tradicionais e dez aplicações alternativas e diferentes analisadas);

- Os checklists de desperdícios de manufatura e de escritório foram desenvolvidos a partir das pesquisas na literatura e o de escritório, especificamente, foi acrescentado de outros desperdícios identificados nas aplicações realizadas durante a pesquisa; e

- O método W-FMEA teve uma proposta estrutura e pronta para ser testada em outros momentos após ser testado em uma aplicação piloto e na aplicação principal deste trabalho.

\subsection{Conclusões}

Ao final de dois ciclos de pesquisa (sendo uma aplicação piloto em um contexto mais simples e a aplicação principal em um contexto mais realista), pôde-se chegar a uma proposta de aplicação do FMEA para priorização de ações visando a redução de desperdícios segundo a abordagem da produção enxuta. A proposta, W-FMEA, caracteriza-se por algumas particularidades:

- Sugestão de uma lista de modos de desperdício em ambiente de escritório;

- Escalas de pontuação para os critérios de severidade, ocorrência adaptados a partir das escalas convencionalmente usadas;

- Índice de prioridade baseado no modo de desperdício (GIND), com maior peso dado ao critério severidade e balanceamento das pontuações de ocorrência e detecção uma vez que a primeira é influenciada pela segunda de acordo com as escalas utilizadas; e

- Índice de prioridade baseado na causa do modo de desperdício (GINC), evidenciando aquelas causas da maior parte dos desperdícios e, portanto as mais impactantes. 
O desenvolvimento da proposta a partir de um trabalho de campo, em paralelo à implantação de produção enxuta e juntamente com a equipe do projeto, contribuiu para a discussão e aprimoramento da proposta planejada a partir da revisão da literatura. Os bons resultados obtidos com a implantação das ações visando a redução de desperdícios sugerem que as prioridades identificadas a partir da aplicação do W-FMEA foram acertadas. A partir das prioridades identificadas, a combinação do W-FMEA com outras técnicas da produção enxuta, tais como, poka-yoke, criação de padrões e procedimentos e automatização de sistemas, foi de fundamental importância para os resultados obtidos. Um aspecto importante a ressaltar é que a proposta de utilização do índice $G I N C$ define prioridades para eliminação ou minimização das causas mais críticas, que geram a maior parte dos desperdícios ou os desperdícios de maior severidade. Essa sistemática é um diferencial em relação a outras aplicações do FMEA. Ainda que não se possa afirmar que esses resultados não seriam obtidos sem a adoção do $W$-FMEA, observou-se que a sistemática proposta, de priorizar ações para eliminação ou minimização das causas fundamentais, responsáveis pela maior parte dos desperdícios, é um caminho interessante a seguir. Esse tipo de priorização também auxilia na identificação das relações entre os diversos desperdícios de um fluxo e na busca por uma solução mais abrangente para os problemas identificados.

Por meio da revisão da literatura, percebe-se que métodos, ferramentas e melhores práticas para aplicação da produção enxuta em ambientes de manufatura estão muito mais difundidos e, talvez por isso, sejam muito mais eficazes e consolidados. A idéia inicial deste trabalho é que o método W-FMEA fosse desenvolvido para ser possível de ser aplicado tanto em ambientes de manufatura quanto em ambientes administrativos. Porém, a percepção é que as principais funções do método e as principais diferenças em relação ao FMEA tradicional não constituem um grande diferencial para aplicação de Produção Enxuta em manufatura, quanto constituem para aplicações em fluxos de informação. Em fluxos de informação, a identificação de desperdícios é muito mais difícil que em fluxos de manufatura, por isso o checklist de desperdícios de escritório se mostrou eficaz durante as aplicações desenvolvidas nesta pesquisa. Da mesma forma, a lógica de análise e implantação de melhorias em ambientes fabris já segue um método sedimentado, testado e aprovado, diferentemente da lógica de implantação em fluxos de informação. Por isso, a priorização de ações de maior impacto e que abrangem mais causas e mais desperdícios se mostra importante em ambientes administrativos. 
Por fim, como na maioria das análises e iniciativas de melhoria de Produção Enxuta, conclui-se que tão mais eficaz é o método quanto mais repetitivo for o fluxo de processos. Isso se dá pelo fato de que a maioria dos desperdícios é resultado da grande interação entre os processos de um fluxo e do grande volume de trabalho imposto a ele.

Em resumo, é possível concluir que os objetivos da pesquisa foram atingidos e que o método elaborado foi eficaz para as aplicações realizadas e, portanto, é passível de ser testado em mais oportunidades para consolidação de seu real potencial.

\subsection{Limitações e Trabalhos Futuros}

Certamente a proposta do W-FMEA pode sofrer várias melhorias e certamente o método deve ser submetido a outros testes. Apesar da percepção de que para manufatura o W-FMEA não tenha a mesma eficácia que teve para fluxos de informação, seria interessante aplicar o método em um fluxo de material de uma fábrica e compará-lo aos métodos tradicionais de identificação e eliminação de desperdícios em manufatura. Além disso, o método precisa ser testado em outros fluxos de informação, principalmente no que diz respeito à identificação de oportunidades de melhoria que se implantadas trazem melhorias significativas como as demonstradas neste trabalho. É importante verificar a validade dos índices de priorização GIND e GINC propostos aqui e se as variações percentuais do GINC depois das implantações em relação ao GINC de antes das implantações é alinhada com a variação de lead time comparando o antes e depois das implantações, também.

Algumas propostas de trabalho futuro também surgem depois das constatações dos resultados desta pesquisa. A abrangência do tema é tanta que a aplicação do método em fluxos de informação de processos internos de uma empresa deve diferenciar muito da aplicação dele em fluxos de informação de empresas prestadoras de serviço. Apesar de ambos os exemplos serem fluxos de informação, a natureza da severidade muda uma vez que o impacto do efeito é direto no cliente e não em um processo interno de determinada organização.

Outro exemplo: a escala de severidade poderia ser revisada de duas formas. Existe a possibilidade, por meio de um trabalho estatístico, de se desenvolver uma escala de severidade mais quantitativa que possa ser usada com mais facilidade por ser mais objetiva e direta. Assim como essa escala de severidade pode ser definida com base no impacto de 
determinado efeito em relação ao lead time, ou seja, tanto maior é a pontuação de severidade quanto maior for o aumento no lead time do fluxo se aquele desperdício ocorre. As escalas de ocorrência e detecção também podem ser adequadas de forma que proporcionem melhor capacidade de análise dos modos de desperdícios.

As próprias fórmulas de cálculo dos índices de priorização também podem ser repensadas e aprimoradas, uma vez que, submetendo o W-FMEA para outras aplicações e comparando os índices GINC antes e depois das implantações com a variação do lead time seja possível identificar algum tipo de relação.

Por último, observou-se que a combinação de técnicas do FMEA com técnicas da Produção Enxuta, para criação do W-FMEA, criou um método híbrido que consegue, por vezes, fornecer visões de problemas locais e, outras vezes, visões de problemas globais do fluxo. Por meio dessa visão híbrida, existe uma grande possibilidade de que boa parte dos problemas e desperdícios de um fluxo é analisada durante a aplicação do método. Portanto, a junção de conceitos do Lean e do W-FMEA surge como uma boa direcionadora para elaboração de um método mais robusto, que transcorra pelo mapeamento do fluxo (com a aplicação da técnica do Mapa de Fluxo de Valor), identificação de desperdícios e problemas e suas causas raízes (com a aplicação da Árvore da Realidade Atual e do checklist de desperdícios do W-FMEA) e priorização das causas que mais impactam negativamente no lead time de um fluxo (com a aplicação do W-FMEA).

Esta pesquisa demonstrou que é possível aliar conceitos existentes e diferentes de gestão de melhoria, geralmente usados em aplicações distintas, para criar métodos eficazes para gerir iniciativas de melhoria combinadas entre estes conceitos. Um dos principais desafios dos métodos de gestão de melhorias, que é garantir a eficácia das implantações por meio de análises estruturadas e rápidas, deve buscar sempre ser contornado e superado. Em ambientes dinâmicos e de mudanças constantes, como os que se encontram hoje em dia nas empresas, as melhorias são fundamentais para o crescimento e perpetuação dos negócios. 


\section{REFERÊNCIAS}

A União entre a sua Empresa e a Gestão de Negócios. Disponível em http://www.fradmon.com.br/default/dados/pgs/quiz/quiz.php. Acesso em 24/08/2011.

ALMEIDA, J. A. R. Elaboração de um Método para Melhoria dos Fluxos de Informação usando Princípios da Mentalidade Enxuta e Reengenharia de Processos. 2009. 99 f. Dissertação (Mestrado em Engenharia de Produção) - Escola de Engenharia de São Carlos, Universidade de São Paulo, São Carlos, 2009.

AUGUST, J. Failure Mode and Effect Analysis. CQA, American Biltrite Inc., Tape Products Division, Moorestown (USA), 2002.

BADURDEEN, F.; WIJEKOON, K.; MARKSBERRY, P. An analytical hierarchy processbased tool to evaluate value systems for lean transformations. Journal of Manufacturing Technology Management. Lexington (USA), v. 22, n. 1, p. 46-65, 2011.

BEN-DAYA, M.; RAOUF, A. A revised failure mode andeffects analysis model. International Journal of Quality \& Reliability Management. Dhahran (Saudi Arabia), v. 13, n. 1, p. 43-47, 1996.

BOWEN, D. E.; YOUNGDAHL, W. E. "Lean" service: in defense of a production-line approach. International Journal of Service Industry Management. Glendale (USA), v. 9, n. 3, p. 207-225, 1998.

CABRAL, R. H. Q.; ANDRADE, R. S. XVIII ENCONTRO NACIONAL DE ENGENHARIA DE PRODUÇÃO, 1998, Niterói (Brasil). Aplicabilidade do Pensamento Enxuto.

CAPALDO, D.; TOLEDO, V. ROZENFELD, H. FMEA (Failure Mode and Effect Analysis). 1999. Disponível em http://www.numa.org.br/ conhecimentos/conhecimentos_port/ pag_conhec/FMEAv2.html. Acesso em 15/03/2011.

CARPINETTI, L. C. R. Gestão da Qualidade: Conceitos e Técnicas. $1^{a}$ edição, São Paulo, Atlas. 2010.

CHOWDHARY, N.; PRAKASH, M. Prioritizing service quality dimensions. Managing Service Quality. Aizawl (India), v. 17, n. 5, p. 493-509, 2007. 
CHUANG, P. Incorporating disservice analysis to enhance percieved servisse quality. Industrial Management \& Data Systems. Kaohsiung City (China), v. 110, n. 3, p. 368-391, 2010.

CORRÊA, H. L; CORRÊA, C. A. Administração de produção e de operações: manufatura e serviços: um enfoque estratégico. $1^{\text {a }}$ edição, São Paulo, Atlas. 2005.

CORRÊA, H. L.; GIANESI, I. G. N.; CAON, M. Planejamento, Programação e Controle da Produção: MRP II/ERP: Conceitos, Uso e Implantação. $4^{\text {a }}$ edição. São Paulo, Atlas, 2001.

CORRÊA, H.L.; GIANESI, I.G.N. Just in Time, MRP II e OPT - um enfoque estratégico. $1^{\text {a }}$ edição. São Paulo, Atlas. 2007.

COUGHLAN, P.; COGHLAN, D. Action research for operations management. International Journal of Operations \& Production Management. Dublin (Ireland), v. 22, n. 2, p. 220240, 2002.

CUATRECASAS, L. A lean management implementation method in service operations. International Journal of Services Technology and Management. Barcelona (Spain), v. 5, n. 5-6, p. 532-544, 2004.

EDVARDSSON, B. Service quality improvement. Managing Service Quality. Karlstad (Sweeden), v. 8, n. 2, p. 142-149, 1998.

FARIA, C. A. Serviços Enxutos. 2011. Disponível em http://www.merkatus.com.br/10_boletim/252.htm. Acesso em 22/02/11.

FERNANDES, J. M. R. Proposição de Abordagem Integrada de Métodos da Qualidade baseada no FMEA. 2005, 59 f. Dissertação (Mestrado em Engenharia de Produção) Pontifícia Universidade Católica do Paraná, Curitiba, 2005.

Ferramentas Básicas da Qualidade. Disponível em http://gestaoindustrial.com/ferramentasdaqualidade.htm. Acesso em 15/03/2011.

FRANCESCHINI, F.; GALETTO, M. A new approach for evaluation of risk priorities of failure modes in FMEA. International Journal of Production Research. v. 29, n. 13, p. 2991-3002, 2001.

FRANCISCHINI, P. G.; MIYAKE, D. I.; GIANNINI, R. XXVI ENCONTRO NACIONAL DE ENGENHARIA DE PRODUÇÃO, 2006, Fortaleza (Brasil). Adaptação de conceitos de melhorias operacionais provenientes do Lean Production em operações de serviços.

FRANK, A. G.; PEDRINI, D. C.; ECHECESTE, M, E. XXVI ENCONTRO NACIONAL DE ENGENHARIA DE PRODUÇÃO, 2008, Rio de Janeiro (Brasil). Integração das visões de QFD e FMEA por meio de um índice de risco de falhas modificado.

FURINI, G. Diretrizes para Avaliação do Uso dos Princípios da Produção Enxuta: Estudo de Caso em uma Empresa do Setor de Siderurgia. 2009. 69 f. Dissertação 
(Mestrado em Engenharia de Produção) - Universidade Federal do Rio Grande do Sul, Porto Alegre, 2009.

GATHIER, N.; FRAZIER, G. Administração da Produção e Operações. $1^{a}$ edição. São Paulo, Ed. Thomson, 2002.

GIL, A. C. Como Elaborar Projetos de Pesquisa. $3^{\text {a }}$ edição. São Paulo, Editora Atlas, 1991.

GILCHRIST, W. Modelling failure modes and effects analysis. International Journal of Quality \& Reliability Management. v. 10, n. 5, p. 16-23, 1993.

GINN, D. M.; JONES, D. V.; RAHNEJAT, H.; ZAIRI, M. The "QFD/FMEA interface". European Journal of Innovation Management. Koeln (Germany), v. 1, n. 1, p. 7-20, 1998.

GODLEVSKAJA, O.; IWAARDEN, J.; WIELE, T. Moving from product-based to servicebased business strategies: Services categorization schemes for the automotive industry. International Journal of Quality \& Reliability Management. Rotterdam (The Nederlands), v. 28, n. 1, p. 62-94, 2011.

HAMMER, M.; CHAMPY, J. Reengenharia: Revolucionando a Empresa em Função dos Clientes, Concorrência e das Grandes Mudanças de Gerência. Rio de Janeiro, Campus, 1994.

HINES, P.; TAYLOR, D. Going Lean. A guide to implementation. Cardiff, Lean Enterprise Research Center, Cardiff, UK. 2000.

INOUE, H.; YAMADA, S. Failure mode and effects analysis in pharmaceutical research. International Journal of Quality and Service Sciences. Tsukuba (Japan), v. 2, n. 3, p. 369$382,2010$.

KUMAR, E. V.; CHATURVEDI, S. K. Prioritization of maintenance tasks on industrial equipment for reliability: A fuzzy approach. International Journal of Quality \& Reliability Management. Kharagpur (India), v. 28, n. 1, p. 109-126, 2011.

LAGO, N.; CARVAlhO, D.; RIBEIRO, L. Lean Office. Contribuições Técnicas, Fundição. Porto (Portugal), v. 248-249, p. 6-8, 2008.

LAREAU, W. Office Kaizen: Transforming Office Operations into a Strategic Competitive Advantage. Milwaukee, American Society for Quality, Quality Press, 2002.

Lean Term: 5 Whys. Disponível em http://www.velaction.com/5-whys/. Acesso em 15/03/2011.

LIKER, J. K. O Modelo Toyota: 14 Princípios de Gestão do Maior Fabricante do Mundo. $1^{\mathrm{a}}$ edição. Porto Alegra, Editora Bookman, 2004. 
LINS, B. E. História da Qualidade: Breve história da engenharia da qualidade. 2009. Disponível em http://gqpgunit.blogspot.com/2009/03/historia-da-qualidade.html. Acesso em 18/03/2011.

LOCHER, D. A. Value Stream Mapping for Lean Development: A How-To Guide for Streamlining Time to Market. $1^{\text {a }}$ edição. New York, Productivity Press, 2008

MCCAIN, C. Usando o FMEA no ambiente de serviços. Revista Banas Qualidade. São Paulo (Brazil), ano XVII, n. 176, 2007.

MCLACHLIN, R. Management initiatives and just-in-time manufacturing. Journal of Operations Management. Winnipeg (Canada), v. 15, n. 4, p. 271-292, 1997.

MELO, H. P.; ROCHA, F.; FERRAZ, G.; DI SABBATO, A.; DWECK, R. O Setor de Serviços no Brasil: Uma Visão Global - 1985/95. $1^{a}$ edição. Rio de Janeiro, IPEA, 1998.

MIGUEL, P. A. C. et al.. Metodologia de pesquisa em engenharia de produção e gestão de operações. $1^{\text {a }}$ edição. Rio de Janeiro, Elsevier Editora, 2010.

NAZARENO, R. R. Desenvolvimento e Aplicação de um Método para Implantação de Sistemas de Produção Enxuta. 2003, 84 f. Dissertação (Mestrado em Engenharia de Produção) - Escola de Engenharia de São Carlos, Universidade de São Paulo, São Carlos, 2003.

NOGUEIRA, A. C; PERES, A. P.; CARVALHO, E. M. Avaliação do risco ambiental utilizando FMEA em um laticínio na região de Lavras-MG. Revista Produção Online. Lavras (Brasil), v. 11, n. 1, p. 194-209, 2011

OHNO, T. The Toyota Production System. $1^{\text {a }}$ tradução (original em japonês Toyota seisan hoshiki, 1978), New York. Productivity Press, 1988.

OOKALKAR, A. D.; JOSHI, A. G.; OOKALKAR, D. S. Quality Improvement in haemodialysis process using FMEA. International Journal of Quality \& Reliability Management. Nagpur (India), v. 26, n. 8, p. 817-830, 2009.

PALADY, P. FMEA: Análise dos Modos de Falha e Efeitos. 5a edição. São Paulo, IMAM. 1997.

PARASURAMAN, A. Service quality and productivity: a synergistic perspective. Managing Service Quality. Miami (USA), v. 12, n 1, p. 6-9, 2002.

PHENG, L. S. Managing total service quality: a systemic view. Managing Service Quality. Singapore, v. 8, n. 1, p. 34-45, 1998.

PIERCY, N.; RICH, N. Lean transformation in the pure service environment: the case of the call service centre. International Journal of Operations \& Production Manegement. Bath, Cardiff (United Kingdom), v. 29, n. 1, p. 54-76, 2009 
PILLAY, A.; WANG, J. "Modified failure mode and effects analysis using approximate reasoning". Reliability Engineering \& System Safety. Liverpool (England), v. 79, n. 1, p. 69-85, 2003.

PINHO, L. A.; GOMES, S. M. S.; PINHO, W. A.; AZEVEDO, T. C. FMEA: análise do efeito e modo de falha em serviços - uma metodologia de prevenção e melhoria dos serviços contábeis. ABCustos. Salvador (Brasil), v. 3, n. 1, 2008.

Quais as motivações para adotar iniciativas BPM? Disponível em http://www.elogroup.com.br/base_pesquisa2008_motivacoes.html. Acesso em 24/08/2011.

RASTEIRO, G.; NAZARENO, R.; SILVA, T. A mentalidade enxuta aplicada ao fluxo de desenvolvimento de $\quad$ produto, 2010. $\quad$ Disponível http://www.hominiss.com.br/newsletter.asp?id=23. Acesso em 24/02/2011.

RENTES, A. F.; SILVA, A. L.; SILVA, V. C. X SIMPEP, 2003, Bauru. Aplicando os conceitos de Lean Production em uma indústria de calçados: Um estudo de caso.

RHEE, R. J.; ISHII, K. Using cost based FMEA to enhance reliability and serviceability. Advanced Engineering Informatics. Stanford (USA). v. 17, p. 179-188, 2003.

ROOS, C.; DIESEL, L.; MORAES, J. A. R.; ROSA, L. C. XXVII ENCONTRO NACIONAL DE ENGENHARIA DE PRODUÇÃO, 2007, Foz do Iguaçu (Brasil). Ferramenta FMEA: uma abordagem voltada para a melhoria da qualiade nos serviços de transporte.

ROTONDARO, R. G. SFMEA: Análise do Efeito e Modo da Falha em Serviços - aplicando técnicas de prevenção na melhoria de serviço. Revista Produção. São Paulo (Brasil), v. 12, n. $2,2002$.

SÁNCHEZ, A. M.; PEREZ, M. P. Lean indicators and manufacturing strategies. International Journal of Operations \& Production Management. Zaragoza (Spain), v. 21, n. 11, p. 1433-1451, 2001.

SANKAR, N. R.;PRABHU, B. S. Modified approach for prioritization of failures in a system failure mode and effects analysis. International Journal of Quality \& Reliability Management. Chennai (India), v. 18, n. 3, p. 324-335, 2001.

SANT'ANA, A. P.; PINTO JÚNIOR, R. P. S. Composição probabilística no cálculo das prioridades na FMEA. Revista Sistema \& Gestão. Niterói (Brasil). v. 5, n. 3, p. 179-191, 2010

SAWHNEY, R.; SUBBURAMAN, K.; SONNTAG, C.; RAO, P. R. V.; CAPIZZI, C. A modified FMEA approach to enhance reliability of lean systems. International Journal of Quality \& Reliability Management. Tenesse (USA), v. 27, n. 7, p. 832-855, 2010. 
SENRRA, S. $\quad$ PDCA. $2010 . \quad$ Disponível http://silviomascarellosenrra.blogspot.com/2010_05_01_archive.html • Acesso em $15 / 03 / 2011$.

SHAH, R.; WARD, P. T. Lean manufacturing: context, practice bundles, and performance. Journal of Operations Management. Minneapolis (USA), v. 21, n. 2, p. 129-149, 2003.

SHARMA, R. K.; KUMAR, D.; KUMAR, P. Systematic failure mode effect analysis (FMEA) using fuzzy linguistic modelling. International Journal of Quality \& Reliability Management. Roorkee (India), v. 22, n. 9, p. 986-1004, 2005.

SHETTY, D; ALI, A.; CUMMINGS, R. Survey-based spreadsheet model on lean implementation. International Journal of Lean Six Sigma. Connecticut (USA), v. 1, n. 4, p. 310-334, 2010.

SHINGO, S. O sistema Toyota de Produção: do Ponto de Vista da Engenharia de Produção. $2^{\text {a }}$ edição. Porto Alegre, Editora Bookman, 1996.

SILVA, A. L.; RENTES, A. F. XXII ENCONTRO NACIONAL DE ENGENHARIA DE PRODUÇÃO, 2002, Curitiba (Brasil). Tornando o layout enxuto com base no conceito de mini-fábricas num ambiente de multi-produtos: um estudo de caso.

SILVA, E. L.; MENEZES, E. M. Metodologia da Pesquisa e Elaboração de Dissertação. $4^{\text {a }}$ edição. Florianópolis, UFSC, 2005.

SILVA, G. G. M. P.; TUBINO, D. F.; SEIBEL, S.; BRAGHIROLLI, L. F.; DAL FORNO, A. J.; MACHADO, M. G. XXVII ENCONTRO NACIONAL DE ENGENHARIA DE PRODUÇÃO, 2007, Foz do Iguaçu (Brasil). A Manufatura Enxuta Aplicada no Setor de Serviços: Um Estudo de Caso.

SILVEIRA, A. O.; COUTINHO, H. H. Trabalho Padronizado: a busca por eliminação de desperdícios. Revista INICIA. Santa Rita do Spaucaí (Brasil), n.8, p. 8-16, 2008

SINGH, B.; GARG, S. K.; SHARMA, S. K.; GREWAL, C. Lean implementation and its benefits to production industry. International Journal of Lean Six Sigma. Greater Noida (India), v. 1, n. 2, p. 157-168, 2010.

SLACK, N. Vantagem competitiva em manufatura: atingindo competitividade nas operações industriais. $1^{\mathrm{a}}$ edição, São Paulo, Ed. Atlas. 2002

SLACK, N.; CHAMBERS, S.; JOHNSTON, R. Administração da Produção. $8^{a}$ edição, São Paulo, Atlas, 2008

SOUTH, S. F. Achieving Breakthrough Improvements With the Application of Lean Six Sigma Tools and Principles Within Process Excellence. LABMEDICINE. Scottsdale (USA), v. 36, n. 4, p. 240-242, 2005.

STAMATIS, D. H. Failure Mode and Effect Analysis: From Theory to Execution. Milwaukee, American Society for Quality, Quality Press. 2003. 
TAJ, S.; MOROSAN, C. The impact of lean operations on the Chinese manufacturing performance. Journal of Manufacturing Technology Management. Houston (USA), v. 22, n. 2, p. 223-240, 2011.

TAPPING, D.; SHUKER, T. Value stream management for the lean office: 8 steps to planning, mapping, and sustaining lean improvements in administrative areas. $1^{\mathrm{a}}$ edição. New York, Productivity Press, 2003.

TENG, S. G.; HO, S. M. Failure mode and effects analysis: An integrated approach for product design and process control. International Journal of Quality \& Reliability Management. Greensboro (USA), v. 13, n. 5, p. 8-26, 1996.

TOLEDO, J. C.; AMARAL, D. C. FMEA - Análise do Tipo e Efeito da Falha. [199-?], 6 f. Pesquisa em Qualidade - GEPEQ (Grupo de Estudos e Pesquisa em Qualidade) Departamento de Engenharia de Produção, Universidade Federal de São Carlos, São Carlos. [199-?].

TURATI, R. C.; MUSETTI, M. A. XXVI ENCONTRO NACIONAL DE ENGENHARIA DE PRODUÇÃO, 2006, Fortaleza (Brasil). Aplicação dos Conceitos de Lean Office no Setor Administrativo Público.

VON ASHEN, A. Cost-oriented failure mode and effects analysis. International Journal of Quality \& Reliability Management. Darmstadt (Germany), v. 25, n. 5, p. 466-476, 2008.

WEBER, A. (traduzido por Odier Tadashi). Estação de Trabalho Lean: organizada para a produtividade. 2005. Disponível em www.strategosinc.com. Acesso em 18/02/2005.

WOMACK, J. P.; JONES, D. T. Lean Thinking - Banish Waste and Create Wealth in Your Corporation. $2^{\mathrm{a}}$ edição. New York, Free Press - Simon \& Schuster, 2003. 


\section{Apêndices}

\subsection{Mapa de Fluxo de Informação dos Produtos de Madeira}

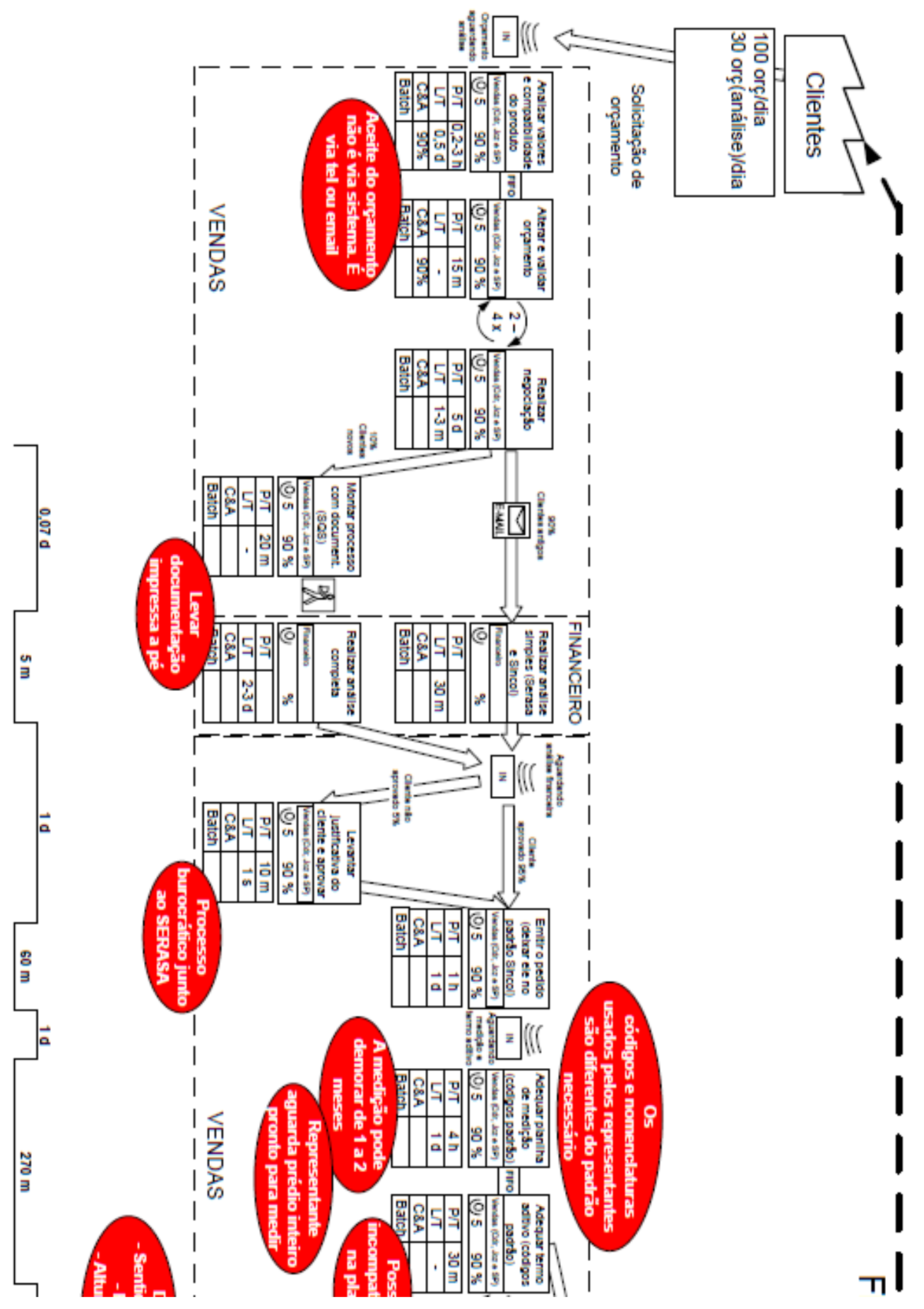




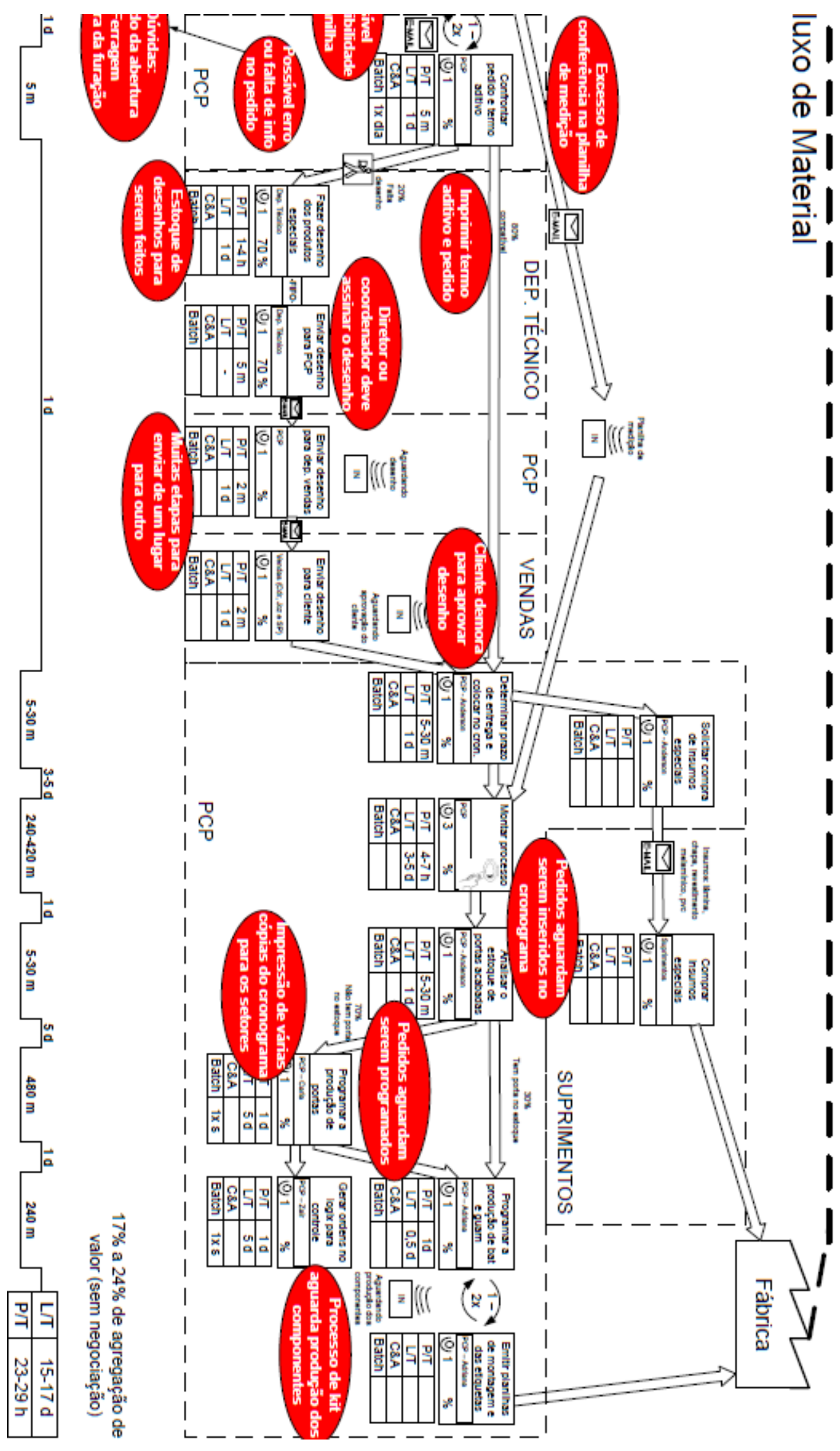


8.2. Análise Crítica do Mapa de Fluxo de Informação dos Produtos de Madeira

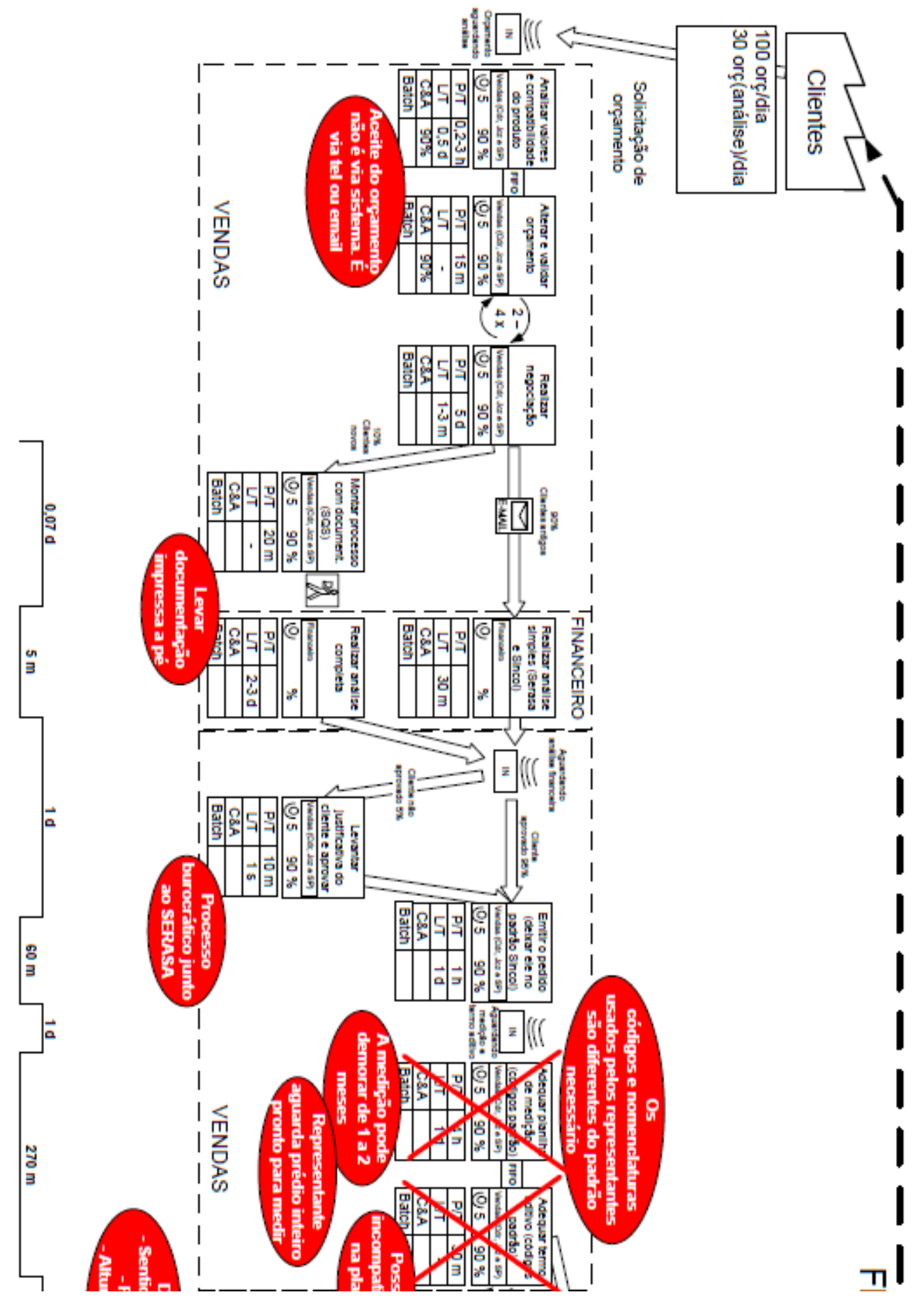




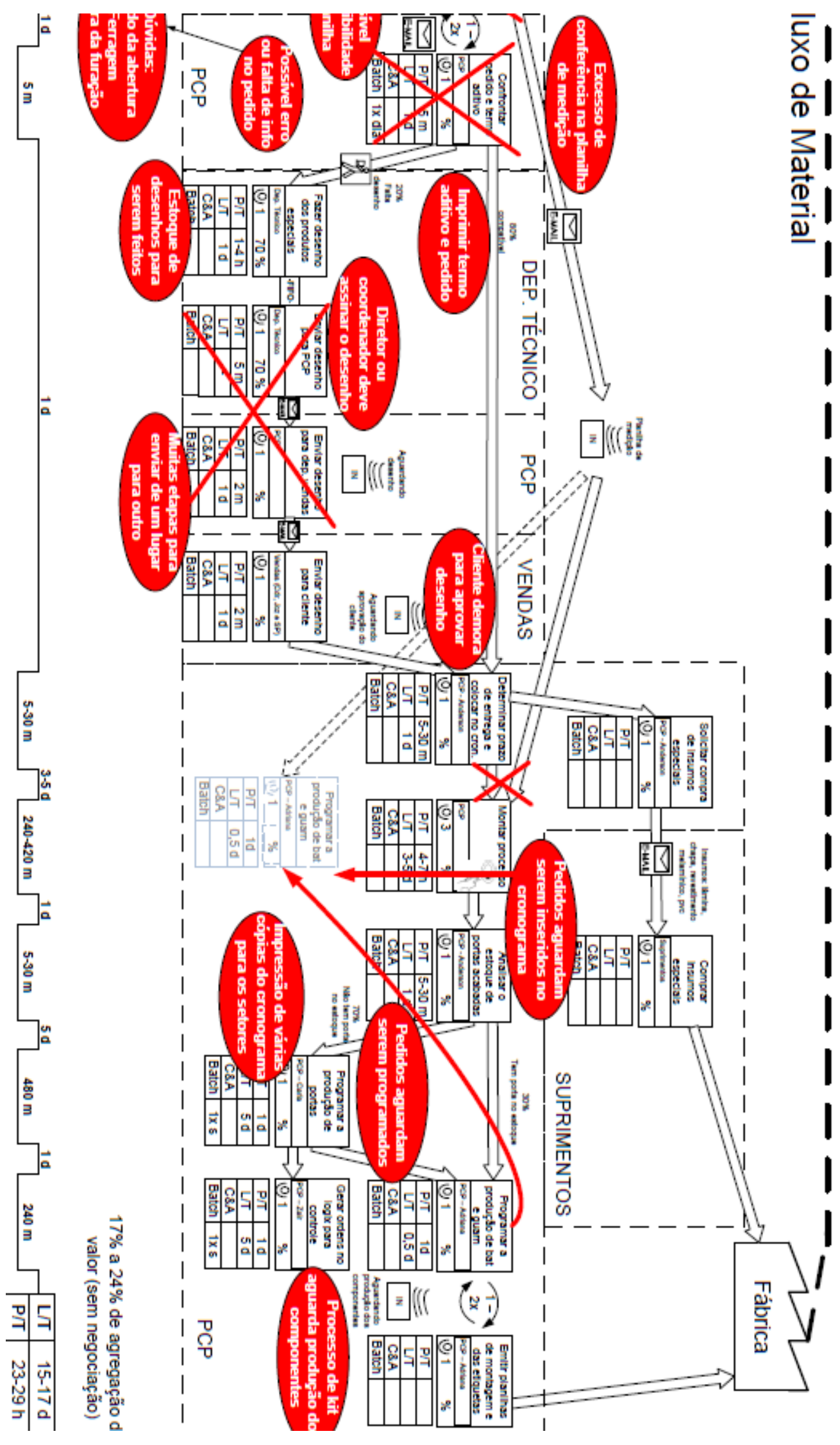

